\title{
PLACE-DEPENDENCE OF RENEWABLE ENERGY TECHNOLOGIES
}

Connecting local and global scale

\author{
Deyu Li
}

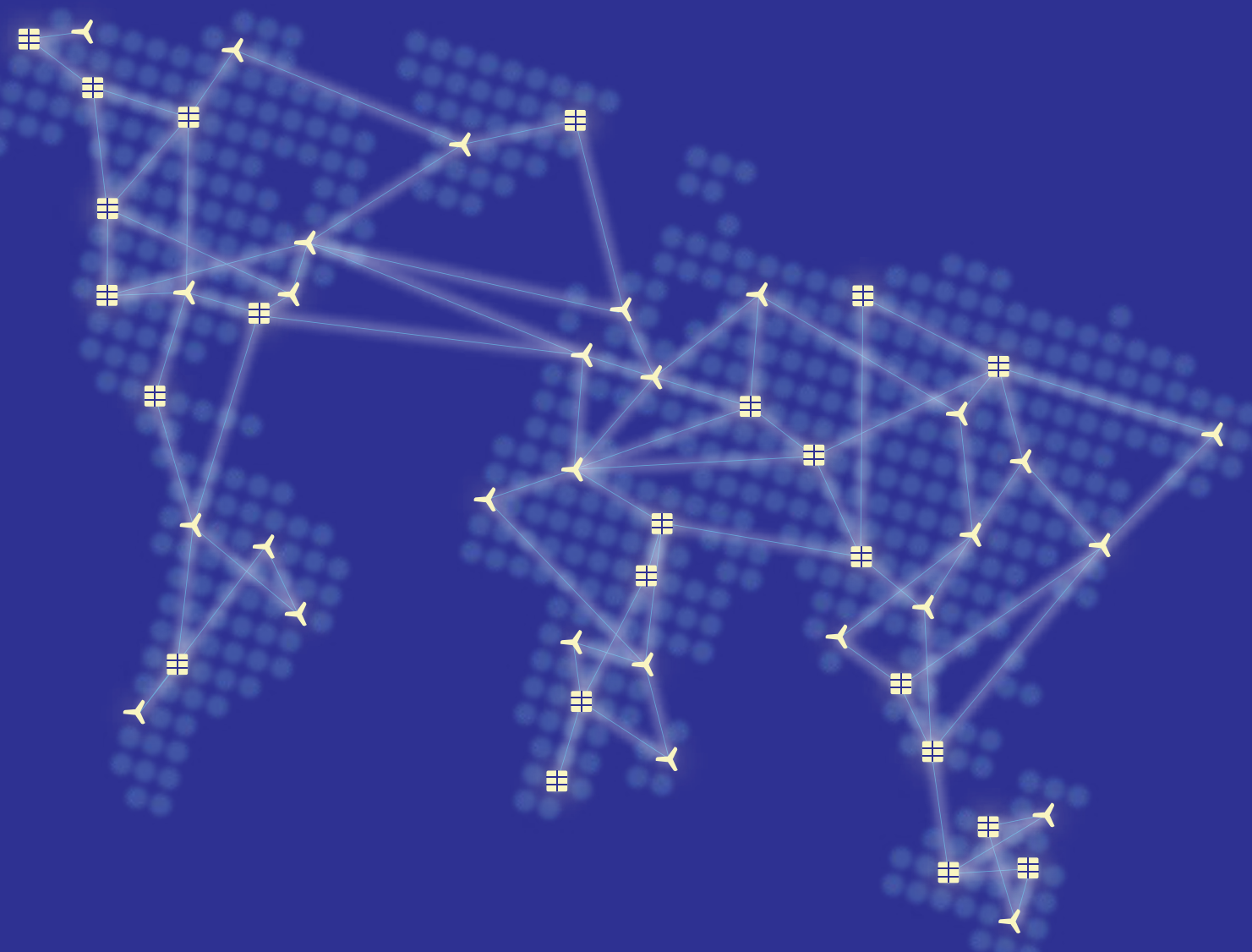




\section{Place-dependence of renewable energy technologies}

Connecting the local and global scale

Deyu Li 
ISBN: 978-94-6380-773-9

Copyright $\odot \mathrm{D}$. Li

Cover design $\odot$ F. Schaap

Printed by: proefschriftmaken.nl

All rights reserved. No part of this publication may be reproduced, stored in a retrieval system, or transmitted in any form or by any means, without prior written permission by the author 


\title{
Place-dependence of renewable energy technologies \\ Connecting the local and global scale
}

\author{
Locatie afhankelijkheid van hernieuwbare \\ energietechnologieën \\ Lokale en globale schaal te verbinden \\ (met een samenvatting in het Nederlands)
}

\section{Proefschrift}

ter verkrijging van de graad van doctor aan de

Universiteit Utrecht

op gezag van de

rector magnificus, prof.dr. H.R.B.M. Kummeling, ingevolge het besluit van het college voor promoties in het openbaar te verdedigen op

vrijdag 15 mei 2020 des middags te 4.15 uur

$$
\text { door }
$$

\section{Deyu Li}

geboren op 23 april 1989

te Chongqing, China 


\section{Promotoren:}

Prof. dr. F. Alkemade

Prof. dr. K. Frenken

\section{Copromotor:}

Dr. G.J. Heimeriks

This thesis was supported by the ViDi grant 452-13-010 funded by the Dutch organization for scientific research (NWO). 


\section{Contents}

Chapter 1 Introduction ........................................................................................... 1

Chapter 2 The emergence of renewable energy technologies at country level .................... 13

Chapter 3 Knowledge flows in global renewable energy innovation systems ...................... 37

Chapter 4 Recombinant invention in solar photovoltaic technology …………………….... 55

Chapter 5 Catching up in clean energy technological paradigm......................................... 75

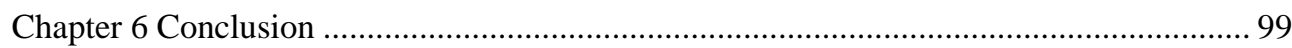

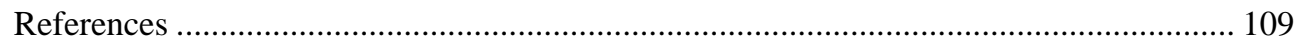

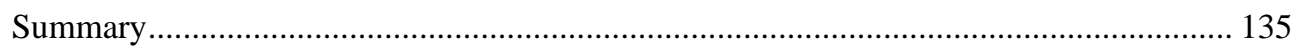

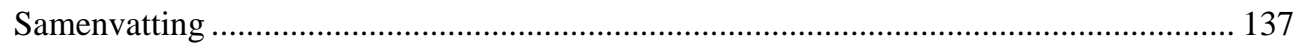

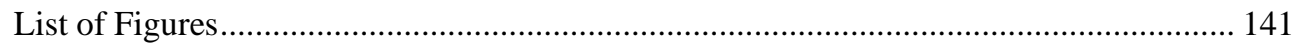

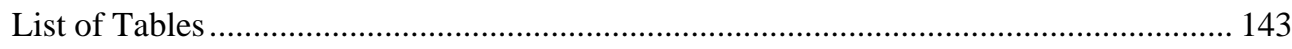

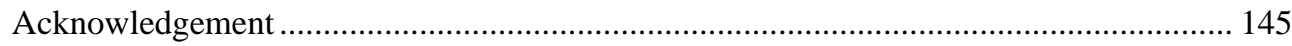

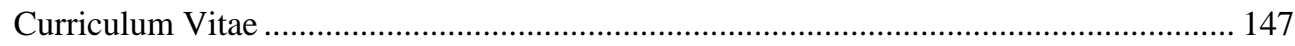

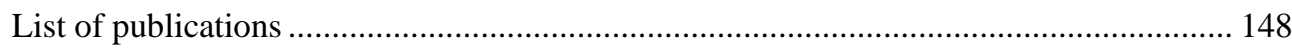



Chapter 1

\section{Introduction}


Climate change mitigation requires rapid decarbonization of the current energy systems worldwide (International Energy Agency, 2019). Over the last decade, advances in clean technologies in energy generation (e.g. solar photovoltaic and wind power), storage (e.g. Li-ion batteries), and consumption (e.g. electric vehicles, solid-state lighting) offer a great promise for achieving this transition.

The increasing global interdependence of energy transitions allows countries to obtain resources like knowledge, market access and finance from other countries in their development of clean energy technologies (Meckling and Hughes, 2018). However, the understanding of place-specificity in developing clean energy technologies is crucial for formulating better policies and transition pathways for individual countries and for facilitating future technology development (Hansen and Coenen, 2015).

First, countries differ in their capabilities and choices of new clean energy technologies (Negro et al., 2012; Sbardella et al., 2018). The innovation performances of countries in clean energy technologies are shaped by their unique history, their existing knowledge base as well as by a broader set of institutional and geographical conditions (Hansen and Coenen, 2015). Thus, countries contribute differently to the rapid cost reduction in clean energy technologies in different stages of the technology life-cycle (Kavlak et al., 2018; Meckling and Hughes, 2018; Nemet, 2019).

Second, national efforts to promote clean energy transitions have become increasingly important over time. The intended nationally determined contributions agreed in the 2015 Paris Agreements replaced the previous national targets and timetables for industrialized states to reduce carbon emissions established in the 1997 Kyoto Protocol. Countries can play a more active role in transforming their energy sectors instead of adopting top-down policies. Thus, the national policy choices aggregate to global commitments.

Third, government intervention is one of the driving forces of the surge in clean energy investment from both developed and emerging countries (Harrison et al., 2017; Rodrik, 2014). The motives of governmental policies go beyond sheer environmental concerns (Matsuo and Schmidt, 2019; Schmidt et al., 2019). Promoting industry development for economic reasons is becoming increasingly important, especially in many emerging countries where the new low-carbon technological paradigm is seen as an opportunity for industrial catching-up (Harrison et al., 2017; Kemp and Never, 2017; Rodrik, 2014).

\subsection{Theoretical background: evolutionary economic geography}

Rooted in evolutionary economics (Dosi, 1982; Nelson and Winter, 1982), recent literature in evolutionary economic geography considers the new path development of a country (region) as a branching process that builds on the existing capabilities of a country (region) (Frenken and Boschma, 2007; Martin and Sunley, 2006). This local related diversification 
process originates from tacitness of knowledge which makes replicating knowledge in other context difficult (Antonelli, 1999; Gertler, 2003). Firms tent to diversify into related industries because of the economies of scale (Klepper, 2007). Labour flows also tend to happen between related industries (Neffke and Henning, 2013). Furthermore, most of the channels for transferring tacit knowledge are geographically bounded, such as spin-off processes, inventor collaborations and labour flows (Klepper, 2007; Breschi and Lissoni, 2009; Eriksson, 2011).

The thesis that countries (and regions) diversify into related industries has been confirmed by recent quantitative studies (for extensive reviews, see Content and Frenken (2016) and Boschma (2017)). The seminal study by Hidalgo et al. (2007) is the first to analyse whether the likelihood of a country exporting new products is conditioned by its national capabilities. They constructed a 'product space' based on the product proximity concept, which is calculated using the frequency of co-occurrence of products in countries' export portfolios. The proximity captures similar capabilities required to make products colocate in the same country. Hence, two products are considered proximate if they co-locate in many countries. Based on this 'product space' concept, Hausmann and Klinger (2007) further provide systematic evidence that countries tend to develop new export products that are related in product space with existing export products.

Inspired by these two seminal papers, Neffke et al. (2011) analyse the regional industry evolution systematically. They calculated the relatedness using labour flows between industries, and found that regional industry structure will condition the new industry entering the region. The related diversification approach has been replicated to study the industry evolution of United States metropolitan regions (Essletzbichler, 2015), European countries or regions (Boschma et al., 2013, 2017b; Boschma and Capone, 2015, 2016; Xiao et al., 2018) and Chinese prefecture-level cities (Guo and He, 2017; He et al., 2018; Zhu et al., 2017). Using different measures of relatedness, these studies all confirm the importance of local related capabilities in developing new industry at the regional and national level.

Inspired by the 'product space' concept, Kogler et al. (2013) construct the 'technology space' using technology proximity measure based on the co-occurrence of technology classes at the patent level. Rigby (2015) and Boschma et al. (2015) further systematically investigate the entry and exit of technologies in US metropolitan regions. Kogler et al. (2017) focus on the technology evolution of NUTS 2 regions in EU 15 countries. Petralia et al. (2017) look at the development of new technology at the country level. The related diversification process is again observed in all these studies that countries and regions are more likely to develop new technologies related to their existing knowledge base.

The impact of relatedness can differ across countries and regions. More importantly, unrelated diversification is important for the long-term development of countries and 
regions (Pinheiro et al., 2018; Saviotti and Frenken, 2008). Petralia et al. (2017) find that the relatedness is more important for countries with a lower level of economic development, whereas developed countries are more likely to develop new technologies less and even unrelated to their existing knowledge bases. Recent empirical studies in EEG literature start to investigate the enabling conditions for unrelated diversifications. Both Zhu et al. (2017) and Xiao et al. (2018) find that regions with a stronger innovation capacity are more likely to make long jumps in their industry evolution. Montresor and Quatraro (2017) show that the presence of key enabling technologies in a region can facilitate the branching process to less related technologies. Both formal and informal institutions play an important role in facilitating unrelated diversification. Boschma and Capone (2015) find that liberal market economies are more likely to develop new products less related to their existing knowledge base. Cortinovis et al. (2017) further show that informal institutions that can bridge different social groups can facilitate unrelated diversification, especially when formal institutions are lacking. At the micro-level, Neffke et al. (2018) find that unrelated diversification mostly originates via new establishments, especially via those with nonlocal roots. Hausmann and Neffke (2019) further show that plants that pioneer an industry in a location hire more workers from outside their industry and from outside their region, especially when workers come from closely related industries or are highly skilled.

The obstacles in developing new technology might differ across technologies. Following the methodologies proposed by Hidalgo and Hausmann (2009) and Balland and Rigby (2017) in calculating technology complexity, Petralia et al. (2017) show that countries are less likely to develop complex technologies. However, Balland et al. (2019) show that develop complex technologies related to the existing knowledge base is a feasible solution for entering complex technologies. A similar pattern is also observed in Heimeriks et al. (2019) that NUTS-2 level regions in EU countries are more likely to develop complex scientific topics related to their existing knowledge base.

The related diversification process has also been observed in the development of emerging technologies, such as rDNA technology (Feldman et al., 2015), nanotechnology (Colombelli et al., 2014), and biotech (Boschma et al., 2014; Heimeriks and Boschma, 2014). The emergence of new technological paradigms offers windows of opportunities for countries and regions to catch up (Perez and Soete, 1988). Several empirical studies in recent EEG literature also confirm the related diversification process in clean technologies (Montresor and Quatraro, 2019; Perruchas et al., 2019; Santoalha and Boschma, 2019; Tanner, 2016, 2014; van den Berge et al., 2019), providing evidences on how countries and regions can catch up in the recent clean technological paradigm (Mathews, 2013; Perez, 2016, 2013). 


\section{Introduction}

The recent empirical studies focusing on the development of clean technologies help understand the role of local capabilities in both green and non-green technologies in the development of clean energy technologies. Although the clean technologies are considered radical and disruptive (Geels, 2018), the knowledge and skills accumulated in the region can be used for the development of clean technologies (Montresor and Quatraro, 2019; Tanner, 2016). Van den Berge et al. (2019) even show that instead of traditional thinking that the presence of dirty technologies may hamper the development of clean technologies, some clean technologies even develop out the capabilities of dirty technologies. Moreover, Perruchas et al. (2019) find that the complexity is not an obstacle for the development of clean technologies, even for emerging countries. Countries move along cumulative paths of specialisation, and towards more complex clean technologies.

In sum, the EEG literature offers successful explanations of the uneven geographical distribution of innovation activities and the unique technology development trajectories of countries (and regions) based on their capabilities accumulated in the past. The unique existing knowledge base of countries (and regions) constrains as well as opens opportunities for the development of new technologies (Boschma, 2017; Boschma et al., 2017a; Content and Frenken, 2016; Henning, 2019; Hidalgo et al., 2018).

\subsection{Limitations of current EEG literature}

Given the significant progress made over the past decade in EEG literature in the understanding the role of local related capabilities in the development of new technologies, there are some still limitations in current EEG literature in providing a comprehensive insight into the global innovation dynamics of renewable energy technologies.

First, the current EEG literature only considers the activities new to a region and whether they build on the existing local related capabilities. There lacks understanding of how local knowledge production can affect the global technology dynamics. How to break out the path-dependent technology development is a key issue for sustainability transitions since clean energy technologies which are usually considered complex and novel (Barbieri et al., 2020), and with the potential to disrupt the energy and transport sector (Alkemade et al., 2009; Geels, 2018; Markard and Truffer, 2006). However, this process is under conceptualized in current EEG literature. If a new activity emerging in a region is also novel to the world, to what extent the novel technology builds on local knowledge base instead of global knowledge base is still less focused in the EEG literature.

The path-dependence of local technological development is assumed to stem from the path-dependence of global technology development in current EEG literature. This is also reflected in the calculation of the technological relatedness using all patents worldwide, i.e., a single distance measure between each pair of technologies that is the same worldwide. 
Hence, the notion of technology evolution being path-dependent is saying that the global technology dynamics is path-dependent (Heimeriks and Boschma, 2014).

Recent attempts in identifying the heterogenous effects of relatedness across countries and regions help better understand the place-dependence of technological change next to the path dependence of technology development at the global level. Some countries (regions) are indeed able to develop less related technologies (Boschma, 2017). However, it is still not clear in these studies whether the less related activities emerging in a region or country are only new to the region, or also new to the world. And, a follow up question holds to what extent the new-to-the-world activities can affect global technological trajectories.

Linking EEG to sustainability transitions literature, Boschma et al. (2017a) proposed a typology of regional diversification along both regional dimension (related versus unrelated diversification) and sectoral dimensions (niche technology vs. regime technology). A new activity emerging in a country (region) can build on its existing knowledge base (related diversification) or on global knowledge base (unrelated diversification). Along the sectoral dimension, a country (region) can develop a new technology which is either only new to the region (an existing regime technology) or new to the world (a new niche technology). Hence, the path-dependence and place-dependence refer two different processes. Pathdependence refers to cumulative technology development within global regime technology, whereas place-dependence refers to the local reproduction of localized knowledge. A placedependent process then, can nevertheless break with global path dependencies. Think of Silicon Valley Internet firms that diversify into related technologies (place dependence) but continue to disrupt many global regimes (e.g., in retail, media, music, cars, tourism, etc.) thus breaking with path dependencies at the global level.

More systematically, from a conceptual point of view, one can distinguish between four diversification trajectories (Boschma et al., 2017a). A country (region) can diversify into already existing global regime technologies (hence, new to the region but not new to the world). They can achieve this by relying on their existing knowledge base through related diversification (replication) or based on external knowledge (transplantation). A country can also diversify into new niche technologies that differ from existing global regime technology (hence, not only new to the region, but also new to the world). They can develop such truly new niche technology by either building on related technologies in the region as the Silicon Valley example illustrated (exaptation) or by developing a new niche technology fully from scratch (saltation). While useful as a conceptual framework, the four trajectories have not been empirically investigated in a systematic manner.

Having established the distinction between global path-dependence and local placedependence, the local-global interactions can be approached from two angles: one can study 
the impact of local technology development on global technology development, and, vice versa, one can study the impact of global technology development on local technology development. The idea of local-global interactions in technology development resonates with the multi-scalar dynamics proposed by Binz and Truffer (2017) in their construction of global innovation system concept. Multi-scalar innovation dynamics consist of the generation of resources at different locations and the connectivity between them (Binz and Truffer, 2017). Emerging technologies like clean energy technologies evolve in interactions between different knowledge and other resources from different technologies in different countries (Carlsson and Stankiewicz, 1991; Hekkert et al., 2007). Both inter-technology knowledge spillovers (Battke et al., 2016; Nemet, 2012; Stephan et al., 2019) and international knowledge spillovers play an important role in the development of renewable energy technologies (Conti et al., 2018; Garrone et al., 2014; Verdolini and Galeotti, 2011; Wu and Mathews, 2012).

However, the global perspective is still under-conceptualized in current EEG literature. Besides the aforementioned lack of understanding of how local capabilities can contribute to the global technology development, it is also unclear how countries can catch up in clean energy technologies by utilizing global knowledge inputs. Although recent empirical studies in EEG have started to look at the role of external linkages in the development of new activities, such as inventor networks (Feldman et al., 2015; Rigby, 2015), trade linkages (Boschma and Capone, 2016; Mao and He, 2019) and geographical adjacencies (Bahar et al., 2014; Boschma et al., 2017b; Kogler et al., 2017), whether countries differ in their ability in utilizing global knowledge remains an open question in EEG.

Moreover, as a result of the lack of distinction between technologies that are new to the world and technologies that are new to the region, the diffusion perspective is also missing in current EEG literature (Henning, 2019). The focus has been on explaining the patenting rates of countries (regions) in different technology classes given the stock of patents already present in related technology classes. However, the understanding of the subsequent diffusion of new technologies, or a lack thereof, is also important especially in the light of sustainability transitions. Without such diffusion taking place, sustainability transitions simply do not happen (Grubler et al., 2016; Sovacool, 2016), so it is important to focus also on the spatial-temporal diffusion of new clean energy technologies.

The diffusion perspective is also relevant in understanding how local contexts can benefit from global knowledge inputs. The process of catching up for lagging countries (regions) is very much driven by the diffusion process of new technologies from particular centres to peripheries. In this process, a real catch-up can be only achieved if countries can enter as early imitators of new technologies, so that lagging countries are not just passive adopters of technologies developed elsewhere, but can also develop an innovation capacity on their 
own and start contributing to the global stock of knowledge and technology as well (Perez and Soete, 1988).

\subsection{Thesis Outline}

The goal of this thesis is to bring the global perspective into EEG literature by investigating the local-global interactions in technology development. I do so by specifically focusing on the development of renewable energy technologies. This thesis consists of four empirical chapters, and focuses on three sets of research questions:

1) What aspects of place-dependence drive the innovation activities of renewable energy technologies?

2) How does place-dependence affect the global development trajectories of renewable energy technologies?

3) How do countries catch up in renewable energy technologies by utilizing local and global knowledge?

Table 1.1 summaries the three research questions, the data used, and unit of analysis, for each of the four empirical chapters. Below, I shortly introduce each of the four empirical chapters. The final chapter of the thesis provides a summary of results discusses the main overall conclusions, contributions and limitations of the thesis, followed by an outlook for future research and policy implications based on the empirical findings of this thesis.

Chapter 2 focuses on the development of new specialisations in different types of renewable energy technology (solar photovoltaic, solar thermal, wind, ocean, biofuel and geothermal) in 64 countries during the post Kyoto protocol period 1998-2012. My goal in this chapter is to investigate the aspects of place-dependence in renewable energy technologies and how countries can develop renewable energy technologies based on both local and global knowledge.

Evolutionary economic geography literature suggests that the place-dependence originates in the path-dependence of the local knowledge production towards related technologies (Boschma et al., 2017a). By contrast, the geography of sustainability transitions and innovation systems literatures suggest that place-dependence originates from the idiosyncratic configuration between resources like knowledge, market, finance and legitimation at different locations and the connectivity between them across locations (Binz and Truffer, 2017; Hansen and Coenen, 2015). For renewable energy technologies, market formation resulting from domestic demand-pull policies has played an important role in facilitating innovation output (Bettencourt et al., 2013; Johnstone et al., 2010; Nicolli and Vona, 2016). However, the role of market formation in the development of new technology is less studied in current EEG literature, with the exception of the study by Tanner (2014). 
Building on these streams of literature, I operationalize the research question in three steps. First, building on established studies in EEG, I investigate whether technological relatedness and international knowledge spillovers help a country to develop renewable energy technologies. Second, I explore the heterogenous benefits from local and global knowledge across countries with different domestic markets for renewables. Third, I compare high-income countries with middle- and low-income countries to test whether the moderating effect of domestic market for renewables on the impact of local and global knowledge differs across income groups.

Although Chapter 2 explores the multi-scalar knowledge dynamics and establishes the presence of place-dependence of renewable energy technologies, it still fails to address how local knowledge production can affect the global technology development. Chapter 3 focuses on the knowledge flows in global renewable energy innovation systems and their impacts on future technology development using 30720 patents in six types of renewable energy technology during the period 1990-2010, and their backward and forward citations.

Building on the global innovation system concept proposed by Binz and Truffer (2017), I argue in this chapter that the comprehensive understanding of the knowledge development in global renewable energy innovation systems requires a consideration of both technological and geographical dimensions. Moreover, I highlight the importance role of absorptive capacity of countries, resulting from the positive feedback loops in the knowledge diffusion between actors in national innovation systems, in moderating the impacts of knowledge flows from different TISs and NISs.

To empirically test the hypotheses, I first categorize, using the backward citations of renewable energy patents, all knowledge flows into four types: along technological dimension (within a TIS and between TISs) and geographical dimensions (within a NIS and between NISs). I proxy the absorptive capacity of a country with the extent of actors in a NIS building knowledge from other actors within the NIS. Then I investigate the impacts of these knowledge flows on the subsequent impact of renewable energy technologies, and the moderating role of the absorptive capacity of countries.

Having established how place-dependence can affect global technology development in Chapter 3, Chapter 4 focuses on the emergence of breakthrough inventions with a potential to set up new technological trajectories in solar photovoltaic technology in 599 regions of OECD and BRICS (Brazil, Russia, India, China and South Africa) countries during 1997 2012. Building on the notion that breakthrough inventions are results from the recombination of existing technologies in novel ways (Arthur, 2007; Henderson and Clark, 1990), Chapter 4 redefines path-dependence as the combination of existing related technologies, and place-dependence as the combination of locally available technologies. In this chapter, I focus on how place-dependence can break the path-dependence in facilitating 
breakthrough inventions in solar photovoltaic technology. Following the policy framework proposed by Janssen and Frenken (2019) that putting crossovers between unrelated technologies within an economy can facilitate radical innovations, I investigate whether breakthrough inventions mostly build on local knowledge base instead of global knowledge base.

The research question is operationalized in three steps. First, I identify breakthrough inventions in solar photovoltaic technology using the co-occurrence analysis of patent classes at the patent level following Verhoeven et al. (2016). Second, I calculate the technological distance between patent classes using backward citations between them. Third, I investigate empirically how likely unrelated technologies strongly present in a region are to be recombined in the breakthrough inventions. Finally, I investigate whether such process is specific to renewable energy technologies by comparing different types of renewable energy technology, and renewable energy technologies with all technologies.

The emerging low-carbon technological paradigm offer windows of opportunity for latecomer countries to catch-up (Mathews, 2013; Perez, 2016, 2013). However, the evolutionary perspective of technological change suggest that an effective catch-up process requires latecomer countries to enter as imitator early on and start improving new technologies on their own (Perez and Soete, 1988). Chapter 5 further investigates the conditions that affect latecomer countries to catch up in clean energy technology paradigm by analysing the spatial-temporal diffusion of these breakthrough inventions in renewable energy technologies.

Empirically, I use the same method in identifying breakthrough inventions as in Chapter 4 by looking at the co-occurrence of patent classes. Furthermore, I trace the time needed for countries to adopt the breakthrough inventions for the first time. In particular, I investigate whether local capabilities - as a source of place dependence - facilitate early adoption. In order to shed light upon the different locational effects of technology specific characteristics, I compare the diffusion patterns of breakthrough inventions in solar photovoltaic technology and wind power technology. 
Introduction

Table 1.1 Summary of empirical chapters

\begin{tabular}{|c|c|c|c|c|c|c|}
\hline & $\begin{array}{l}\text { RQ } \\
1\end{array}$ & $\begin{array}{l}\text { RQ } \\
2\end{array}$ & $\begin{array}{l}\text { RQ } \\
3\end{array}$ & $\begin{array}{l}\text { Type of } \\
\text { invention }\end{array}$ & Data & Unit of analysis \\
\hline $\mathrm{Ch} 2$ & $\mathrm{X}$ & & $\mathrm{X}$ & $\begin{array}{l}\text { New } \\
\text { specialisation }\end{array}$ & $\begin{array}{l}\text { Renewable energy patents } \\
\text { between 1998-2012 }\end{array}$ & $\begin{array}{l}\text { Six renewable } \\
\text { energy } \\
\text { technologies, } 64 \\
\text { countries } \\
\end{array}$ \\
\hline Ch 3 & $\mathrm{X}$ & $\mathrm{X}$ & & $\begin{array}{l}\text { Technological } \\
\text { impact of } \\
\text { renewable } \\
\text { energy patents } \\
\end{array}$ & $\begin{array}{l}\text { Renewable energy patents } \\
\text { between 1990-2010 and their } \\
\text { backward and forward } \\
\text { citations }\end{array}$ & $\begin{array}{l}30720 \text { patents in } \\
\text { six renewable } \\
\text { energy } \\
\text { technologies }\end{array}$ \\
\hline $\mathrm{Ch} 4$ & $\mathrm{X}$ & $\mathrm{X}$ & & $\begin{array}{l}\text { New } \\
\text { combinations of } \\
\text { technological } \\
\text { classes }\end{array}$ & $\begin{array}{l}\text { Solar PV patents between } \\
1997-2012\end{array}$ & $\begin{array}{l}599 \text { regions in } \\
\text { OECD + BRICS } \\
\text { countries }\end{array}$ \\
\hline Ch 5 & $\mathrm{X}$ & & $\mathrm{X}$ & $\begin{array}{l}\text { Adoption of new } \\
\text { combinations }\end{array}$ & $\begin{array}{l}\text { Solar PV and wind power } \\
\text { patents between 1993-2007 }\end{array}$ & $\begin{array}{l}49 \text { countries } \\
(\mathrm{OECD}+ \\
\text { BRICS } \\
\text { countries })\end{array}$ \\
\hline
\end{tabular}




\section{Chapter 2}

\section{The emergence of renewable energy technologies at country level: relatedness, international knowledge spillovers and domestic energy markets}

This chapter is co-authored with Gaston Heimeriks and Floor Alkemade, and has been published in Industry and Innovation as "Deyu Li, Gaston Heimeriks \& Floor Alkemade (2020) The emergence of renewable energy technologies at country level: relatedness, international knowledge spillovers and domestic energy markets, Industry and Innovation, DOI: 10.1080/13662716.2020.1713734" 


\begin{abstract}
Global sustainable development critically depends on a fundamental transformation of our current energy systems. This paper looks at how countries develop different types of renewable energy technology to achieve this transformation. We highlight the placedependence in the global innovation systems of renewable energy technologies by focusing on how countries benefit from local and global knowledge. We show that both the relatedness of a country's knowledge base, and international knowledge spillovers contribute to the development of renewable energy technologies. For low- and middleincome countries, domestic markets for renewables play a crucial role in absorbing and utilizing these international knowledge spillovers. The results provide a better understanding of how countries can acquire new knowledge in renewable energy technologies.
\end{abstract}




\subsection{Introduction}

Global sustainable development critically depends on a fundamental transformation of the current energy systems (IEA, 2015). This low-carbon transition requires worldwide innovation efforts to develop and deploy renewable energy technologies (Wilson and Grubler, 2011), although the energy transition pathways in individual countries may differ (Geels et al., 2016b; Cherp et al., 2017).

Of all the elements that shape energy transition pathways, knowledge is the most fundamental and powerful driver of innovation for climate change mitigation (Gallagher et al., 2012; Negro et al., 2012). Although the knowledge base of renewable energy technologies is increasingly global (Bettencourt et al., 2013; Noailly and Ryfisch, 2015), the development of new knowledge is unevenly distributed (Dechezleprêtre et al., 2011), and individual countries contribute markedly different knowledge to the global knowledge stock of renewable energy technologies (Sbardella et al., 2018). This paper analyses these differences in how countries benefit from local and global knowledge in developing renewable energy technologies.

Several bodies of literature provide relevant insights. First, evolutionary perspectives consider knowledge production as a path- and place-dependent process (Dosi, 1982; Nelson and Winter, 1982; Boschma et al., 2017a), where countries tend to develop new knowledge that is related to their existing knowledge bases (Boschma, 2017; Hidalgo et al., 2018). Second, the sustainability transitions literature highlights the multi-scalar knowledge dynamics in the global innovation systems of sustainable technologies (Binz and Truffer, 2017). On the one hand, this literature suggests that the place-dependence of sustainable innovations results from the idiosyncratic social-technical configuration processes at the local level (Hansen and Coenen, 2015). More specifically, innovation activities in renewable energy technologies are heavily influenced by the energy and environmental policies at the national level (Johnstone et al., 2010; Nicolli and Vona, 2016). On the other hand, this literature suggests a role for international knowledge spillovers, especially when a country lacks capabilities in developing renewable energy technologies (Binz and Anadon, 2018; Gosens et al., 2015). But countries benefit differently from these international knowledge spillovers due to different levels of absorptive capacities (Cohen and Levinthal, 1990; Mancusi, 2008; Verdolini and Galeotti, 2011). Both effects may thus be location-specific.

In order to systematically analyse the place-dependent impacts of relatedness and international knowledge spillovers, we study renewable energy patents for the post-Kyoto period between 1998 and 2012. We use transnational priority patents of inventors from 64 countries in the Worldwide Patent Statistical Database (PATSTAT, October 2015 version) 
maintained and distributed by the European Patent Office (EPO). We identify patents protecting inventions related to renewable energy technologies using the Y02 class in the Cooperative Patent Classification (Veefkind et al., 2012a). For our econometric analysis, we investigate whether the technological relatedness of a country's existing knowledge base to renewables and international knowledge spillovers help it develop renewable energy technologies. We further test whether their effects are location-specific by including the effects of domestic markets for renewables in our analyses.

Our contribution is twofold. First, we operationalize the global innovation systems concept proposed by Binz and Truffer (2017) by taking both the local knowledge base and international knowledge spillovers into consideration in explaining why countries differ markedly in their contributions to the global knowledge stock. Second, we highlight the place-dependent development trajectories of renewable energy technologies by focusing on the heterogenous impacts of relatedness and international knowledge spillovers across countries following the call for more place-based evidences in related diversification research (Boschma, 2017).

The remaining sections are organized as follows: Section 2 summarises the theoretical debates and describes the conceptual framework for the empirical analysis. Section 3 describes the data, methodology and variables. Section 4 contains the results of our descriptive and econometric analyses. We discuss these results and conclude in Section 5.

\subsection{Conceptual framework}

In evolutionary thinking, technological change is considered a path-dependent process (Dosi, 1982; Nelson and Winter, 1982). As a consequence, not every country has the same opportunities to develop new knowledge in energy technologies. Inventors and firms in a country tend to search locally, because they are able to understand, absorb and utilize external knowledge close to their own knowledge bases (Cohen and Levinthal, 1990; Kauffman, 1993; March, 1991). Thus, the existing knowledge base is a relevant determinant of the direction and rate of technological change (Breschi et al., 2003; Malerba, 2002).

The path-dependence of technological change thus leads to the place-dependence, in that a country's existing knowledge base creates opportunities, and sets constraints for future knowledge production within that country (Heimeriks and Boschma, 2014; Boschma et al., 2017a). Knowledge is localized in tacit learning processes, is specific to the context in which it is created, and consequently costly to use elsewhere (Antonelli, 1999). Moreover, most of the channels for transferring tacit knowledge are geographically bounded, such as spin-off processes, inventor collaborations and labour flows (Klepper, 2007; Breschi and 
Lissoni, 2009; Eriksson, 2011). Knowledge production is also strongly affected by national institutions (Malerba and Orsenigo, 1996; Antonelli, 1999; Boschma and Capone, 2015).

Technological relatedness plays an important role in technological diversification by facilitating the learning process, and creating opportunities for combining related technologies (Boschma, 2017; Breschi et al., 2003; Hidalgo et al., 2018). Knowledge spillovers from related technologies reduce the uncertainty in developing new technologies (Mowery and Rosenberg, 1998a). Given the fact that renewable energy technologies draw knowledge heavily from related technologies (Nemet, 2012; van den Berge et al., 2019), their presence will help a country develop new knowledge in such technology. In addition, the presence of related technologies provides opportunities for successful and less risky recombinant innovation (Fleming, 2001; Fleming and Sorenson, 2001). This is especially important for renewable energy technologies that can be considered as radical innovations resulting from the combination of existing technologies in novel ways (Markard and Truffer, 2006; Alkemade et al., 2009; Barbieri et al., 2020). We thus expect a positive effect of relatedness on developing renewable energy technologies.

The effect of relatedness may differ across countries (Boschma and Capone, 2015; Montresor and Quatraro, 2017; Petralia et al., 2017). The geography of sustainability transitions literature highlights that the place-dependence of sustainable innovations results from the unique social-technical configuration process at different locations (Hansen and Coenen, 2015). The development of renewable energy technologies is strongly affected by environmental and energy policies, and market liberalization processes at the national level (Johnstone et al., 2010; Nesta et al., 2014; Nicolli and Vona, 2016; Veugelers, 2012). Market formation and development have been identified as important for the development of technological innovation systems in renewable energy technologies (Hekkert et al., 2007; Negro et al., 2012). Growing markets have formed a vital complement to public R\&D in driving innovation activities through various channels, including learning by doing, economies of scale, and private R\&D investments (Bettencourt et al., 2013; Trancik et al., 2015). However, these market stimulating policies are also found to mostly introduce incremental innovations in renewable energy technologies (Nemet, 2009; Hoppmann et al., 2013; Schmidt et al., 2016; Trancik et al., 2015). Thus, we expect that the presence of a domestic market for renewables will strengthen the path-dependent process towards related renewable energy technologies.

With increasing globalization, international knowledge spillovers have become an important input for the inventive processes, either embodied in traded goods or services, or in various disembodied forms through cross-border flows of people, ideas and face-to-face contacts (Keller 2004). Many studies have shown how geographical proximity facilitates the flow of knowledge (Jaffe et al., 1993). More recently, the role of social proximity 
The emergence of renewable energy technologies at country level

through inventor collaborations has also been studied (Breschi and Lissoni, 2001). Inventor collaborations can accelerate the knowledge spillover process, especially for complex knowledge (Singh, 2005; Sorenson et al., 2006). Thus, social proximity can compensate for the lack of cognitive proximity in the innovation process (Boschma, 2005; Breschi and Lissoni, 2009).

Countries benefit from these international knowledge spillovers when developing new technologies (Mancusi, 2008; Malerba et al., 2013). International knowledge spillovers are especially important for producing knowledge in renewable energy technologies (Conti et al., 2018; Garrone et al., 2014; Verdolini and Galeotti, 2011; Wu and Mathews, 2012). Countries can utilize international knowledge to reduce their energy R\&D investments (Bosetti et al., 2008). This is vital in preventing underinvestment in R\&D for renewable energy technologies due to the 'double externality problem' - the unappropriated social benefits from both the positive knowledge spillovers during the R\&D process, as well as the reduced greenhouse gas emissions during the deployment of renewable energy technologies (Rennings, 2000; Jaffe et al., 2002). In addition, the exchange of external knowledge is essential for reducing uncertainty in the inventive process and for introducing successful innovations (Antonelli, 1999; Giuliani et al., 2016; Singh and Fleming, 2010). This is especially important as renewable energy technologies are often characterized by high uncertainty (Negro et al., 2012). Thus, we expect a positive effect of international spillovers on developing renewable energy technologies.

Countries may benefit differently from international knowledge spillovers due to different levels of absorptive capacity (Cohen and Levinthal, 1990; Mancusi, 2008; Verdolini and Galeotti, 2011). Cohen and Levinthal (1990) suggested that R\&D has two faces: innovation and learning. Knowledge accumulated in previous R\&D helps absorbing and utilizing external knowledge. Furthermore, learning during the adoption and diffusion of new technologies can also increase the absorptive capacity of a country (Carlsson and Stankiewicz, 1991; Hekkert et al., 2007). In addition, we thus expect that countries with larger domestic markets for renewables can benefit more from international knowledge spillovers from renewable energy technologies.

\subsection{Data, methods and variables}

\subsubsection{Patent data}

Patent data is widely used to study knowledge generation and diffusion (Jaffe and Trajtenberg, 2002). Although patents do not capture the overall innovative output (Pavitt, 1985; Griliches, 1990), they provide one of the most comprehensive and systematic overviews of knowledge production. Technology classifications of patents are widely used 
to study technological change (Fleming, 2001; Fleming and Sorenson, 2001) and to characterize firms and countries' knowledge bases (Antonelli et al., 2010; Nesta and Saviotti, 2005). Inventor information enables studies on the evolution of inventor collaborations and the ensuing knowledge spillovers (Breschi and Lissoni, 2009; Singh, 2005). Integrating these earlier methods, we use the filing date of patent applications, the inventor's address, and technology classifications from the Worldwide Patent Statistical Database (PATSTAT, 2015 October edition, maintained and distributed by European Patent Office, EPO) to empirically test how countries' knowledge bases and international knowledge spillovers shape the technological changes in renewable energy technology.

We use transnational priority patents (i.e. with subsequent filings protecting the same invention abroad) filed between 1998 and 2012, at whichever patent office. This methodology gives us a global perspective of technological development and a comprehensive assessment of countries' inventive performance suitable for international comparison (Alkemade et al., 2015; Haščič et al., 2015). We assign patents based on the inventor's country of residence, following de Rassenfosse et al. (2013), who employed a systematic approach to retrieve missing information on inventors in the PATSTAT database by examining subsequent filings of the same invention that may include this information. The inventor's country of residence better reflects the geographical origin of the inventive activity, as counting patents based on the applicant country tends to underestimate a country's inventive output when there are a large number of foreign-owned R\&D laboratories located in the country (Alkemade et al., 2015; Guellec and van Pottelsberghe de la Potterie, 2001). We fractionally split patents with multiple inventors across countries based on the proportion of inventors located in each country. For example, if a patent document lists three inventors, two living in country A and one in country B, two-thirds of that patent is allocated to country A and one-third to country B.

To identify patents relating to renewable energy technologies, we use the Y02 class taken from the Cooperative Patent Classification (CPC) table in the PATSTAT database. The Y02 class identifies patents relating to inventions or technologies for mitigation or adaptation against global climate change. EPO experts developed this class by combining existing International and European Patent Classifications with a lexical analysis of abstracts or claims (Veefkind et al., 2012a), and this has been widely adopted by researchers (Fankhauser et al., 2013; Bointner, 2014; Haščič and Migotto, 2015; Laurens et al., 2017; Choi, 2018).

To measure the knowledge bases of renewable energy technologies at the country level, we use an extended version of the IPC-based WIPO technology classification developed by Alkemade et al. (2015), which identifies 401 technologies. We fractionally split patents across technologies based on the share of IPC codes in each technology. For example, if the 
The emergence of renewable energy technologies at country level

patent lists three different IPC codes, two in Semiconductor Devices and one in Data Processing Systems, two thirds of the patent are allocated to Semiconductor Devices and one third to Data Processing Systems. Furthermore, we assume that all inventors contribute the same technological information to the patent.

Of the total sample of 3,960,563 transnational priority patents, 40,264 are inventions in renewable energy technologies. Figure 1 shows the number of patents for different types of renewable energy technology in the post-Kyoto period between 1998 and 2012. Solar photovoltaics and wind (left-axis) have the highest number of patents, followed by solar thermal, biofuel and waste (right axis). Patenting in all types of renewable energy technology, except geothermal, has increased rapidly since 2000. The number of transnational priority patents in recent years on the right of Figure 1 is potentially underestimated, due to censoring issues and incomplete data. The time needed for filing a subsequent application varies between international patenting strategies, from one year under the Paris Convention to 30 months under the Patent Cooperation Treaty (Dechezleprêtre et al., 2017).

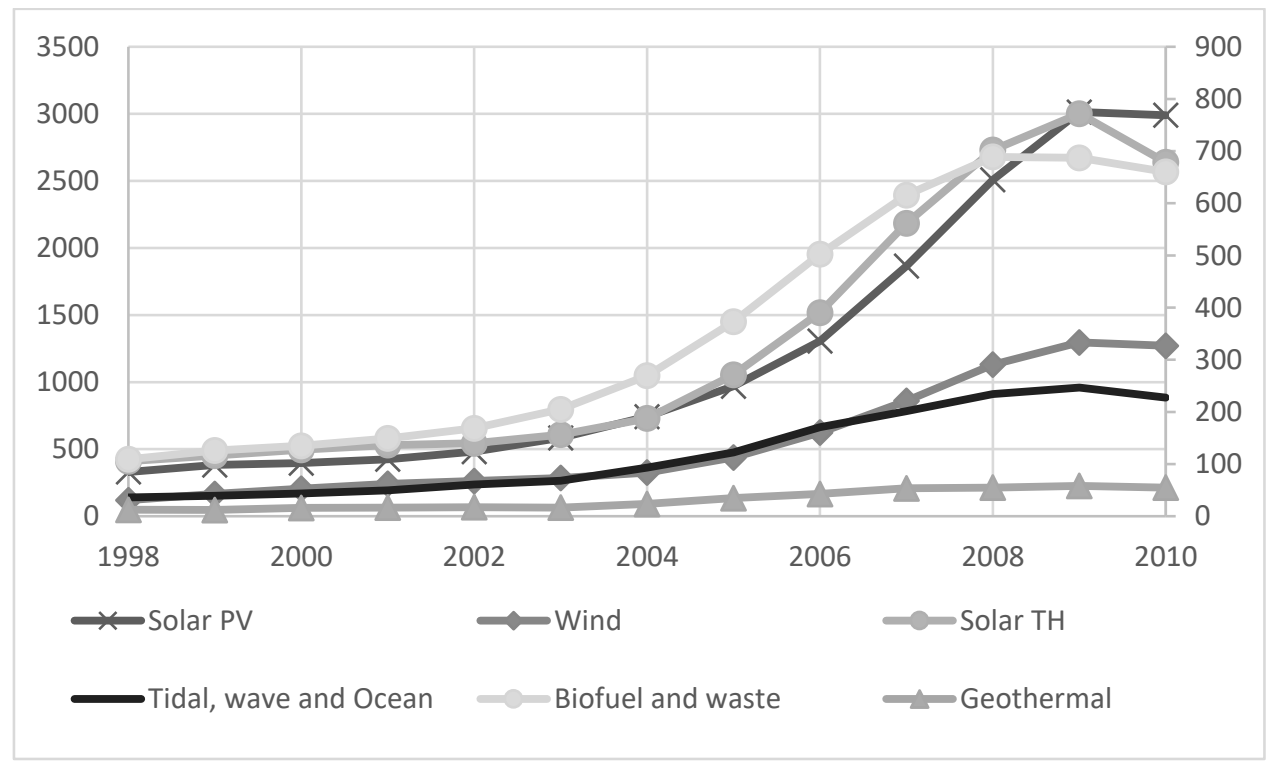

Figure 2.1 Number of patents by type of renewable energy technology (3-year moving average). Note: Solar thermal, tidal, wave and ocean, biofuel and waste and geothermal are shown on the right axis. 


\subsubsection{Variables}

\subsubsection{Measuring specialisation patterns of countries}

We use the revealed symmetric technological advantage (RSTA) index proposed by Laursen (2015) to indicate a country's specialisation in different renewable energy technologies. This index captures a country's share of technological knowledge produced in a given technology relative to the world average:

$$
R S T A_{c, i, t}=\frac{\left(R T A_{c, i, t}-1\right)}{\left(R T A_{c, i, t}+1\right)}
$$

with:

$$
R T A_{c, i, t}=\frac{\frac{P_{c, i, t}}{\sum_{i} P_{c, i, t}}}{\frac{\sum_{c} P_{c, i, t}}{\sum_{i} \sum_{c} P_{c, i, t}}}
$$

where $P_{c, i, t}$ denotes the number of patents in a given technology $i$ in country $c$ at time $t$. The value of $R S T A_{c, i, t}$ equals -1 if country $c$ holds no patent in technology $i$, is equal to 0 if country $c$ 's share in technology $i$ equals its share in all technologies (no specialisation) and is greater than 0 if a specialisation is observed. The RSTA index corrects for the differences in patenting propensity across technologies and countries (Soete and Wyatt, 1983).

\subsubsection{Characterizing a country's knowledge base}

We characterize a country's knowledge base by mapping the technological knowledge production in the country on the global technology space. Inspired by the "product space" framework (Hidalgo et al., 2007), the global technology space is a network representation of technological knowledge production, where nodes represent technological fields and ties indicate their degree of proximity. Related technologies are close together on the global technology space. We quantify the proximity between each pair of technologies by counting their co-occurrences at the patent level. The proximity between technology $i$ and $j$ at time $t$ is measured as follows:

$$
\Phi_{i, j, t}=\frac{P_{i, j, t}}{\sqrt{P_{i, t} * P_{j, t}}}
$$

where $P_{i, j, t}$ is the number of patents which list both technology $i$ and $j$ in the patent document at time $t . P_{i, t}$ and $P_{j, t}$ are the numbers of patents in technology $i$ and $j$ at time $t$.

The density index (Hidalgo et al., 2007) captures the relatedness of a given technology to the knowledge base of a given country by measuring the extent to which new technology produced in a given country tends to cluster around existing technologies within that 
The emergence of renewable energy technologies at country level

country. To calculate the relatedness of renewable energy technologies to a country's knowledge base requires a number of steps. First, Density $_{c, i, t}$ is defined as the degree to which technology $i$ is related to all other technologies $j$ that country $c$ specializes in at time $t$, divided by the total relatedness of technology $i$ to all other technologies in the global technology space at time $t$ :

$$
\operatorname{Density}_{c, i, t}=\frac{\sum_{j \neq i} \Phi_{i, j, t} * \chi_{c, j, t}}{\sum_{j \neq i} \Phi_{i, j, t}}
$$

where $\chi_{c, j, t}$ is a binary variable, indicating whether country $c$ specializes in technology $j$ $\left(\chi_{c, j, t}=1\right)$, or not $\left(\chi_{c, j, t}=0\right)$.

Finally, the relatedness of the country $c$ 's knowledge base to renewable energy technology $r$ at time $t$ is defined as the weighted average of the Density $y_{c, i, t}$ measure:

$$
\text { Relatedness }_{c, r, t}=\sum_{i} \text { Density }_{c, i, t} * \chi_{c, i, t} * \frac{P_{i, r, t}}{P_{r, t}}
$$

where $\chi_{c, i, t}$ denotes whether country $c$ specializes in technology $i\left(\chi_{c, i, t}=1\right)$, or not $\left(\chi_{c, i, t}=0\right) . P_{i, r, t}$ denotes the number of patents in renewable energy technology $r$ which lists technology $i$ in the patent document. $P_{r, t}$ denotes the number of patents in renewable energy technology $r$ at time $t$. A higher value of Relatedness $s_{c, r, t}$ indicates that renewable energy technology $r$ is more related to the knowledge base of country $c$ at time $t$.

\subsubsection{International knowledge spillovers}

Co_inv $v_{c, r, t}$ captures international knowledge spillovers measured as the number of coinvented patents between country $c$ and countries which specialized in renewable energy technology $r$ at time $t$ (Rigby, 2015). We only include the top 10 co-inventing countries for each renewable energy technology, focussing on knowledge spillovers from the global technological frontier. These countries account for $70-90 \%$ of all patents in the different renewable energy technologies.

\subsubsection{The domestic market for renewables}

We calculated the share of electricity generated from non-hydro renewable sources in country $c$ at time $t$, Renewables Re $_{c, t}$, to capture the development of the domestic market for renewables following Schimdt and Sewerin (2018). Electricity production data is extracted from the World Energy Balances (International Energy Agency, 2014 edition).

\subsubsection{Level of economic development}

We control for the level of economic development of countries using the constant (based on 2005) and PPP adjusted GDP per capita (Petralia et al., 2017). The data on PPP adjusted GDP and population of countries are extracted from the World Bank's Open Data Catalog. 
We thereby distinguish high-, and or low- and middle- income countries using the World Bank income classifications.

\subsubsection{Econometric Specification}

To empirically test our research questions, we estimate the following econometric equation:

$$
\begin{aligned}
& \chi_{c, r, t}=\beta_{0}+\beta_{1} \chi_{c, r, t-1}+\beta_{2} \text { Relatedness }_{c, r, t-1}+\beta_{3} \text { Co }_{-} \text {inv }_{c, r, t-1} \\
&+\beta_{4} \text { Relatedness }_{c, r, t-1} * \text { Renewables }_{c, t-1}+\beta_{5} \operatorname{Co}_{\text {inv }_{c, r, t-1}} \\
& * \text { Renewables }_{c, t-1}+\beta_{6} \text { Relatedness }_{c, r, t-1} * G D P_{c, t-1}+\beta_{7} \operatorname{Co}_{\text {inv }_{c, r, t-1}} \\
& * \text { GDP } P_{c, t-1}+\emptyset_{c, t}+\varphi_{r, t} \\
&+\epsilon_{c, r, t}
\end{aligned}
$$

where $\chi_{c, r, t}$ is a binary variable, indicating whether country $\mathrm{c}$ has a specialisation in renewable energy technology $\mathrm{r}\left(\chi_{c, r, t}=1\right)$, or not $\left(\chi_{c, r, t}=0\right)$. $\beta_{1}$ captures the correlation between specialisation at time $t-1$ with specialisation at time $t . \beta_{2}$ and $\beta_{3}$ capture the correlation between relatedness and international knowledge spillovers with specialisation. $\beta_{4}$ and $\beta_{5}$ capture whether the correlations between relatedness and international knowledge spillovers with specialisation differ among countries with different domestic market for renewables. $\beta_{6}$ and $\beta_{7}$ capture whether the correlations between relatedness and international knowledge spillovers with specialisation differ among countries with different levels of economic development. All the independent variables are lagged for one period to avoid potential endogeneity issues.

We also include fixed effects in the econometric equation, $\emptyset_{c, t}$ for the time-varying characteristics of a country $c$ and $\varphi_{i, t}$ for those of a renewable energy technology $i$. The time-varying country fixed effects and time-varying technology fixed effects are included in the model using dummy variables for each country-time pair and each technology-time pair. $\epsilon_{c, r, t}$ denotes the regression residue.

In the econometric analysis, we estimate equation (6) using a linear probability ordinary least square regression through which we can estimate the probability of observing 0 (no specialisation) or 1 (with specialisation). Scholars usually use logit or probit models if the dependent variable is binary because the linear probability model suffers from drawbacks; it usually generates biased and inconsistent estimates (Horrace and Oaxaca, 2006), and it does not deal with measurement error in the dependent variable (Hausman et al., 1998). However, fixed effects logit or probit models with a large number of dummy variables may lead to biased and inconsistent coefficients due to incidental parameter problems when the number of time periods is limited (Greene, 2011). The linear probability model does not suffer from this problem. Moreover, the average effects obtained from the linear probability model are quite similar to marginal effects from non-linear models (Riedl and Geishecker, 2014). Thus, the linear probability model is widely used in diversification literature 
The emergence of renewable energy technologies at country level

(Colombelli et al., 2014; Montresor and Quatraro, 2017; Petralia et al., 2017). Our use of the RSTA index as a robustness check thereby addresses the measurement error.

We include the lagged dependent variable to capture the persistence of knowledge production in renewable energy technologies at the country level. The time-varying country fixed effects in our model exploit variation within technologies, and the technology-time fixed effects exploit variation of countries, thus not correlating with time shocks in the error term, which is the usual bias in a fixed effects panel with lagged dependent variable (Arellano and Bond, 1991; Boschma and Capone, 2015). Furthermore, we use the systemGMM technique to estimate dynamic panel data models as a robustness check to ensure consistent estimates and address potential endogeneity problems (Blundell and Bond, 1998). All independent variables and the lagged dependent variable are treated endogenous, and all possible lags are used as instruments.

We divide the period 1998-2012 into five non-overlapping intervals of 3 years: 19982000, 2001-2003, 2004-2006, 2007-2009, and 2010-2012 following existing empirical studies in the regional diversification literature to avoid the impact of volatility in patent statistics on the calculation of our dependent variable (Montresor and Quatraro, 2017; Petralia et al., 2017). We include those countries with more than 10 patents in all five intervals resulting in 1920 observations; 64 countries, 6 renewable energy technologies and 5 time periods (see Table A1). Table A2 shows the correlation statistics of the independent variables. The correlations between independent variables are not high. 


\subsection{Empirical results}

\subsubsection{Descriptive analysis}

Table 2.1 shows the main specialisations in renewable energy technology of the top 10 patenting countries in renewable energy over time. Countries differ greatly in their contribution to the global knowledge stock. For most countries, the most specialized renewable energy technologies remain stable over time. Emerging economies like Korea, China and Taiwan contributed intensively in recent periods.

Table 2.1 Specialisations of top 10 patenting countries in renewable energies

\begin{tabular}{|c|c|c|c|c|c|}
\hline \multicolumn{2}{|l|}{$1998-2000$} & \multicolumn{2}{|l|}{ 2004-2006 } & \multicolumn{2}{|l|}{ 2010-2012 } \\
\hline Japan & $\begin{array}{l}\text { Solar PV, } \\
\text { Biofuel }\end{array}$ & $\begin{array}{l}\text { United } \\
\text { States }\end{array}$ & $\begin{array}{l}\text { Biofuel, } \\
\text { Solar PV }\end{array}$ & Japan & $\begin{array}{l}\text { Solar PV, } \\
\text { Wind }\end{array}$ \\
\hline Germany & $\begin{array}{l}\text { Wind, Solar } \\
\text { TH }\end{array}$ & Japan & $\begin{array}{l}\text { Solar PV, } \\
\text { Biofuel }\end{array}$ & $\begin{array}{l}\text { United } \\
\text { States }\end{array}$ & $\begin{array}{l}\text { Biofuel, Geo } \\
\text { TH }\end{array}$ \\
\hline United States & $\begin{array}{l}\text { Geo TH, } \\
\text { Biofuel }\end{array}$ & Germany & $\begin{array}{l}\text { Geo TH, } \\
\text { Solar TH }\end{array}$ & Germany & $\begin{array}{l}\text { Solar TH, } \\
\text { Wind }\end{array}$ \\
\hline Netherlands & $\begin{array}{l}\text { Ocean, Solar } \\
\text { TH }\end{array}$ & $\begin{array}{l}\text { United } \\
\text { Kingdom }\end{array}$ & Ocean, Wind & Korea & $\begin{array}{l}\text { Solar PV, } \\
\text { Ocean }\end{array}$ \\
\hline $\begin{array}{l}\text { United } \\
\text { Kingdom }\end{array}$ & $\begin{array}{l}\text { Ocean, Solar } \\
\text { TH }\end{array}$ & Korea & $\begin{array}{l}\text { Solar PV, } \\
\text { Geo TH }\end{array}$ & Taiwan & $\begin{array}{l}\text { Solar PV, } \\
\text { Geo TH }\end{array}$ \\
\hline France & $\begin{array}{l}\text { Biofuel, } \\
\text { Solar TH }\end{array}$ & France & $\begin{array}{l}\text { Solar TH, } \\
\text { Geo TH }\end{array}$ & Denmark & $\begin{array}{l}\text { Wind, } \\
\text { Biofuel }\end{array}$ \\
\hline Denmark & Wind, Ocean & Spain & $\begin{array}{l}\text { Wind, } \\
\text { Solar TH }\end{array}$ & France & $\begin{array}{l}\text { Ocean, Solar } \\
\text { TH }\end{array}$ \\
\hline Switzerland & $\begin{array}{l}\text { Geo TH, } \\
\text { Solar TH }\end{array}$ & Denmark & $\begin{array}{l}\text { Wind, } \\
\text { Biofuel }\end{array}$ & China & $\begin{array}{l}\text { Solar TH, } \\
\text { Wind }\end{array}$ \\
\hline Sweden & $\begin{array}{l}\text { Geo TH, } \\
\text { Wind }\end{array}$ & Canada & $\begin{array}{l}\text { Geo TH, } \\
\text { Ocean }\end{array}$ & $\begin{array}{l}\text { United } \\
\text { Kingdom }\end{array}$ & Ocean, Wind \\
\hline Australia & $\begin{array}{l}\text { Solar TH, } \\
\text { Ocean }\end{array}$ & Italy & $\begin{array}{l}\text { Geo TH, } \\
\text { Solar TH }\end{array}$ & Italy & $\begin{array}{l}\text { Solar TH, } \\
\text { Geo TH }\end{array}$ \\
\hline
\end{tabular}

Summary statistics in Table 2.2 show that the knowledge production of renewable energy technologies is persistent over time. $23.8 \%$ of the observations are countries maintaining their specialisations, whereas only $14.3 \%$ of the observations represent the development of 
The emergence of renewable energy technologies at country level

new specialisations ${ }^{1}$.

We further show the top 10 countries in the share of electricity generated from renewables. These are mostly European countries that have been promoting renewables to diversify energy supply and decrease their dependence on fossil fuel imports.

Table 2.2 Summary statistics of knowledge production in renewable energy technologies

\begin{tabular}{|c|c|c|c|c|c|}
\hline Independent Variables & Observations & Mean & SD & Min & Max \\
\hline \multirow{2}{*}{$\chi_{c, r, t-1}$} & 1,920 & 0.345 & 0.475 & 0 & 1 \\
\hline & \multicolumn{2}{|l|}{$\chi_{c, r, t}=0$} & \multicolumn{3}{|c|}{$\chi_{c, r, t}=1$} \\
\hline$\chi_{c, r, t-1}=0$ & \multicolumn{2}{|l|}{$51.3 \%$} & \multicolumn{3}{|c|}{$14.3 \%$} \\
\hline$\chi_{c, r, t-1}=1$ & \multicolumn{2}{|l|}{$10.7 \%$} & \multicolumn{3}{|l|}{$23.8 \%$} \\
\hline Relatedness $s_{c, r, t-1}$ & 1,920 & 0.168 & 0.169 & 0 & 0.810 \\
\hline Co_inv $v_{c, r, t-1}$ & 1,920 & 0.235 & 0.626 & 0 & 4.317 \\
\hline \multicolumn{6}{|c|}{ Country level independent variables } \\
\hline Renewables $_{r, c, t-1}$ & 1,920 & 0.03 & 0.049 & 0 & 0.276 \\
\hline$G D P_{c, t-1}$ & 1,920 & 9.715 & 0.748 & 7.617 & 11.498 \\
\hline
\end{tabular}

\subsubsection{Model outcomes}

Table 2.3 shows the estimation results of equation (2.6). A specialisation at time $t-1$ is significantly correlated with a specialisation at time $t$, supporting the path-dependence of knowledge production in renewable energy technologies at the country level. As expected, the coefficient of Relatedness $s_{r, c, t-1}$ is significantly positive in all columns of Table 2.3, confirming a correlation between specialisation and a country's knowledge base in related technologies. The results suggest that for renewable energy technologies which are considered more radical and complex, relatedness is still an important driver of knowledge production (Boschma, 2017; Hidalgo et al., 2018).

Regarding the interaction terms, the coefficients of Relatedness $s_{r, c, t-1}$ * Renewables $_{c, r, t-1}$ are significantly positive in both columns (4) and (5), suggesting that specialisation is more likely to be observed in countries with both higher relatedness and a larger domestic market for renewables. Thus, domestic markets for renewables are likely to

${ }^{1}$ The tetrachoric correlation between dependent variable and lagged dependent variable is 0.67 , also indicating the path-dependence and place-dependence of knowledge production in renewable energy technologies. 
strengthen the path-dependence towards related technologies given the positive correlation between relatedness and specialisation.

The coefficients of Relatedness $s_{r, c, t} * G D P_{c, t-1}$ are negative in column (2) and (6). The results imply that specialisation is less likely to be observed in countries that have higher relatedness and at the same time higher levels of economic development. However, the interaction term is not significant. A possible explanation could be that although higher income countries tend to have more capabilities, like larger public R\&D investment in renewable energy technologies, to support the development of less related technologies (Bointner, 2014; Hidalgo and Hausmann, 2009), they also tend to have larger domestic markets for renewables favouring more related technologies. As shown in Table 2.2, of the top 10 countries with the largest share of electricity generated from renewable sources 9 are high-income countries. These two effects offset each other.

When we consider the effects of international knowledge spillovers, the coefficients of $C o \_i n v_{r, c, t-1}$ are significantly positive in columns (3) and (5), indicating that specialisation are correlated with international knowledge spillovers. Binz and Truffer (2017) argue that the knowledge dynamics of the global innovation systems consist the generation of knowledge in locational subsystems, and the structural coupling among them. Our findings that both relatedness at the national level, and international knowledge spillovers are important for the development of renewable energy technologies provide a first empirical support of these multi-scalar dynamics.

The coefficients of $C o_{-} i n v_{r, c, t-1} *$ Renewables $_{c, r, t-1}$ and $C o_{-} i n v_{r, c, t-1} * G D P_{c, t-1}$ are both positive, suggesting that specialisation is more likely to be observed in countries with more collaborations with countries that are on the technological frontier, and at the same time have larger domestic markets for renewables or higher level of economic development. Interestingly, these two interaction terms are not significant. This result is not in line with our expectations.

In Table 2.4 we further investigate this by looking at the subsamples of high-, of lowand middle-income countries. The coefficients of Relatedness ${ }_{r, c, t-1}$ are significantly positive in both subsamples, confirming path-dependence. However, the coefficient of Co_inv $v_{r, c, t-1}$ is only significantly positive independently in the subsample of high-income countries. High-income countries tend to have larger absorptive capacities for utilizing international knowledge spillovers resulting from previous public R\&D (Bointner, 2014; Mancusi, 2008). 
The emergence of renewable energy technologies at country level

Table 2.3 Model outcomes (1998-2012)

\begin{tabular}{|c|c|c|c|c|c|c|}
\hline & \multicolumn{6}{|c|}{ Dependent variable: $\chi_{c, r, t}$} \\
\hline & $(1)$ & $(2)$ & $(3)$ & (4) & $(5)$ & $(6)$ \\
\hline \multirow{2}{*}{$\chi_{c, r, t-1}$} & $0.252^{* * *}$ & $0.252^{* * *}$ & $0.287^{* * *}$ & $0.287^{* * *}$ & $0.246^{* * *}$ & $0.245^{* * *}$ \\
\hline & $(0.039)$ & $(0.038)$ & $(0.039)$ & $(0.039)$ & $(0.038)$ & $(0.038)$ \\
\hline \multirow[t]{2}{*}{ Relatedness $_{c, r, t-1}$} & $0.656^{* * *}$ & $0.681^{* * *}$ & & & $0.648^{* * *}$ & $0.676^{* * *}$ \\
\hline & $(0.101)$ & $(0.196)$ & & & $(0.098)$ & $(0.196)$ \\
\hline \multirow[t]{2}{*}{ Co_inv $v_{c, r, t-1}$} & & & $0.048^{*}$ & 0.041 & $0.038^{*}$ & 0.018 \\
\hline & & & $(0.024)$ & $(0.075)$ & $(0.021)$ & $(0.069)$ \\
\hline \multirow{2}{*}{$\begin{array}{l}\text { Relatedness }_{c, r, t-1} \\
* \text { Renewables }_{c, r, t-1}\end{array}$} & & $3.737^{* *}$ & & & & $3.848^{* *}$ \\
\hline & & $(1.652)$ & & & & $(1.709)$ \\
\hline \multirow{2}{*}{$\begin{array}{l}\text { Relatedness }_{c, r, t-1} \\
* G D P_{c, t-1}\end{array}$} & & -0.006 & & & & -0.006 \\
\hline & & $(0.007)$ & & & & $(0.007)$ \\
\hline \multirow{2}{*}{$\begin{array}{l}\text { Co_inv }_{c, r, t-1} \\
* \text { Renewables }_{c, r, t-1}\end{array}$} & & & & -0.036 & & 0.191 \\
\hline & & & & $(0.434)$ & & $(0.337)$ \\
\hline \multirow{2}{*}{$\begin{array}{l}C o_{i n v_{c, r, t-1}} \\
* G D P_{c, t-1}\end{array}$} & & & & 0.0003 & & 0.0004 \\
\hline & & & & $(0.002)$ & & $(0.002)$ \\
\hline \multirow[t]{2}{*}{ Constant } & $0.169^{* * *}$ & $0.187^{* * *}$ & $0.125^{* * *}$ & $0.125^{* * *}$ & $0.170^{* * *}$ & $0.189^{* * *}$ \\
\hline & $(0.033)$ & $(0.037)$ & $(0.035)$ & $(0.035)$ & $(0.034)$ & $(0.038)$ \\
\hline Observations & 1,920 & 1,920 & 1,920 & 1,920 & 1,920 & 1,920 \\
\hline $\mathrm{R}^{2}$ & 0.466 & 0.467 & 0.450 & 0.450 & 0.467 & 0.468 \\
\hline
\end{tabular}

Note: country-clustered standard errors are in parentheses. Country + time and technology + time dummy variables are included in the linear probability model; ***,**, * statistically significant at .01 percent, .05 percent and .1 percent, respectively.

An important exception here are low- and middle-income countries with large domestic markets for renewables. Although the coefficient of $\mathrm{Co}_{-} i n v_{r, c, t-1}$ is significantly negative, the coefficient of $C_{-} i n v_{r, c, t-1} *$ Renewables $_{c, t-1}$ is significantly positive in column (4). The results suggest an important role for domestic markets for renewables in low- and middle-income countries in utilizing international knowledge spillovers. Although low- and middle-income countries can succeed in developing renewable energy technologies without the development of domestic markets, this type of exporting-oriented development is vulnerable to external shocks. An example is the Chinese solar PV industry which rapidly increased manufacturing output for international markets (Binz and Anadon, 2018; de la Tour et al., 2011; Luo et al., 2017; Quitzow, 2015). The innovation output of the Chinese solar PV industry lagged behind the manufacturing output and the industry experienced a 
great shake-out during the trade conflicts with EU and US (Binz et al., 2017b; Binz and Anadon, 2018).

The coefficient of Relatedness $s_{r, c, t-1} *$ Renewables $_{c, t-1}$ is only significantly positive in the subsample of low- and middle-income countries, suggesting that the role of domestic market for renewables in strengthening the path-dependent process towards related renewable energy technology is more prominent in low- and middle-income countries. High-income countries tend to have more capabilities for developing less related technologies (Hidalgo and Hausmann, 2009; Petralia et al., 2017).

Table 2.4 Model outcomes (1998-2012): Income level

\begin{tabular}{|c|c|c|c|c|}
\hline & (1) & (2) & (3) & (4) \\
\hline Model & \multicolumn{4}{|c|}{ Linear Probability } \\
\hline Dependent variable & \multicolumn{4}{|c|}{$\chi_{c, r, t}$} \\
\hline Subsamples & \multicolumn{2}{|c|}{ High-income } & \multicolumn{2}{|c|}{ Low- and Middle- income } \\
\hline \multirow{2}{*}{$\chi_{c, r, t-1}$} & $0.268^{* * *}$ & $0.269^{* * *}$ & $0.203^{* * *}$ & $0.178^{* * *}$ \\
\hline & $(0.054)$ & $(0.053)$ & $(0.053)$ & $(0.051)$ \\
\hline \multirow{2}{*}{ Relatedness $_{c, r, t-1}$} & $0.680^{* * *}$ & $0.558^{* * *}$ & $0.598^{* * *}$ & $0.429^{* *}$ \\
\hline & $(0.117)$ & $(0.146)$ & $(0.183)$ & $(0.194)$ \\
\hline \multirow{2}{*}{ Co_inv $v_{c, r, t-1}$} & $0.048^{*}$ & 0.051 & 0.034 & $-0.094^{* *}$ \\
\hline & $(0.028)$ & $(0.037)$ & $(0.066)$ & $(0.046)$ \\
\hline \multirow{2}{*}{$\begin{array}{l}\text { Relatedness }_{c, r, t-1} \\
* \text { Renewables }_{c, r, t-1}\end{array}$} & & 2.714 & & $12.278^{* * *}$ \\
\hline & & $(1.744)$ & & $(4.677)$ \\
\hline \multirow{2}{*}{$\begin{array}{l}\operatorname{Co}_{\text {inv }}, r, t-1 \\
* \text { Renewables }_{c, r, t-1}\end{array}$} & & -0.051 & & $5.412^{* * *}$ \\
\hline & & $(0.389)$ & & $(0.616)$ \\
\hline \multirow{2}{*}{ Constant } & $0.181^{* * *}$ & $0.181^{* * *}$ & $0.237^{* * *}$ & $0.240^{* * *}$ \\
\hline & $(0.058)$ & $(0.059)$ & $(0.037)$ & $(0.038)$ \\
\hline Observations & 960 & 960 & 960 & 960 \\
\hline $\mathrm{R}^{2}$ & 0.461 & 0.462 & 0.430 & 0.446 \\
\hline
\end{tabular}

Note: country-clustered standard errors are in parentheses. Country + time and technology + time dummy variables are included in the linear probability model; ***, **, * are statistically significant at .01 percent, .05 percent and .1 percent, respectively. 
The emergence of renewable energy technologies at country level

\subsubsection{Robustness check}

We run two additional analyses to check the robustness of our results. First, we re-estimate equation (2.6) using the RSTA index directly as our dependent variable. Second, we apply the system-GMM techniques. The results are shown in Table 2.5 and 2.6. The Sargan test tests whether the model is weakened by overidentifying restrictions. Only model column (3) in Table 5 suffers from this issue with a Sargen test $p$ value smaller than 0.05 . All $p$ values from Autoregressive test (1) are smaller than 0.05 and all $p$ values from Autoregressive test (2) are larger than 0.05, indicating that all system-GMM estimations are valid. The coefficients of the lagged dependent variable, Relatedness $s_{c, r, t-1}$ and $C o \_i n v_{c, r, t-1}$ are consistent with our estimations in Table 3 and Table 4.

The coefficients of Relatedness $s_{r, c, t-1} *$ Renewables $_{c, r, t-1}$ are significantly positive in column (2) in Table 2.5 and column (3) in Table 6 under a linear model setting using the RSTA index as dependent variable, so also consistent with the results in Table 2.3 and Table 2.4. However, this interaction term is not significant under system-GMM setting. We interpret this result as the presence of reverse causality as past successes in renewable energy technologies may facilitate the legitimation and implementation of market stimulating policies for renewables (Popp et al., 2011). For example, maintaining industry leadership is an explicit goal of German energy policy in addition to conventional goals like reducing environmental burden, reducing energy cost, and securing energy supply (Cherp et al., 2017; Schmidt et al., 2019). The effect of the domestic market for renewables is biased upwardly when endogeneity is not properly controlled for; it disappears under the systemGMM setting. This result is in line with recent papers of Popp, Hascic, and Medhi (2011) and Nesta, Vona, and Nicolli (2014).

The coefficient of $C o \_i n v_{r, c, t-1}$ is significantly positive in column (2) in Table 2.6, indicating that high-income countries can benefit from international knowledge spillovers. This is consistent with the findings in column (1) in Table 2.5. The coefficients of Relatedness $_{r, c, t-1} *$ Renewables $_{c, r, t-1}$ and $C o_{i n v_{r, c, t-1}} *$ Renewables $_{c, t-1}$ remain significantly positive in the system-GMM model for low- and middle- income countries, further confirming the importance of domestic markets for renewables in low- and middleincome countries for utilizing both domestic knowledge base in related technologies and international knowledge spillovers. 
Chapter 2

Table 2.5 Robustness check (1998-2012)

\begin{tabular}{|c|c|c|c|c|}
\hline & (1) & $(2)$ & (3) & $(4)$ \\
\hline Model & \multicolumn{2}{|c|}{ OLS } & \multicolumn{2}{|c|}{ System GMM } \\
\hline Dependent variable & \multicolumn{2}{|c|}{$R S T A_{c, r, t}$} & \multicolumn{2}{|c|}{$\chi_{c, r, t}$} \\
\hline \multirow[t]{2}{*}{$R S T A_{c, r, t-1}$} & $0.227^{* * *}$ & $0.223^{* * *}$ & & \\
\hline & $(0.041)$ & $(0.039)$ & & \\
\hline \multirow{2}{*}{$\chi_{c, r, t-1}$} & & & $0.257^{* * *}$ & $0.257^{* * *}$ \\
\hline & & & $(0.047)$ & $(0.047)$ \\
\hline \multirow{2}{*}{ Relatedness $_{c, r, t-1}$} & $0.606^{* * *}$ & $0.796^{* * *}$ & $1.074^{* * * *}$ & $0.995^{* * *}$ \\
\hline & $(0.114)$ & $(0.272)$ & $(0.127)$ & $(0.224)$ \\
\hline \multirow[t]{2}{*}{ Co_inv $v_{c, r, t-1}$} & $0.048^{*}$ & 0.076 & $0.066^{* *}$ & 0.011 \\
\hline & $(0.028)$ & $(0.089)$ & $(0.027)$ & $(0.066)$ \\
\hline \multirow[t]{2}{*}{ Relatedness $_{c, r, t-1}$ Renewables $_{c, r, t-1}$} & & $4.721^{* *}$ & & 1.123 \\
\hline & & $(2.235)$ & & $(1.582)$ \\
\hline \multirow{2}{*}{ Relatedness $_{c, r, t-1} * G D P_{c, t-1}$} & & -0.013 & & 0.008 \\
\hline & & $(0.009)$ & & $(0.008)$ \\
\hline \multirow{2}{*}{$\operatorname{Co}_{\text {inv }_{c, r, t-1}} *$ Renewables $_{c, r, t-1}$} & & $0.936^{* *}$ & & -0.245 \\
\hline & & $(0.421)$ & & $(0.341)$ \\
\hline \multirow{2}{*}{$C o_{i n v_{c, r, t-1}} * G D P_{c, t-1}$} & & -0.003 & & 0.001 \\
\hline & & $(0.003)$ & & $(0.002)$ \\
\hline \multirow[t]{2}{*}{ Constant } & $-0.337^{* * * *}$ & $-0.299^{* * *}$ & & \\
\hline & $(0.049)$ & $(0.056)$ & & \\
\hline $\mathrm{R}^{2}$ & 0.496 & 0.499 & & \\
\hline Sargan test $p$ value & & & 0.017 & 0.112 \\
\hline AR test (1) in first difference $p$ value & & & 0.000 & 0.000 \\
\hline AR test (2) in first difference $p$ value & & & 0.132 & 0.106 \\
\hline Observations & 1,920 & 1,920 & 1920 & 1920 \\
\hline
\end{tabular}

Note: In the linear probability model, country-clustered standard errors are in parentheses. In system-GMM model, robust standard errors are in parentheses. Country + time and technology + time dummy variables are included in the linear probability model; ***, **, * are statistically significant at .01 percent, .05 percent and .1 percent, respectively. 
The emergence of renewable energy technologies at country level

Table 2.6 Robustness check (1998-2012): Income level

\begin{tabular}{|c|c|c|c|c|}
\hline & (1) & $(2)$ & (3) & (4) \\
\hline Subsamples & \multicolumn{2}{|c|}{ High income } & \multicolumn{2}{|c|}{ Low- and Middle- income } \\
\hline Model & OLS & $\begin{array}{l}\text { System- } \\
\text { GMM }\end{array}$ & OLS & $\begin{array}{l}\text { System- } \\
\text { GMM }\end{array}$ \\
\hline Dependent variable & $R S T A_{c, r, t}$ & $\chi_{c, r, t}$ & $R S T A_{c, r, t}$ & $\chi_{c, r, t}$ \\
\hline \multirow[t]{2}{*}{$R S T A_{c, r, t-1}$} & $0.283^{* * *}$ & & $0.134^{* *}$ & \\
\hline & $(0.043)$ & & $(0.056)$ & \\
\hline \multirow[t]{2}{*}{$\chi_{c, r, t-1}$} & & $0.279^{* * * *}$ & & $0.209^{* * *}$ \\
\hline & & $(0.062)$ & & $(0.078)$ \\
\hline \multirow[t]{2}{*}{ Relatedness $_{c, r, t-1}$} & $0.438^{* * * *}$ & $1.148^{* * * *}$ & 0.393 & $1.165^{* * *}$ \\
\hline & $(0.152)$ & $(0.181)$ & $(0.293)$ & $(0.187)$ \\
\hline \multirow[t]{2}{*}{ Co_inv $v_{c, r, t-1}$} & 0.008 & $0.060^{*}$ & -0.066 & -0.018 \\
\hline & $(0.031)$ & $(0.037)$ & $(0.061)$ & $(0.049)$ \\
\hline \multirow{2}{*}{$\begin{array}{l}\text { Relatedness }_{c, r, t-1} \\
* \text { Renewables } \\
\end{array}$} & 2.923 & 1.363 & $25.646^{* * * *}$ & 3.947 \\
\hline & $(1.995)$ & $(1.395)$ & $(6.988)$ & $(6.982)$ \\
\hline \multirow{2}{*}{$\begin{array}{l}\operatorname{Co}_{i n v_{c, r, t-1}} \\
* \text { Renewables }_{c, r, t-1}\end{array}$} & $0.643^{* * *}$ & -0.345 & $8.013^{* * *}$ & $3.378^{* * *}$ \\
\hline & $(0.242)$ & $(0.332)$ & $(1.055)$ & $(1.202)$ \\
\hline \multirow[t]{2}{*}{ Constant } & $-0.279^{* * *}$ & & $-0.379^{* * *}$ & \\
\hline & $(0.080)$ & & $(0.082)$ & \\
\hline $\mathrm{R}^{2}$ & 0.504 & & 0.451 & \\
\hline Sargan $j$ test $p$ value & & 0.208 & & 0.855 \\
\hline $\begin{array}{l}\text { AR test (1) in first difference } p \\
\text { value }\end{array}$ & & 0.000 & & 0.000 \\
\hline $\begin{array}{l}\text { AR test (2) in first difference } p \\
\text { value }\end{array}$ & & 0.094 & & 0.700 \\
\hline Observations & 960 & 960 & 960 & 960 \\
\hline
\end{tabular}

Note: In linear probability model, country-clustered standard errors are in parentheses. In systemGMM model, robust standard errors are in parentheses. Country + time and technology + time dummy variables are included in the linear probability model; ***, **, * are statistically significant at .01 percent, .05 percent and .1 percent, respectively. 


\subsection{Conclusion and implications}

This paper systematically studies the development of knowledge for renewable energy technologies at the country level during the post-Kyoto period from 1998 to 2012. Building on evolutionary economics and the sustainability transitions literature, we empirically test the impacts of relatedness and international knowledge spillovers. Overall our study confirms the path- and place-dependencies of renewable energy technology development: countries tend to produce more knowledge in renewable energy technologies related to their existing knowledge base.

Furthermore, our results confirm our expectations based on the sustainability transitions literature that the development of emerging sustainable technologies requires both local and global knowledge inputs. The paper thereby provides a first empirical operationalization of global innovation systems framework proposed by Binz and Truffer (2017). More specifically, we find that international knowledge spillovers help countries to develop new renewable energy technologies. Additionally, in our sample for low- and middle- income countries, we found an important role for domestic market development in utilizing these international knowledge spillovers. This provides implications for the catching-up strategy of latecomer countries. Sustainability transitions open new opportunities for latecomer countries to catch up by engaging with the global innovation systems of clean energy technologies (Mathews, 2013; Meckling and Hughes, 2018; Perez, 2016) and the creation of domestic markets can help latecomer countries to seize these opportunities (Binz et al., 2017a; Yap and Truffer, 2019).

In this paper we highlighted the place-dependence in the global innovation systems of renewable energy technologies. A better understanding of how knowledge and other resources are articulated and combined in the global innovation systems requires further study to also investigate (1) what type of policy can facilitate more radical and unrelated innovations in sustainable technologies to avoid technological lock-in caused by the focus on related technology (Janssen and Frenken, 2019; Safarzyńska and van den Bergh, 2013; Zeppini and van den Bergh, 2011); (2) whether countries also benefit from international knowledge spillovers from other technologies in developing renewable energy technologies (Nemet, 2012), and through which channels international knowledge can be better transferred across countries (Popp, 2011). 
The emergence of renewable energy technologies at country level

Appendices

Table 2.A.1: Countries included in the econometric analyses and the number of transnational priority patents in each country between 1998 and 2012

\begin{tabular}{|c|c|c|}
\hline Country & ISO country code & Number of patents \\
\hline Argentina & $\mathrm{AR}$ & 1571 \\
\hline Australia & $\mathrm{AU}$ & 28591 \\
\hline Austria & AT & 27787 \\
\hline Belarus & BY & 297 \\
\hline Belgium & $\mathrm{BE}$ & 20879 \\
\hline Brazil & BR & 5396 \\
\hline Bulgaria & BG & 428 \\
\hline Canada & $\mathrm{CA}$ & 60748 \\
\hline Chile & $\mathrm{CL}$ & 698 \\
\hline China (PR of China and Hong Kong) & $\mathrm{CN}$ & 89355 \\
\hline Chinese Taipei & TW & 116691 \\
\hline Colombia & $\mathrm{CO}$ & 448 \\
\hline Croatia & HR & 621 \\
\hline Cuba & $\mathrm{CU}$ & 205 \\
\hline Cyprus & $\mathrm{CY}$ & 155 \\
\hline Czech Republic & $\mathrm{CZ}$ & 3092 \\
\hline Denmark & DK & 17215 \\
\hline Egypt & EG & 249 \\
\hline Estonia & $\mathrm{EE}$ & 418 \\
\hline Finland & FI & 26124 \\
\hline France & FR & 136374 \\
\hline Germany & $\mathrm{DE}$ & 426272 \\
\hline Greece & GR & 1419 \\
\hline Hungary & $\mathrm{HU}$ & 3089 \\
\hline Iceland & IS & 480 \\
\hline India & $\mathrm{IN}$ & 13387 \\
\hline Indonesia & ID & 222 \\
\hline Ireland & IE & 5680 \\
\hline Israel & IL & 25916 \\
\hline
\end{tabular}


Chapter 2

\begin{tabular}{|c|c|c|}
\hline Italy & IT & 73456 \\
\hline Japan & JP & 910112 \\
\hline Kazakhstan & $\mathrm{KZ}$ & 110 \\
\hline Korea & $\mathrm{KR}$ & 236260 \\
\hline Latvia & LV & 279 \\
\hline Lithuania & LT & 242 \\
\hline Luxembourg & LU & 1209 \\
\hline Malaysia & MY & 2117 \\
\hline Mexico & MX & 2401 \\
\hline Morocco & MA & 102 \\
\hline Netherlands & NL & 46995 \\
\hline New Zealand & NZ & 5519 \\
\hline Norway & NO & 9578 \\
\hline Philippines & $\mathrm{PH}$ & 400 \\
\hline Poland & PL & 3309 \\
\hline Portugal & PT & 1349 \\
\hline Romania & RO & 518 \\
\hline Russian Federation & RU & 9459 \\
\hline Saudi Arabia & SA & 706 \\
\hline Serbia & $\mathrm{RS}$ & 256 \\
\hline Singapore & SG & 8873 \\
\hline Slovakia & SK & 700 \\
\hline Slovenia & SI & 1615 \\
\hline South Africa & $\mathrm{ZA}$ & 4492 \\
\hline Spain & ES & 20003 \\
\hline Sweden & SE & 42634 \\
\hline Switzerland & $\mathrm{CH}$ & 42564 \\
\hline Thailand & $\mathrm{TH}$ & 659 \\
\hline Turkey & TR & 3226 \\
\hline Ukraine & UA & 2063 \\
\hline United Arab Emirates & $\mathrm{AE}$ & 245 \\
\hline United Kingdom & GB & 120499 \\
\hline United States & US & 732948 \\
\hline
\end{tabular}


The emergence of renewable energy technologies at country level

\begin{tabular}{|l|l|l|}
\hline Uruguay & UY & 161 \\
\hline Venezuela & VE & 177 \\
\hline
\end{tabular}

Table 2.A.2. Correlation Statistics

\begin{tabular}{|c|c|c|c|c|c|}
\hline & $\chi_{c, r, t}$ & Relatedness $_{c, r, t}$ & Co_inv $_{c, r, t}$ & Renewables $_{c, t}$ & $G D P_{c, t}$ \\
\hline$\chi_{c, r, t}$ & 1.000 & 0.461 & 0.237 & 0.130 & 0.153 \\
\hline Relatedness $_{c, r, t}$ & 0.461 & 1.000 & 0.172 & 0.121 & 0.127 \\
\hline Co_inv $_{c, r, t}$ & 0.237 & 0.172 & 1.000 & 0.168 & 0.231 \\
\hline Renewables $_{c, t}$ & 0.130 & 0.121 & 0.168 & 1.000 & 0.128 \\
\hline GDP $_{c, t}$ & 0.153 & 0.127 & 0.231 & 0.128 & 1.000 \\
\hline
\end{tabular}




\section{Chapter 3}

\section{Knowledge flows in global renewable energy innovation systems: the role of technological and geographical distance}

This chapter is co-authored with Gaston Heimeriks and Floor Alkemade, and is under review. 


\begin{abstract}
Understanding the global knowledge dynamics of renewable energy technologies requires consideration of both technological and geographical dimensions. This paper assesses the relative importance of technological and geographical distant knowledge flows in the future knowledge development of technological innovation systems (TIS) of renewables. Using global renewable energy patents, we quantify the absorptive capacity of countries as the knowledge diffusion between domestic actors in a TIS. Our results show that international knowledge flows within a TIS are more important for countries with smaller absorptive capacity, whereas countries with larger absorptive capacity benefit more from domestic knowledge originating in other TISs. Consequently, each country faces unique opportunities and constraints with respect to global technological developments when developing renewable energy technologies. These findings lead to policy implications that are specific to developing renewable energy technologies in different countries.
\end{abstract}




\subsection{Introduction}

The development and deployment of clean energy innovations play a key role in the global sustainability transitions (Gallagher et al., 2012). Technological change, i.e. the invention, innovation and diffusion of new technologies, is considered a cumulative and recombinant process in which new technologies result from the recombination of existing technologies in novel ways (Arthur, 2007; Dosi, 1982; Henderson and Clark, 1990). This process requires interactions between actors with different backgrounds for knowledge development and diffusion, which is a key mechanism highlighted in the innovation system approaches (Carlsson et al., 2002; Lundvall, 1992; Malerba, 2002; Nelson, 1993).

Among the different innovation system approaches, the technological innovation system (TIS) concept contributed significantly to the understanding of the emergence of sustainable technologies in energy, transport and water sectors (Bergek et al., 2015, 2008; Carlsson and Stankiewicz, 1991; Hekkert et al., 2007; Markard et al., 2015). A focal TIS evolves in interactions with parts of various national innovation systems and with various other TISs which in turn, are embedded in national system of innovations (Carlsson and Stankiewicz, 1991; Hekkert et al., 2007). These interactions have however been underconceptualized in TIS literature (Bergek et al., 2015), leading to the insight that both the endogenous and exogenous factors that influence the dynamics of a TIS should be taken into account (Bergek et al., 2015; Markard et al., 2015).

More specifically, knowledge originating in other TISs has been found to play an important role in emerging TISs (Andersen et al., 2019; Mäkitie et al., 2018; Malhotra et al., 2019; Stephan et al., 2017; van den Berge et al., 2019). Furthermore, the knowledge needed for the development of a renewable energy TIS may originate in different countries resulting from their distinct knowledge development trajectories (Boschma, 2017; Hidalgo et al., 2018; Petralia et al., 2017; Sbardella et al., 2018). Although the TIS concept inherently embraces this global perspective (Carlsson, 2006; Carlsson et al., 2002; Hekkert et al., 2007), most of the early empirical TIS applications were carried out within national boundaries (Coenen et al., 2012).

Both knowledge flows between TISs (Battke et al., 2016; Malhotra et al., 2019; Nemet, 2012; Stephan et al., 2019) and international knowledge flows (Conti et al., 2018; Verdolini and Galeotti, 2011; Wu and Mathews, 2012) are found to be important for the development of renewable energy technologies. While the recent literature on global innovation systems acknowledge these multi-scalar knowledge dynamics (Binz and Truffer, 2017; Martin, 2016; Weber and Truffer, 2017), there is a lack of systematic evidence on how different knowledge flows between TISs and NISs influence future knowledge development in global renewable energy innovation systems. 
In order to address this gap, we investigate knowledge flows along both technological and geographical dimensions. We thereby take the role of the absorptive capacity of countries, resulting from the positive feedback loops in the knowledge diffusion between actors within renewable energy TISs in a country into account. We base our analysis on patents, and their backward and forward citations. Insights in the relative importance of the different knowledge flows helps to identify the opportunities and constraints for the development of successful energy technologies at different locations.

The paper is structured as follows. In section 2, we review the literature and establish our conceptual framework. In section 3, we describe the data, variables and specifications of econometric models. In section 4 , we present the results of descriptive analysis and econometric analyses. We conclude by discussing the implications of our findings in section 5 .

\subsection{Theoretical background}

The production of economically useful new knowledge is considered to result from the collective actions of different actors within an innovation system connected by linkages ranging from informal to formalized network relationships (Lundvall, 1992). Based on different delineations of system boundaries, several innovation system approaches have emerged over the years. National innovation systems (Lundvall, 1992; Nelson, 1993) set system boundaries along the geographical boundaries of countries. In other cases, system boundaries are set along a technology (Carlsson and Stankiewicz, 1991) or a sector (Malerba, 2002).

In recent years, the technological innovation systems (TISs) concept has been prominently applied in analysing the dynamics of system building and industry formation of emerging sustainable technologies (Bergek et al., 2015; Markard et al., 2015). The TIS functions and system building literature help understand how specific technological fields have evolved in interaction with firms and knowledge institutions (Bergek et al., 2008; Hekkert et al., 2007; Hekkert and Negro, 2009; Suurs and Hekkert, 2009).

The interaction between a focal TIS and its specific context is less studied but equally important. Initially, emerging technologies have to build on and recombine the available knowledge and institutions of existing technologies (Arthur, 2007; Henderson and Clark, 1990). Technologies mature by developing their own technological trajectories and supporting institutions, thereby reducing their reliance on other technologies over time (Cohen and Levinthal, 1990; Dosi, 1982).

Knowledge flows between TISs are therefore considered important, as they often underlie successful new knowledge recombination (Arthur, 2007; Henderson and Clark, 1990; Mowery and Rosenberg, 1998b; Scherer, 1982). Several studies have aimed at 
identifying their impact on subsequent technology development in low-carbon TISs. Both Nemet (2012) and Battke et al. (2016) found that knowledge flows between TISs are more likely to increase the impacts of low-carbon innovations. Moreover, without knowledge from other TISs to provide new technological opportunities, the limits to incremental improvement to existing technologies can soon be reached (Safarzyńska and van den Bergh, 2013; Zeppini and van den Bergh, 2011).

\subsubsection{The geographical dimension of TIS}

Although the TIS approach was originally formulated as a critique of territorial innovation system approaches (Carlsson, 2006; Carlsson and Stankiewicz, 1991) by explicitly claiming that new technologies may emerge in fluid global networks with actors simultaneously operating at multiple geographical scales (Carlsson et al., 2002; Hekkert et al., 2007), most earlier empirical applications of the TIS concept were carried out within national boundaries (Coenen et al., 2012). Recent systematic empirical evidence shows that countries contribute markedly different new knowledge to the global knowledge base of low-carbon technologies (Sbardella et al., 2018), suggesting that countries differ in their capabilities for identifying, absorbing and exploiting global technological opportunities.

Rooted in evolutionary economics, recent literature in evolutionary economic geography highlights the path- and place-dependence of knowledge production (Boschma et al., 2017a). The unique existing knowledge base of countries (and regions) constrains, as well as opens up, opportunities for the development of new technologies (Boschma et al., 2014; Heimeriks and Boschma, 2014). Countries (and regions) are more likely to develop new technologies that are related to their existing knowledge bases (Boschma, 2017; Hidalgo et al., 2018, 2007; Petralia et al., 2017). This related diversification process at the local level is also observed in the development of sustainable technologies (Montresor and Quatraro, 2019; Perruchas et al., 2019; Tanner, 2016; van den Berge et al., 2019).

The place-dependence matters for the knowledge development of emerging low-carbon TISs in two ways. First, although the emerging low-carbon technologies are often considered radical (Markard and Truffer, 2006), the skills and competences required may still emerge from the existing technologies in the country (Hansen and Coenen, 2015). In a recent review of social-technical transitions research, Geels (2018) pointed out that 'incumbent actors can resist, delay or derail low-carbon transitions, but they can also accelerate them if they reorient their strategies and resources towards niche-innovations'. Empirically, Van den Berge et al. (2019) found that some clean technologies may even partly have developed out of fossil fuel knowledge. The recent case study of the Norwegian oil and gas industries and their roles in the development of offshore wind technology also supports this argument (Mäkitie et al., 2018). Given the disruptive role of emerging lowcarbon technologies in the energy sector, bringing together technologically distant 
technologies within an economy will face less pressure from existing institutions (Frenken, 2017; Janssen and Frenken, 2019).

Second, the uneven distribution of knowledge across countries also points to the importance of global knowledge networks in tapping into knowledge developed elsewhere (Bergek et al., 2015; Binz and Truffer, 2017; Coenen et al., 2012; Hansen and Coenen, 2015; Markard et al., 2015; Meckling and Hughes, 2018). For example, Binz et al. (2014) analysed how actors in the TIS of membrane bioreactor technology are connected through knowledge networks at the global scale. Gosens et al. (2015) summarized how global linkages can influence the formation of TISs in emerging economies. Quitzow (2015) analysed the co-evolution of the solar photovoltaic TIS in Germany and China to show how TIS functions in different countries build upon, and complement each other. Similarly, Bento and Fontes (2015) demonstrated the coupled dynamics between wind energy TISs in Denmark and Portugal. These studies point to the importance of international knowledge flows within a global innovation system.

\subsubsection{Multi-scalar knowledge dynamics}

The recent theoretical and empirical attempts in bringing a geographical dimension into TIS research cumulated into the formation of the global innovation systems (GIS) concept (Binz and Truffer, 2017; Martin, 2016). Global innovation systems can be understood as resulting from two dynamics, the generation of resources in different locational subsystems, and the strategic coupling among them (Bergek et al., 2015; Binz and Truffer, 2017).

The multi-scalar dynamics are important for analysing the knowledge flows in emerging TISs. Along the technological dimension, innovations vary in the extent to which they build knowledge along a technology's own trajectory (within a TIS) or other technologies (between TISs). Along the geographical dimensions, innovations vary in the extent to which they build on domestic sources of knowledge (within a NIS) and international sources of knowledge (between NISs).

Knowledge development processes in emerging TISs often bridge technological and/or geographical distance to bring together and recombine knowledge originating in different TISs and NISs (Arthur, 2007; Henderson and Clark, 1990). This is particularly true for renewable energy technologies: First, renewable energy technologies are considered as complex technologies which require knowledge input from various technologies (Barbieri et al., 2020; Malhotra et al., 2019; Nemet, 2012); Second, knowledge in renewable energy technologies is unevenly distributed across countries (Conti et al., 2018; Sbardella et al., 2018). Thus, a proper analysis of the knowledge flows in global renewable energy innovation systems has to take into account both technological and geographical dimensions. 
Although the novelty associated with external knowledge flows tends to increase with the distance of knowledge in geographical or technological dimensions (Boschma, 2005), the difficulties in absorbing and integrating this external knowledge also increase (Baldwin and Clark, 2000; Cohen and Levinthal, 1990; Nooteboom, 2000). The impacts of technologically or geographically distant knowledge flows thus also depend on the absorptive capacity of countries (Guan and Yan, 2016; Mancusi, 2008; Phene et al., 2006). This absorptive capacity results from the knowledge diffusion through networks of domestic actors within the TIS (Carlsson et al., 2002); the interactions between actors in an innovation system create positive feedback loops that are important for innovation system functioning and growth (Suurs and Hekkert, 2009). Consequently, we expect the impacts of technologically or geographically distant knowledge on future technology development to differ for countries with different levels of absorptive capacity.

\subsection{Data and Methods}

\subsubsection{Patent data}

The data used in this paper are patent applications filed at the European patent office (EPO), the United States Patent and Trademark Office (USPTO) and through the Patent Cooperation Treaty (PCT-route) from 1980 to 2015. Patent applications are extracted from the European Patent Office Worldwide Patent Statistics Database PATSTAT (EPO, 2018 Autumn Version). Since multiple equivalent patent applications can be filed at different patent offices to protect the intellectual property rights of the same invention, we use the DOCDB patent family as the unit of analysis in this paper (Martínez, 2011). The year of a DOCDB patent family is based on the application year of the earliest patent in the family. In the following, one "patent" represents one "DOCDB patent family", and citations between patents represent citations between patent families. Moreover, we only focus on patents assigned to companies and institutions following Mancusi (2008). The type of applicant is identified using the PATSTAT Standardized Name Table developed by ECOOM in KU Leuven (Du Plessis et al., 2009; Magerman et al., 2009). 
Patents relating to different types of renewable energy technology are identified using the Y02 class in the newly launched Cooperative Patent Classification (CPC) ${ }^{2}$. The Y02 class is developed by EPO experts by combining existing International Patent Classifications (IPC) and European Patent Classifications with a lexical analysis of abstracts or claims (Veefkind et al., 2012b), and has been widely adopted by researchers to study climate change mitigation and adaptation technologies (Haščič and Migotto, 2015; Sbardella et al., 2018).

\subsubsection{Variables}

\subsubsection{Dependent variable: technological impact within TIS}

We aim to assess the impacts of technologically or geographically distant knowledge on subsequent technology development in renewable energy TISs. Hence, we are interested in the relative technological impact of inventions drawing on knowledge from the past in various ways. Counts of forward citations received by patents have been widely used as a proxy for the technological impact of inventions (for a review, see Jaffe \& de Rassenfosse (2017)). Following Nemet (2012) and Battke et al. (2016), we count the number of forward citations within the same type of renewable energy technology received by a patent to measure its technological impact within the focal TIS. We count the number of forward citations within the 5-year citation buffer window. As a result, we include patents applied until 2010 in the analyses. In the robustness check, we also use a 10-year citation buffer window.

\subsubsection{Technological and geographical distance}

Backward citations of patents are frequently used as an indicator of the extent to which an invention relies on previous technology (Jaffe and de Rassenfosse, 2017). We identify a backward citation as a knowledge flow between TISs (i.e., an innovation building on technologically distant knowledge) when the cited patent is not labelled as the same type of renewable energy technology as the citing patent following Battke et al. (2016). Since our sample started from 1980, we only consider patents applied after 1990 to ensure that each patent has a minimum of 10 years of patent history from which it can cite prior art following Nemet (2012).

${ }^{2} \mathrm{We}$ focus on six types of non-hydro renewable energy technology: solar photovoltaic (Y02E10/5), solar thermal (Y02E10/4), wind (Y02E10/7), Ocean (Y02E10/3), biofuel (Y02E50/1) and geothermal (Y02E10/1). 
Backward citations are also frequently used to trace knowledge flows across geographical boundaries (Jaffe et al., 1993). We assign each patent to the country of residence of the first named inventor in the patent document following Mancusi (2008). The inventor's address can better identify where the R\&D was performed given the significant presence of multinational corporations (Alkemade et al., 2015; de Rassenfosse and Seliger, 2019). A knowledge flow is considered international when the focal patent cited a foreign patent. Otherwise, the knowledge flow is considered domestic.

We then classify each of the backward citations into four mutually exclusive categories along both geographical and technological dimensions: Domestic Proximate (domestic knowledge flows within the focal TIS), Domestic Distant (domestic knowledge flows between TISs), International Proximate (international knowledge flows within the focal TIS), and International Distant (international knowledge flows between TISs). We count the numbers of backward citations of a focal patent in all four categories and include them in the regression as independent variables. To avoid strategic citations to prior art, selfcitations are excluded by removing backward citations in which the cited patent is assigned to the same applicant as the citing patent (Hall et al., 2005).

\subsubsection{Absorptive capacity of countries}

We proxy the Absorptive Capacity of a country in a specific type of renewable energy technology with the average number of backward citations to domestic patents in this technology per patent. We calculate this variable using patents applied in the five years to the application year of the focal renewable energy patent. This variable is adapted from the absorptive capacity variable used in Mancusi (2008) who counted the average number of self-citations per patent in a country in an industry and argued that self-citations indicate knowledge accumulation internal to the firm, and thus are a good proxy for absorptive capacity resulting from internal $R \& D$.

Similarly, we use the domestic knowledge flows within the focal TIS per patent to capture the domestic knowledge accumulation within the focal TIS. Since self-citations are excluded in the calculation, this variable captures the positive feedback loops resulting from the knowledge diffusions in the interactions between domestic actors in an innovation system (Suurs and Hekkert, 2009). This variable thus captures both the size of the knowledge stock of a focal renewable energy TIS in a country, and how strongly the actors in a country build upon knowledge created by other domestic actors in the focal TIS.

\subsubsection{Control variables}

Following earlier work on knowledge flows and forward citations, we included five control variables. First, we control for the size of the patent family (Family size). Since filing patent applications at different patent offices is costly, companies will only do so for their 
important innovations. A positive effect of Family size is therefore expected. Second, we control for the size of the team by including the number of inventors (Team size). A positive effect of Team size is expected since larger teams tend to have a more diverse knowledge pool to tap from previous inventions, and larger teams also tend to have larger collaboration network which increases the likelihood of the invention being used by other inventors in the future (Singh and Fleming, 2010). Third, we include the dummy variable Public to indicate whether a patent is assigned to universities or public research institutes. Nemet (2012) found that patent assigned to companies are more likely to receive more citations. Fourth, the existing literature shows that patents incorporating scientific knowledge are more likely to receive more forward citations (Sorenson and Fleming, 2004). We control for this influence by including the number of citations to the non-patent literature by the focal patent (Non-Patent Literature). Since the distribution of the number of non-patent literature citations is highly skewed, we include the log transformed value in the model. Finally, following Nemet (2012), we control for the average backward citation lag. A negative effect of Citation lag is expected since the value of the cited patent decreases with its age (Criscuolo and Verspagen, 2008). For patents without any backward citation, we use zero for citation lag, following Battke et al. (2016). In the robustness check, we exclude the patents without backward citations. The results are consistent.

\subsubsection{Empirical strategy}

Since our dependent variable, the number of forward citations, is a count variable, we use the negative binominal regression model to test our hypotheses. We included the country, technology, and time dummies to control for unobserved heterogeneities. Summary statistics for variables used in the regression are presented in Table 3.1. The independent variables are not highly correlated. 
Chapter 3

\begin{tabular}{|c|c|c|c|c|c|c|c|c|c|c|c|}
\hline 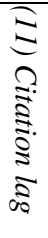 & 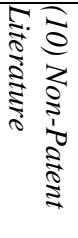 & 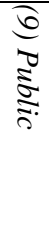 & 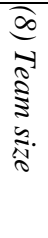 & 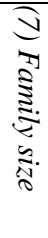 & 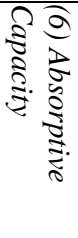 & 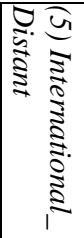 & 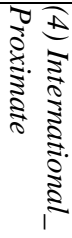 & 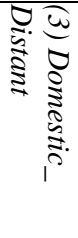 & 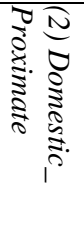 & 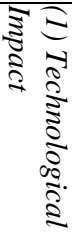 & \\
\hline$\dot{8}$ & $\begin{array}{l}0 \\
\infty \\
\infty \\
\infty\end{array}$ & $\stackrel{0}{\dot{E}}$ & $\begin{array}{l}\text { Na } \\
\text { g్ర }\end{array}$ & $\begin{array}{l}+\vec{g} \\
\dot{\sigma}\end{array}$ & $\underset{\sim}{\stackrel{N}{\sim}}$ & 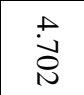 & $\underset{\text { ஸे }}{\stackrel{\omega}{\circ}}$ & $\underset{\vec{D}}{\vec{\sim}}$ & $\underset{\omega}{\tilde{w}}$ & $\dot{8}$ & $\stackrel{\S}{\S}$ \\
\hline $\begin{array}{l}\stackrel{1}{0} \\
\dot{0}\end{array}$ & $\check{\sigma}$ & $\begin{array}{l}\underset{\infty}{\infty} \\
\underset{\infty}{\infty}\end{array}$ & $\underset{\infty}{\stackrel{\infty}{\phi}}$ & $\stackrel{\vec{N}}{\stackrel{\sim}{N}}$ & $\begin{array}{l}\text { N } \\
\text { N } \\
\text { N }\end{array}$ & $\begin{array}{l}\bar{u} \\
\dot{u}\end{array}$ & $\begin{array}{l}\stackrel{a}{ } \\
\dot{\infty}\end{array}$ & 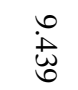 & $\begin{array}{l}u \\
\dot{N} \\
\stackrel{D}{n}\end{array}$ & $\stackrel{\vec{\omega}}{\omega}$ & $\xi$ \\
\hline 0 & 0 & 0 & - & - & 0 & 0 & 0 & 0 & 0 & 0 & 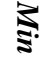 \\
\hline$\stackrel{w}{\sigma}$ & $\checkmark$ & - & $\underset{\infty}{N}$ & $\vec{\sim}$ & $\begin{array}{l}\infty \\
\text { in } \\
\tilde{\sigma}\end{array}$ & 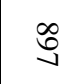 & స్ & $\underset{\sim}{\infty}$ & $\stackrel{\infty}{a}$ & 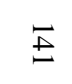 & స్ำ \\
\hline $\begin{array}{l}\stackrel{0}{0} \\
\stackrel{W}{+} \\
\end{array}$ & $\stackrel{0}{\dot{\omega}}$ & $\begin{array}{l}\dot{b} \\
\dot{1} \\
0\end{array}$ & $\begin{array}{l}\stackrel{0}{0} \\
\stackrel{\leftrightarrow}{\perp}\end{array}$ & $\stackrel{0}{\dot{\vec{u}}}$ & $\stackrel{\ominus}{\Xi}$ & $\stackrel{\circ}{\circ}$ & $\begin{array}{l}\stackrel{0}{\text { N }} \\
\dot{t}\end{array}$ & $\stackrel{\circ}{\stackrel{0}{\infty}}$ & $\begin{array}{l}0 \\
\underset{N}{\infty} \\
\stackrel{N}{N}\end{array}$ & - & $\Xi$ \\
\hline$\stackrel{\circ}{\circ}$ & 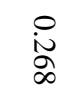 & $\begin{array}{l}\dot{0} \\
\text { ᄋ̆ }\end{array}$ & $\begin{array}{l}1 \\
\dot{8}\end{array}$ & $\begin{array}{l}0 \\
\dot{O} \\
\stackrel{+}{N}\end{array}$ & $\begin{array}{l}\stackrel{0}{1} \\
\stackrel{+}{u}\end{array}$ & $\begin{array}{l}0 \\
\dot{8} \\
ن\end{array}$ & 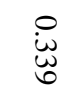 & $\underset{\underset{\sim}{\sim}}{0}$ & - & $\begin{array}{l}0 \\
\text { N } \\
\text { N }\end{array}$ & $\mathbb{N}$ \\
\hline$\stackrel{0}{\circ}$ & $\begin{array}{l}\text { o } \\
\text { 訔 }\end{array}$ & $\begin{array}{l}1 \\
\dot{0} \\
\frac{1}{N}\end{array}$ & $\begin{array}{l}\stackrel{0}{0} \\
\dot{0}\end{array}$ & $\stackrel{0}{\dot{u}^{\prime}}$ & $\stackrel{0}{\dot{w}}$ & 怘 & $\begin{array}{l}\text { : } \\
\dot{8}\end{array}$ & - & $\underset{\underset{w}{\sim}}{\stackrel{0}{W}}$ & $\stackrel{0}{\stackrel{0}{N}}$ & (્) \\
\hline 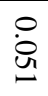 & $\stackrel{\circ}{\circ}$ & $\begin{array}{l}\dot{1} \\
\dot{0} \\
\text { ర్d }\end{array}$ & $\begin{array}{l}\stackrel{0}{0} \\
\text { N } \\
+\end{array}$ & $\stackrel{\circ}{\vec{\nabla}}$ & $\begin{array}{l}\stackrel{0}{\circ} \\
\dot{0}\end{array}$ & $\begin{array}{l}0 \\
\text { il } \\
\infty \\
\omega\end{array}$ & - & $\begin{array}{l}0 \\
0 \\
0 \\
\end{array}$ & $\stackrel{0}{\mathcal{W}_{0}}$ & $\begin{array}{l}0 \\
\text { i } \\
\dot{E}\end{array}$ & $\Phi$ \\
\hline $\begin{array}{l}0 \\
\text { O } \\
\text { N }\end{array}$ & $\begin{array}{l}\text { o } \\
\text { నू }\end{array}$ & $\begin{array}{l}\dot{0} \\
\dot{0} \\
\text { ర్N }\end{array}$ & ஜ & $\stackrel{\circ}{\stackrel{0}{\omega}}$ & $\begin{array}{l}\stackrel{\circ}{ } \\
\dot{\sim}\end{array}$ & - & $\begin{array}{l}\text { o } \\
\dot{\leftrightarrow} \\
\infty \\
\infty\end{array}$ & 定 & $\begin{array}{l}0 \\
\dot{8} \\
\text { ur }\end{array}$ & $\stackrel{\circ}{\circ}$ & $\tilde{\sigma}_{1}$ \\
\hline $\begin{array}{l}0 \\
\text { O্ర } \\
0\end{array}$ & $\underset{\infty}{\stackrel{0}{\leftrightarrows}}$ & $\begin{array}{l}1 \\
\dot{8}\end{array}$ & 용 & $\begin{array}{l}\dot{1} \\
\text { ஜ }\end{array}$ & - & $\begin{array}{l}\stackrel{0}{0} \\
\text { N } \\
\text { un }\end{array}$ & $\begin{array}{l}\stackrel{0}{0} \\
\dot{0}\end{array}$ & $\stackrel{0}{\dot{w}}$ & $\begin{array}{l}\stackrel{0}{1} \\
\stackrel{+}{U}\end{array}$ & $\stackrel{\ominus}{\Xi}$ & $\widehat{a}$ \\
\hline $\begin{array}{l}\circ \\
\stackrel{\infty}{8}\end{array}$ & $\begin{array}{l}0 \\
\text { ia } \\
\text { a }\end{array}$ & $\begin{array}{l}\dot{1} \\
\dot{0} \\
\dot{0}\end{array}$ & $\begin{array}{l}0 \\
\dot{0} \\
\dot{\omega}\end{array}$ & - & $\begin{array}{l}1 \\
\dot{2} \\
2 \\
2\end{array}$ & 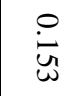 & 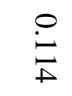 & 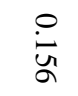 & $\begin{array}{l}\text { } \\
\dot{O} \\
\text { 品 }\end{array}$ & $\stackrel{0}{\stackrel{0}{u}}$ & తิ \\
\hline $\begin{array}{l}\dot{0} \\
\dot{0} \\
\infty\end{array}$ & $\stackrel{\circ}{\exists}$ & $\begin{array}{l}\text { ㅇ } \\
\text { Na }\end{array}$ & - & $\begin{array}{l}\stackrel{0}{0} \\
\dot{0} \\
\text { 心 }\end{array}$ & $\begin{array}{l}\stackrel{\circ}{8} \\
\dot{8}\end{array}$ & $\begin{array}{l}\circ \\
\stackrel{\circ}{9}\end{array}$ & $\begin{array}{l}0 \\
\dot{O} \\
\stackrel{+}{0}\end{array}$ & $\begin{array}{l}\dot{ } \\
\dot{ }\end{array}$ & $\begin{array}{l}1 \\
\dot{8}\end{array}$ & $\stackrel{\stackrel{0}{O}}{\underset{+}{+}}$ & (0) \\
\hline $\begin{array}{l}\dot{b} \\
\dot{0} \\
\text { 茨 }\end{array}$ & $\stackrel{\circ}{\dot{y}}$ & - & $\stackrel{0}{\text { Na }}$ & $\begin{array}{l}\dot{b} \\
\dot{\omega} \\
\dot{\omega}\end{array}$ & $\begin{array}{l}1 \\
\text { டூ }\end{array}$ & $\begin{array}{l}\dot{b} \\
\dot{W} \\
\text { ర్ల. }\end{array}$ & $\begin{array}{l}\dot{b} \\
\dot{\mathscr{W}} \\
\text { La }\end{array}$ & $\begin{array}{l}1 \\
\stackrel{\circ}{+} \\
\text { N }\end{array}$ & $\begin{array}{l}1 \\
8 \\
8 \\
\text { ㅇ }\end{array}$ & $\begin{array}{l}\dot{b} \\
\dot{\circ} \\
\text { d }\end{array}$ & 6 \\
\hline $\begin{array}{l}\dot{b} \\
0 \\
0 \\
0\end{array}$ & - & $\stackrel{0}{\dot{v}}$ & $\stackrel{\circ}{\exists}$ & 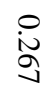 & 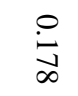 & $\begin{array}{l}\text { o } \\
\text { నू } \\
\text { ă }\end{array}$ & $\stackrel{\circ}{\circ}$ & $\begin{array}{l}\text { O } \\
\text { 岀 } \\
\text { a }\end{array}$ & $\begin{array}{l}0 \\
\text { ஸे } \\
\text { Oे }\end{array}$ & $\stackrel{0}{\dot{n}}$ & $\widehat{\mathbb{a}}$ \\
\hline- & $\begin{array}{l}\dot{1} \\
\dot{0} \\
a\end{array}$ & $\begin{array}{l}\dot{b} \\
\dot{O} \\
\text { 崩 }\end{array}$ & $\begin{array}{l}\dot{b} \\
\dot{0} \\
\stackrel{\infty}{\infty}\end{array}$ & $\begin{array}{l}\circ \\
\stackrel{8}{8} \\
\end{array}$ & $\begin{array}{l}\stackrel{0}{0} \\
\stackrel{1}{0}\end{array}$ & $\begin{array}{l}\text { ㅇ } \\
\text { 岕 } \\
\text { S }\end{array}$ & $\begin{array}{l}\stackrel{0}{0} \\
\dot{O}\end{array}$ & $\stackrel{\circ}{\stackrel{0}{0}}$ & $\stackrel{\circ}{\circ}$ & $\stackrel{\stackrel{0}{O}}{\underset{+}{+}}$ & $\Xi$ \\
\hline
\end{tabular}


Knowledge flows in global renewable energy innovation systems

\subsection{Results}

\subsubsection{Results}

Table 3.2 presents the results of the econometric analyses. Domestic_Proximate and International_Proximate are positively associated with the technological impacts of renewable energy inventions in both columns, suggesting the cumulative knowledge development within a TIS (Suurs and Hekkert, 2009). The coefficient of International_Proximate is larger than the coefficient of Domestic_Proximate in column (1), indicating the importance of international origins of knowledge flows within a TIS. However, the coefficients of their interactions with Absorptive_Capacity are significantly negative, indicating that there exist diminishing returns to the incremental improvements along a technology's own trajectory. Furthermore, the absolute value of the coefficient of Domestic_Proximate* Absorptive_Capacity is larger than the coefficient of International_Proximate* Absorptive_Capacity, indicating that international origins can also compensate for the diminishing return of knowledge flows within a TIS.

Domestic_Distant and International_Distant are negatively correlated with the technology impacts of renewable energy technology inventions. This finding is different from the findings in previous studies (Battke et al., 2016; Nemet, 2012; Stephan et al., 2019). However, the interaction term Domestic_Distant*Absorptive_Capacity is significantly positive, whereas the interaction term International_Distant*Absorptive_Capacity is significantly negative. The results suggest that only countries with larger absorptive capacity are likely to benefit from technologically distant knowledge of domestic sources.

Of the controls, Family size and Team size are positively correlated with the technological impact of renewable energy innovations, as expected. Citation Lag is negatively correlated with the technological impact, also as expected. Non-Patent Literature is positively correlated with the technological impact, probably indicating the role of science as an especially relevant source for invention. The coefficient of Public is, however, significantly negative. This indicates that universities or public research institutes have a relatively minor role in generating high-impact inventions compared to businesses. 
Table 3.2 Negative Binominal Regression Results:

\begin{tabular}{|c|c|c|}
\hline & $(1)$ & $(2)$ \\
\hline Time period & $1990-2010$ & $1990-2010$ \\
\hline \multirow[t]{2}{*}{ Domestic_Proximate } & $0.026^{* * *}$ & $0.099^{* * *}$ \\
\hline & $(0.002)$ & $(0.005)$ \\
\hline \multirow[t]{2}{*}{ Domestic_Distant } & $-0.004^{* * *}$ & $-0.022^{* * *}$ \\
\hline & $(0.001)$ & $(0.002)$ \\
\hline \multirow[t]{2}{*}{ International_Proximate } & $0.053^{* * *}$ & $0.071^{* * * *}$ \\
\hline & $(0.001)$ & $(0.002)$ \\
\hline \multirow[t]{2}{*}{ International_Distant } & $-0.010^{* * *}$ & $-0.008^{* * *}$ \\
\hline & $(0.001)$ & $(0.001)$ \\
\hline Domestic_Proximate & & $-0.011^{* * *}$ \\
\hline *Absorptive_Capacity & & $(0.001)$ \\
\hline Domestic_Distant & & $0.004^{* * * *}$ \\
\hline *Absorptive_Capacity & & $(0.0005)$ \\
\hline International_Proximate & & $-0.008^{* * *}$ \\
\hline *Absorptive_Capacity & & $(0.001)$ \\
\hline International_Distant & & $-0.002^{* * *}$ \\
\hline *Absorptiv_Capacity & & $(0.0004)$ \\
\hline \multirow[t]{2}{*}{ Family size } & $0.041^{* * *}$ & $0.041^{* * * *}$ \\
\hline & $(0.002)$ & $(0.002)$ \\
\hline \multirow[t]{2}{*}{ Team size } & $0.036^{* * *}$ & $0.038^{* * *}$ \\
\hline & $(0.004)$ & $(0.004)$ \\
\hline \multirow[t]{2}{*}{ Public } & $-0.159^{* * *}$ & $-0.167^{* * *}$ \\
\hline & $(0.023)$ & $(0.022)$ \\
\hline \multirow[t]{2}{*}{ Non-Patent Literature } & $0.082^{* * *}$ & $0.077^{* * *}$ \\
\hline & $(0.008)$ & $(0.008)$ \\
\hline \multirow[t]{2}{*}{ Citation lag } & -0.003 & -0.003 \\
\hline & $(0.002)$ & $(0.002)$ \\
\hline \multirow[t]{2}{*}{ Constant } & $-0.970^{* * *}$ & $-1.063^{* * *}$ \\
\hline & $(0.135)$ & $(0.135)$ \\
\hline Observations & 30,720 & 30,720 \\
\hline Log Likelihood & $-70,186.110$ & $-69,962.870$ \\
\hline
\end{tabular}

* Significant at $0.1, * *$ Significant at 0.05 and $* * *$ significant at 0.01 . Robust standard errors are reported in the parentheses. Country, technology and time fixed effects are included. 
Knowledge flows in global renewable energy innovation systems

\subsubsection{Robustness check}

Several complementary analyses were run in order to check the robustness of our findings. Table 3.3 presents the results. First, we use a 10-year citation buffer window.

Consequently, we limit the period to 1990-2005. Second, we exclude patents without any backward citation following Battke et al. (2016) to test the robustness of using zero for citation lag in patents without any backward citation. Third, we change the estimation strategy and employ a logit regression model to explore the correlation between different types of knowledge flows of a patent with the likelihood of being highly-cited. Following Arts and Veugelers (2015), we consider a patent as highly-cited if the number of its forward citations is larger than the mean plus two standard deviations of the number of forward citations in the cohort of the same type of renewable energy technology patents applied in the same year. The results of these robustness checks in Table 3.3 show that our findings considering the heterogenous impacts of different types of knowledge flows on the technological impact of renewable energy innovations are highly robust. 
Table 3.3 Robutness check

\begin{tabular}{|c|c|c|c|}
\hline & (1) & (2) & (3) \\
\hline Model & Negative Binomial & Negative Binomial & Logit \\
\hline Dependent variable & 10 -year citations & $\begin{array}{c}\text { Patent with at least } \\
\text { one backward citation }\end{array}$ & Highly-cited \\
\hline Time period & $1990-2005$ & $1990-2010$ & $1990-2010$ \\
\hline \multirow{2}{*}{ Domestic_Proximate } & $0.159^{* * *}$ & $0.095^{* * *}$ & $0.122^{* * *}$ \\
\hline & $(0.014)$ & $(0.005)$ & $(0.013)$ \\
\hline \multirow{2}{*}{ Domestic_Distant } & $-0.037^{* * *}$ & $-0.022^{* * *}$ & $-0.036^{* * *}$ \\
\hline & $(0.006)$ & $(0.002)$ & $(0.008)$ \\
\hline \multirow{2}{*}{ Intentational_Proximate } & $0.114^{* * *}$ & $0.069^{* * *}$ & $0.067^{* * *}$ \\
\hline & $(0.005)$ & $(0.002)$ & $(0.007)$ \\
\hline \multirow{2}{*}{ International_Distant } & $-0.007^{* * *}$ & $-0.008^{* * *}$ & $-0.015^{* * *}$ \\
\hline & $(0.002)$ & $(0.001)$ & $(0.004)$ \\
\hline \multirow{2}{*}{$\begin{array}{l}\text { Domestic_Proximate } \\
\text { *Absorptive_Capacity }\end{array}$} & $-0.020^{* * *}$ & $-0.010^{* * *}$ & $-0.013^{* * *}$ \\
\hline & $(0.004)$ & $(0.001)$ & $(0.002)$ \\
\hline \multirow{2}{*}{$\begin{array}{l}\text { Domestic_Distant } \\
\text { *Absorptive_Capacity }\end{array}$} & $0.010^{* * *}$ & $0.004^{* * *}$ & $0.007^{* * *}$ \\
\hline & $(0.002)$ & $(0.0005)$ & $(0.001)$ \\
\hline \multirow{2}{*}{$\begin{array}{l}\text { Intentational_Proximate } \\
\text { *Absorptive_Capacity }\end{array}$} & $-0.022^{* * *}$ & $-0.008^{* * *}$ & $-0.007^{* * *}$ \\
\hline & $(0.002)$ & $(0.001)$ & $(0.002)$ \\
\hline \multirow{2}{*}{$\begin{array}{l}\text { International_Distant } \\
\text { *Absorptive_Capacity }\end{array}$} & $-0.004^{* *}$ & $-0.002^{* * *}$ & -0.001 \\
\hline & $(0.002)$ & $(0.0004)$ & $(0.002)$ \\
\hline \multirow{2}{*}{ Family size } & $0.040^{* * *}$ & $0.039^{* * *}$ & $0.062^{* * *}$ \\
\hline & $(0.003)$ & $(0.002)$ & $(0.005)$ \\
\hline \multirow{2}{*}{ Team size } & $0.027^{* * *}$ & $0.036^{* * *}$ & $0.092^{* * *}$ \\
\hline & $(0.008)$ & $(0.004)$ & $(0.015)$ \\
\hline \multirow{2}{*}{ Public } & $-0.137^{* * *}$ & $-0.163^{* * *}$ & $-0.278^{* * *}$ \\
\hline & $(0.038)$ & $(0.023)$ & $(0.094)$ \\
\hline \multirow{2}{*}{ Non-Patent Literature } & $0.111^{* * *}$ & $0.075^{* * *}$ & $0.155^{* * *}$ \\
\hline & $(0.014)$ & $(0.008)$ & $(0.027)$ \\
\hline \multirow{2}{*}{ Citation lag } & 0.003 & $-0.009^{* * *}$ & $-0.014^{*}$ \\
\hline & $(0.004)$ & $(0.002)$ & $(0.008)$ \\
\hline \multirow{2}{*}{ Constant } & -0.194 & $-0.943^{* * *}$ & $-4.569^{* * *}$ \\
\hline & $(0.169)$ & $(0.138)$ & $(0.532)$ \\
\hline Observations & 9,203 & 29,383 & 30,720 \\
\hline Log Likelihood & $-27,991.640$ & $-67,842.070$ & $-5,024.277$ \\
\hline
\end{tabular}

$*$ Significant at $0.1, * *$ Significant at 0.05 and $* * *$ significant at 0.01 . Robust standard errors are reported in the parentheses. Country, technology and time fixed effects are included. 
Knowledge flows in global renewable energy innovation systems

\subsection{Conclusions and implications}

\subsubsection{Conclusions}

Both geographical and technological dimensions are important in understanding the impacts of external knowledge flows on future knowledge development in emerging TISs (Andersen et al., 2019; Bergek et al., 2015; Binz et al., 2020, 2014; Köhler et al., 2019; Stephan et al., 2017). This paper provides a systematic empirical analysis of the multiscalar knowledge dynamics in the global innovation systems proposed by Binz and Truffer (2017). Most importantly, our results show the relative importance of different external knowledge flows critically depends on the absorptive capacity of countries, which results from the knowledge diffusion between domestic actors in an innovation system.

Understanding this place-specificity in the global renewable energy innovation systems is crucial for formulating country-specific transition pathways and facilitating future technology development (Hansen and Coenen, 2015).

More specifically, our results point at the importance of the domestic origin of technological distant technologies in future technology development, which is understudied in previous studies focusing on such knowledge flows in TIS research (Battke et al., 2016; Stephan et al., 2019). Furthermore, our results indicate that geographical proximity alone is not enough to compensate for a lack of cognitive proximity in integrating technological distant knowledge from other TISs. Sufficient absorptive capacity of a country is required for identifying and utilizing technological opportunities outside the focal TIS (Carlsson et al., 2002; Cohen and Levinthal, 1990). Since actors may be active in multiple TISs at the same time, the knowledge diffusion between domestic actors in a TIS can facilitate the learning between different TISs to generate the positive feedback loops which are important for system functioning and growth (Malhotra et al., 2019; Suurs and Hekkert, 2009).

Our results also highlight the importance of international knowledge flows, especially in countries without a well-functioning TIS. In contrast to the findings of Mancusi (2008) that latecomer countries are mostly recipients of international knowledge, our results suggest that the diffusion of existing technologies in latecomer countries can still generate new insights for future technology development. Latecomer countries like China and India have unique social-technical systems which can help to further improve the existing technological trajectory within a TIS (Hansen and Coenen, 2015). At the same time, latecomer countries can also benefit from 'learning-by-doing' integrating international knowledge flows and initiate positive feedback loops for building domestic renewable energy innovation systems (Gosens et al., 2015). 


\subsubsection{Limitations and future research}

In this paper, we explore the multi-scalar knowledge dynamics in global renewable energy innovation systems and highlight the important role of national systems of innovations in moderating the impacts of knowledge flows between TISs and NISs. Several authors have found that the innovation dynamics of renewable energy technologies are also affected by technology-related differences (Quitzow et al., 2017; Schmidt and Huenteler, 2016). Different types of renewable energy technology exhibit different levels of complexity in terms of the structure of supply chain network and the reliance on scientific knowledge (Binz and Truffer, 2017; Huenteler et al., 2016; Malhotra et al., 2019; Schmidt and Huenteler, 2016). It might be more difficult for latecomer countries to develop complex renewable energy technologies by utilizing international knowledge since the spatial diffusions of complex knowledge is difficult (Balland and Rigby, 2017; Sorenson et al., 2006).

Since many countries intend to build innovation systems to better deploy renewable energy technologies at home, insights into how to mobilize resources from different sources are crucial for overcoming the difficulties associated with this complexity. The emergence of global supply chains of renewable energy technologies offers opportunities for latecomer countries to start from the less complex segments of the supply chains and move to core segments through learning-by-doing (Malhotra et al., 2019; Meckling and Hughes, 2018). Furthermore, the role of scientific knowledge and government funded research have become increasingly important in the development of renewable energy technologies (Popp, 2017, 2016). Future research therefore should focus on the impacts of knowledge flows between different supply chain segments of renewable energy technologies (Battke et al., 2016; Malhotra et al., 2019; Stephan et al., 2019), and knowledge flows from scientific research (Fleming et al., 2019; Popp, 2017, 2016).

\subsubsection{Policy implications}

Our results offer policy implications for developing renewable energy technologies in different locations. The policy focus should be on how to facilitate the knowledge diffusion between both domestic and international actors within the focal TIS. Our results suggest an important role of international knowledge for latecomer countries in line with previous studies (Binz and Anadon, 2018; Gosens et al., 2015; Quitzow, 2015). Moreover, the international diffusion of new knowledge in latecomer countries can also influence the technology development globally. Therefore, policy makers from both advanced countries and latecomer countries should work together to facilitate technology transfer.

However, for countries with an already well-functioning renewable energy innovation system (e.g. advanced countries like United States, Germany and Japan), the focus should 
Knowledge flows in global renewable energy innovation systems

be shifted to bringing in knowledge, skills and experiences from other domestic technologies to facilitate learning process for knowledge recombination. Such an approach has been successfully employed by Denmark in developing modern wind turbine technologies (Garud and Karnøe, 2003). The 'cross-specialisation' policy framework proposed by Janssen and Frenken (2019) also suggest that promoting crossovers between distant technologies in an economy can help facilitate radical innovations. The learning process between TISs in these countries can generate great impacts on future development of renewable energy technologies. 


\section{Chapter 4}

\section{Recombinant invention in solar photovoltaic technology: can geographical proximity bridge technological distance?}

This chapter is co-authored with Gaston Heimeriks and Floor Alkemade, and is under review. 


\begin{abstract}
This paper explores the emergence of new combinations of technologies with a large technological distance at the regional level. Our analyses show that such unrelated technologies are more likely to be recombined in solar photovoltaic inventions when they strongly co-locate in the same region rather than in different regions. Furthermore, we show that this pattern is common to different types of renewable energy technology, while such a pattern is not observed in all technologies. This paper helps understand how placedependence can break the path-dependence of recombining related technologies.
\end{abstract}




\subsection{Introduction}

New inventions often result from the recombination of existing technologies, knowledge and capabilities in new and often more complicated ways (Arthur, 2007; Henderson and Clark, 1990). Cognitive capabilities play an important role in this recombination process (Cohen and Levinthal, 1990; Galunic and Rodan, 1998; Kogut and Zander, 1992; Nooteboom, 2000). Recombinant innovation involves the reconfiguration of different types and pieces of knowledge in a new way, generating unexpected effects. Hence, it is generally easier to recombine technologies that are technologically related then unrelated (Caviggioli, 2016). This effect of technological distance has indeed been shown in that the presence of related technological variety enhances the rate of patenting (Castaldi et al., 2015; Miguelez and Moreno, 2018; Tavassoli and Carbonara, 2014).

The processes behind the recombination of unrelated technologies are less clear. Assuming that breakthrough inventions often stem from new combinations of unrelated technologies, the occurrence of breakthrough inventions can be associated with the presence of 'unrelated variety' within a region. Indeed, Castaldi, Frenken and Los (2015) found that breakthrough inventions, as measured by highly cited patents, occurrs more often in regions with more unrelated variety. However, this study did not investigate whether the breakthrough inventions were, indeed, the result of the recombination of unrelated technologies that are strongly present in the same region. Only then, promoting crossovers between unrelated technologies strongly present in a region, which Janssen and Frenken (2019) called "cross-specialisation", may be an effective technology policy.

The objective of this paper is therefore to investigate empirically whether breakthrough inventions in renewable energy technologies are place-dependent in the sense of building mostly on the local knowledge base rather than on the global knowledge base. Inventions in renewable energy technologies not only require knowledge input from various unrelated technologies (Barbieri et al., 2020; Nemet, 2012), but also face legitimacy challenges because of their disruptive roles in energy sector (Alkemade et al., 2009; Markard and Truffer, 2006). The recombination of unrelated technologies strongly present in a region can expect support from the strongly present technologies it builds upon (Janssen and Frenken, 2019).

We operationalize the research question by testing how likely unrelated technologies are to be recombined when they are both strongly present in the same region using patents applied at USPTO, EPO, and through the PCT route between 1980 and 2012. We focus on the new combinations in renewable energy technologies from regions in OECD countries and BRICS countries (Brazil, Russia, India, China and South Africa) during the period 1998-2012. This paper aims to contribute to existing literature in two ways. First, we 


\section{Recombinant invention in solar photovoltaic technology}

provide the first empirical support of the "cross-specialisation" policy framework proposed by Janssen and Frenken (2019) which extends the recent smart specialisation strategies by highlighting the importance of linking strong but unrelated technologies in an economy in facilitating radical innovations. Second, we discuss how our results can be relevant for supporting a regional perspective on innovation policies aimed at solving societal challenges like climate change (Coenen et al., 2015; Wanzenböck and Frenken, 2018).

The paper is structured as follows. In Section 2, we review the literature on the path- and place-dependencies of technological change, and how they interact in introducing recombinant innovations. In Section 3, we describe the data, econometric model and variables. In Section 4, we present the results of descriptive analysis and econometric analysis. We conclude by discussing the implications of our findings in Section 5.

\subsection{Literature Review}

\subsubsection{Recombinant inventions and renewable energy technology}

In line with the combinatorial view of technological change, new inventions can be viewed as either new combinations of existing and/or new technological components, or as refinements of previous combinations of technological components (Fleming, 2001; Strumsky and Lobo, 2015; Verhoeven et al., 2016). Although most inventions reuse existing combinations, recombining existing technologies in novel ways can increase the likelihood of achieving high impact inventions (Arts and Veugelers, 2015; Strumsky and Lobo, 2015; Verhoeven et al., 2016).

Compared to recombining related technologies, recombining unrelated technologies is more risky and uncertain because inventors need cognitive capabilities to understand how technologies interact with each other to achieve recombination (Cohen and Levinthal, 1990; Galunic and Rodan, 1998; Kaplan and Tripsas, 2008; Nooteboom et al., 2007). Thus, one can expect that new combinations of related technologies occur more frequent than new combinations of unrelated technologies (Caviggioli, 2016). Ferguson and Carnabuci (2017) further showed that patents that combine knowledge from unrelated technology domains are also less likely to be granted.

However, the recombination of unrelated technologies is important for the evolution of the knowledge base of technologies over the technology life cycle. Leydesdorff (2015) found that the technology life-cycle of solar PV technology is correlated with the increases and decreases of the variety of its knowledge base. Krafft, Quatraro and Saviotti (2011) further showed that unrelated variety is more important at the earlier stage of technology life-cycle, whereas in the later stage related variety is more prominent. These results are 
consistent with the assumption that unrelated variety supports radical innovation (Castaldi et al., 2015), which concentrate at early stages of a technology life-cycle.

Renewable energy technologies are considered more complex and radical than non-green technology because they rely on diverse knowledge inputs from unrelated technologies (Barbieri et al., 2020; Nemet, 2012). Barbieri, Perruchas, and Consoli (2018) found a similar pattern as in the aforementioned study by Krafft, Quatraro and Saviotti (2011) that unrelated variety is the main driver of the development of green technology in early stages whereas related variety becomes more prominent as the technology becomes mature. Sbardella et al. (2018) also found that innovation in green technology went through a period of deeper specialisation within diverse domains.

However, there is a trade-off between short-term and long-term benefits (Zeppini and van den Bergh, 2011). The recombination of related technologies can facilitate the immediate technology improvement. The recent rapid growth of innovative activities in renewable energy technologies results from private sector activities incentivized by growing markets supported by government demand-pull policies (Bettencourt et al., 2013; Trancik et al., 2015). Evidence suggests that private sector activities tend to focus on incremental refinements to technology and manufacturing (Hoppmann et al., 2013; Trancik et al., 2015). Without the recombination of unrelated technologies to facilitate the convergence of unrelated technologies and offer new opportunities for future technology development, it may soon reach the limits to incremental improvements and lead to lock-in (Safarzyńska and van den Bergh, 2013).

\subsubsection{Path-dependence and place-dependence}

Although technology opportunities increase as the number of technological components increases, the difficulty and uncertainty of the recombinant search process also increase along with the opportunity (Baldwin and Clark, 2000). Inventors and decision-makers in firms have limited cognitive capabilities, limiting their abilities to identify potentially fruitful combinations of technologies that seem unrelated to their existing knowledge bases and/or to each other (Cohen and Levinthal, 1990; Nooteboom, 2000). Thus, their innovation patterns are myopic, cumulative and path-dependent in that inventors typically explore new combinations of related rather than unrelated technologies (Dosi, 1982; Nelson and Winter, 1982).

This path-dependence can be also observed at the regional level: The growth trajectories of regions are simultaneously the outcome of the path-dependent process of economic evolution and a major determinant of future development (Henning et al., 2013; Martin, 2010; Martin and Sunley, 2006). Inspired by the seminal work by Hidalgo et al. (2007), recent systematic empirical studies of regional diversification find that regions tend to develop new technologies which are related to the technologies in their current portfolio 


\section{Recombinant invention in solar photovoltaic technology}

(Boschma, 2017; Colombelli et al., 2014; Feldman et al., 2015; Tanner, 2016). Thus, the path-dependent process of regional development is to a large extent conditioned by the past economic structure and knowledge base of regions, and hence place-dependent (Heimeriks and Boschma, 2014; Martin and Sunley, 2006).

The place-dependence also suggests that regions may develop new technologies which are less related or even unrelated to their existing knowledge bases, provided that supportive conditions are present (Heimeriks \& Boschma, 2014; Montresor \& Quatraro, 2017; Petralia, Balland, \& Morrison, 2017). However, technological relatedness does not need be defined visavis the region (the new thing being related or unrelated to what was already present in the region). Following the combinatory view of new inventions, the place-dependence could be redefined as the recombination of locally available technologies. Indeed, individuals working on unrelated technologies might nonetheless be using similar skills and thus learn quite easily from each other (Desrochers and Leppälä, 2011). Thus, a region's capability of introducing new combinations is associated with the diversity of its knowledge base (Breschi and Lenzi, 2015; Castaldi et al., 2015; Desrochers and Leppälä, 2011; Miguelez and Moreno, 2018). However, the question whether these new combinations, especially the new combinations of unrelated technologies, are indeed building on the locally available technologies remains open.

\subsubsection{Cross-specialisation: interaction of path-dependence and place- dependence}

Although path-dependence and place-dependence refer to two distinct processes, these processes interact with each other in the knowledge production process. Place-dependence may help to break the path-dependent logic of new technologies building on related technologies, through the recombination of locally available, unrelated technologies.

Though technological distance can indeed be a challenge in the recombination process, it can most easily be bridged through the frequent face-to-face interactions of diverse individuals, which is obviously facilitated if they are all located in close geographical proximity (Desrochers and Leppälä, 2011; Storper and Venables, 2004). Learning is the mechanism behind the dynamics of cognitive proximity between actors with different backgrounds (Balland et al., 2015). The creation of a new combination requires a minimum level of knowledge in both technological components to reduce the uncertainty in the inventive process (Clancy, 2018; Fleming, 2001; Perez and Soete, 1988). Thus, the presence of critical mass of unrelated technologies in the same region can facilitate the learning process between them, a logic that has been referred to as "cross-specialisation" (Janssen and Frenken, 2019).

Geographical proximity can facilitate the learning process between unrelated technologies in two ways. On the one hand, co-location in close geographical proximity 
enables cooperating actors to monitor each other constantly, closely and almost without effort or cost (Malmberg and Maskell, 2002). Such local knowledge spillovers can increase the cognitive proximity between two cooperating actors and as a result the knowledge bases of the two actors become more similar (Balland et al., 2015). This increases their capacity to identify and test potential new combinations (Desrochers and Leppälä, 2011; Galunic and Rodan, 1998), which is especially useful in immature technological environments where the effects of interactions are uncertain or unknown and alternative technological options compete (Sbardella et al., 2018).

On the other hand, geographical proximity can also facilitate cognitive proximity through other forms of proximity (Balland et al., 2015; Boschma, 2005; Torre and Rallet, 2005). For example, geographical proximity can facilitate social proximity. Most of the carriers of social proximity tend to be geographically bounded, such as spin-off processes, inventive collaborations and labour mobility (Breschi and Lissoni, 2009; Eriksson, 2011; Klepper, 2007). The formal or informal collaboration of individuals possessing different skills and backgrounds is important for the creation of new combinations (Desrochers and Leppälä, 2011).

In sum, we expect that unrelated technologies are more likely to be recombined when they are both strongly present in the same region. That is, geographical proximity can bridge technological distance in creating new combinations.

\subsection{Research Design}

\subsubsection{Sample}

For our empirical analyses we focus on new combinations in solar PV technology during the period 1998-2012. We focus on solar PV as it represents the leading renewable energy technology and has long-term potential (Trancik et al., 2015). Both electricity production capacities and patenting activities of solar PV grow the fastest among all renewable sources since 1997 when The Kyoto Protocol was signed (Bettencourt et al., 2013). Solar PV is selected by many countries as the main solution to achieve their intended national determined contributions (IRENA, 2017).

Although the existing literature suggests renewable energy technologies might enter a mature phase because of the observed relative dominance of related variety, we also observe novel developments. Whereas crystalline silicon PV modules have a long history and dominant market share in PV technologies, new generations of solar PV technologies emerged during the period of investigation (Fraunhofer Institute, 2019; National Renewable Energy Laboratory, 2019). These new generations of solar PV technologies are different from current dominant crystalline silicon PV technology in terms of efficiency, materials 


\section{Recombinant invention in solar photovoltaic technology}

use, and manufacturing complexity and cost (Jean et al., 2015). However, given the fact that most of these new generations of PV technologies are still far from commercialization, continuous innovation efforts are required in improving these emerging PV technologies (MIT Energy Initiative, 2015).

Moreover, considering the growth potential of the solar PV market share under the intended national determined contributions of The Paris Agreement, both the material scalability and the intermittency of solar resources require to be addressed (Trancik et al., 2015). On one hand, reaching full growth potential of solar PV requires finding more abundant active cell materials for some emerging PV technologies and substituting a more abundant material for the silver electrodes for current dominant crystalline silicon PV technology (Trancik et al., 2015). On the other hand, further development of system integration and interoperability between solar PV technology and other climate change mitigation technologies like storage technologies and long-distance transmission technology are required (Sbardella et al., 2018). Therefore, both the difference between PV and existing energy technologies and the large innovation needs make this an interesting technology for our analysis.

However, in order to gain evidence on whether the observed patterns are common to other technology fields, we first compare solar PV technology to another two leading renewable energy technologies, wind and biofuel technology. Then, we compare the results of renewable energy technologies with results of all technologies.

\subsubsection{Data}

Technological classifications capture the technological components and principles of an invention, and are widely used to assess the recombination of technologies (Fleming, 2001; Strumsky and Lobo, 2015). We use the pairwise combinations of subclass-level International Patent Classification (IPC) codes assigned to a patent to proxy recombination following Verhoeven, Bakker, and Veugelers (2016). More specifically, for each pair of IPC subclasses, we assess its previous existence in the body of solar PV patents filed before the application date of the patent under consideration.

We use all patent applications filed at European patent office (EPO), United States Patent and Trademark Office (USPTO) and through the Patent Cooperation Treaty (PCT-route) between 1980 and 2012. The patent applications are extracted from European Patent Office Worldwide Patent Statistics Database PATSTAT (EPO, 2017 Spring Version). Since nongranted USPTO patent applications are only partly present from 2001 onwards, we excluded non-granted EPO patents and patents through PCT-route which are not granted by any patent office.

In order to remedy the issue of multiple equivalent patent applications protecting the intellectual property rights of the same invention in different patent offices, we use 
residence addresses of inventors and IPC codes of all patents in the same DOCDB patent family as the locations and technological classifications of the invention under consideration (Martínez, 2011). The year of a DOCDB patent family is based on the application year of the first patent application in the patent family.

The solar PV patents are identified using the Y02E10/5 code in the Cooperative Patent Classification (CPC). The Y02 classes are developed by EPO experts by combining existing International Patent Classifications (IPC) and European Patent Classifications with lexical analyses of abstracts or claims in the patent documents (Veefkind et al., 2012a), and have been widely adopted by researchers to study the technology change of climate change mitigation technologies (Haščič and Migotto, 2015; Leydesdorff et al., 2015; Sbardella et al., 2018).

Patents, and their combination of IPC subclasses are assigned to regions based on the residential addresses of inventors listed in the patent documents. Inventors' addresses of patents filed at EPO and through the PCT-route are extracted from OECD REGPAT database (OECD, REGPAT database, March 2018). Inventors' addresses of USPTO patents are extracted from PatentsView database (2018 May Version) and assigned to regions based on their geographical coordinates. We use the Territorial Level 2 regions in the REGPAT database for OECD countries, and the highest administrative breakdowns for BRICS countries (Brazil, Russia, India, China and South Africa). There are 599 regions in all OECD and BRICS countries.

\subsubsection{Variables}

\subsubsection{Dependent Variable}

In order to explore the emergence of new combinations at the regional level, we use the binary variable $N C_{r, i j}$ to indicate whether region $r$ recombines IPC subclass $i$ and $j$ for the first time in history in the body of solar PV patents. Although assessing new combinations in the body of all patents can better capture the novelty of inventions (Verhoeven et al., 2016), the combinations of technologies might function differently in different technology fields (Boschma et al., 2017a). We therefore measure novelty as new-to -solar-PVtechnology instead of new-to-the-world in this paper.

For the construction of the dependent variable, we only consider patents in which only inventors located in the focal region were reported in the document following Breschi and Lenzi (2015). Cross-region collaborations can also facilitate the creation of new combinations by bringing together individuals with different backgrounds in different locations (Breschi and Lenzi, 2015; Giuliani et al., 2016). By excluding new combinations that are the outcome of cross-region collaborative patents, this variable can be considered as a measure of a region's indigenous combinatorial and inventive capabilities. New 


\section{Recombinant invention in solar photovoltaic technology}

combinations introduced by inventors from the same region account for 66 percent of all new combinations introduced between 1998 and 2012.

\subsubsection{Independent Variables}

As independent variables we use the technological relatedness between IPC subclasses $i$ and $j, T R_{i j}$, as a measure of path-dependence, and the level of cross-specialisation of region $r$ in IPC subclasses $i$ and $j C S_{r, i j}$ to measure place-dependence. We will describe each variable in more detail below.

$T R_{i j}$ measures the technological relatedness between IPC subclasses $i$ and $j$ at each moment in time. Two IPC subclasses are considered related if they cite each other frequently (Caviggioli, 2016; Rigby, 2015), a widely used measure of the relatedness between technologies (Jaffe and de Rassenfosse, 2017). We first calculate the share of patents in IPC subclass $j$ citing patents in IPC subclass $i$ over the total number of patents in IPC subclass $j\left(\mathrm{P}_{j i}\right)$ in the five years before they were recombined. Then, the $T R_{i j}$ takes the average value of $\mathrm{P}_{j i}$ and $\mathrm{P}_{i j}$.

$C S_{r, i j}$ captures whether the IPC subclasses being recombined are strongly co-present in the region. It takes the minimum value of the number of regional patents in IPC subclass $i$ and the number of regional patents in IPC subclass $j$ in region $r$ in the five years before the recombination following Clancy (2018). We exclude patents with inventors external to the region to capture the scale effects associated with the agglomeration of inventive activities at the regional level (Breschi and Lenzi, 2015; Lobo and Strumsky, 2008). The larger value of $C S_{r, i j}$ indicates regions have larger knowledge stock in both IPC subclasses.

\subsubsection{Control variables}

In order to control the regional factors' impacts on the recombination of IPC subclasses, we include three regional level variables in the econometric model.

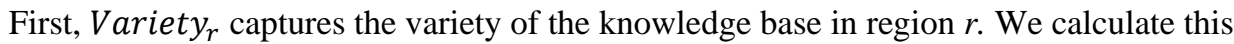
variable using the entropy index following Castaldi, Los and Frenken (2015):

$$
\text { Variety }_{r}=\sum_{k} P_{k, r} * \ln \left(\frac{1}{P_{k, r}}\right)
$$

where $P_{k, r}$ is share of internal patents in IPC subclass $k$ in region $r$ over the total number of internal patents in region $r$ in the five years before the recombination of IPC subclass $i$ and IPC subclass $j$.

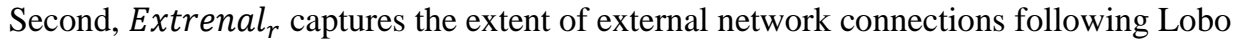
and Strumsky(2008). It is the ratio of the number of patents with inventors from outside the focal region over the number of internal patents. We use this variable to control the potential impacts of extra-regional knowledge spillovers. 
Third, Count_field $r$ captures the knowledge stock of region $r$ in solar PV technology.

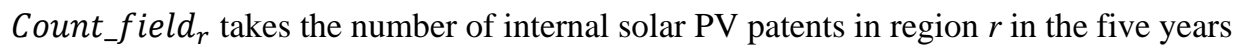
before IPC subclass $i$ and IPC subclass $j$ were recombined.

\subsubsection{Empirical Model}

Our estimation strategy is based on a conditional logit model that is similar to those used in studies on location choice of firms (Schmidheiny and Brülhart, 2011). More specifically, at each point in time $t$, the probability of a new combination of IPC subclass $i$ and IPC subclass $j$ emerging in a region $r$ is a function of the observable characteristics of region $r$ described by equation (4.2):

$$
\begin{aligned}
P\left(N C_{r, i j}\right)= & \beta_{1} C_{r, i j}+\beta_{2} \text { Variety }_{r}+\beta_{3} \text { External }_{r}+\beta_{4} \text { Count }_{\text {field }_{r}} \\
& + \text { Country }+N C_{i j}+\varepsilon
\end{aligned}
$$

where $\beta_{1}$ captures the impact of cross-specialisation of regions on introducing new combination. We expect the positive value of $\beta_{1}$ due to the place-dependence of technological change. $\beta_{2}, \beta_{3}$ and $\beta_{4}$ capture the impacts of regional factors on recombining IPC subclasses $i$ and $j$. We also include country dummies to control for the unobserved heterogeneities of regions in different countries since the inventive patterns of solar PV technology differ significantly across countries (Kalthaus, 2019).

In order to test whether geographical proximity can indeed bridge technological distance, we add the interaction term of cross-specialisation $C S_{r, i j}$ and technological relatedness $T R_{i j}$ to the model. As the fixed effect of new combinations is already included in the conditional logit model, technological relatedness $T R_{i j}$ is not introduced in the model individually because $T R_{i j}$ is invariable across regions, thus correlating with the error term. We estimate equation (4.3) as follows:

$$
\begin{gathered}
P\left(N C_{r, i j}\right)=\beta_{1} C S_{r, i j}+\beta_{2} \text { Variety }_{r}+\beta_{3} \text { External }_{r}+\beta_{4} \text { Count_field }_{r}+\beta_{5} \text { CS }_{r, i j} * T R_{i j} \\
+ \text { Country }+N C_{i j}+\varepsilon
\end{gathered}
$$

where $\beta_{5}$ measures whether the impact of cross-specialisation differs across new combinations with different levels of technological relatedness. We expect a negative coefficient of $\beta_{5}$, as we expect that the impact of cross-specialisation is larger for new combinations of unrelated technologies than for related technologies. Table 4.1 and Table 4.2 present summary and correlation statistics. 
Recombinant invention in solar photovoltaic technology

Table 4.1 Descriptive statistics

\begin{tabular}{|c|c|c|c|c|c|}
\hline Variable & Obs & Mean & Std. Dev. & Min & Max \\
\hline$C S_{r, i j}$ & $1,568,182$ & 1.633 & 16.534 & 0 & 5362.98 \\
\hline$T R_{i j}$ & $1,568,182$ & 0.087 & 0.101 & 0 & 0.764 \\
\hline Variety $_{r}$ & $1,568,182$ & 2.914 & 1.760 & 0 & 5.477 \\
\hline External $_{r}$ & $1,568,182$ & 0.373 & 0.835 & 0 & 40 \\
\hline Count_field $_{r}$ & $1,568,182$ & 4.402 & 30.623 & 0 & 969 \\
\hline
\end{tabular}

Table 4.2 Correlation statistics

\begin{tabular}{|c|c|c|c|c|c|}
\hline & $C S_{r, i j}$ & $T R_{i j}$ & Variety $_{r}$ & External $_{r}$ & Count_field $_{r}$ \\
\hline CS $_{r, i j}$ & 1 & & & & \\
\hline TR $_{i j}$ & 0.037 & 1 & & & \\
\hline Variety $_{r}$ & 0.105 & 0.001 & 1 & & \\
\hline External $_{r}$ & 0.018 & 0.038 & 0.292 & 1 & \\
\hline Count_field $_{r}$ & 0.341 & 0.001 & 0.146 & 0.020 & 1 \\
\hline
\end{tabular}




\subsection{Results}

\subsubsection{Descriptive results}

Figure 4.1 shows the number of solar PV patents (left y-axis), the number of solar PV patents with new combinations of IPC subclasses (left y-axis) and the share of patents with new combinations among all solar PV patents (right y-axis) over time. The share of patents with new combinations among all solar PV patents starts to decrease after 2004 because of the rapid growth of the number of solar PV patents and the relatively stable growth of the number of solar PV patents with new combinations. The rapid growth of incremental inventions are the results of market stimulating policies which incentive the private sector activities in focusing on refinement to technology and manufacturing (Hoppmann et al., 2013; Trancik et al., 2015). The relative dominance of increment innovations suggest the development of solar PV technology might enter a more mature stage (Barbieri et al., 2018; Sbardella et al., 2018).

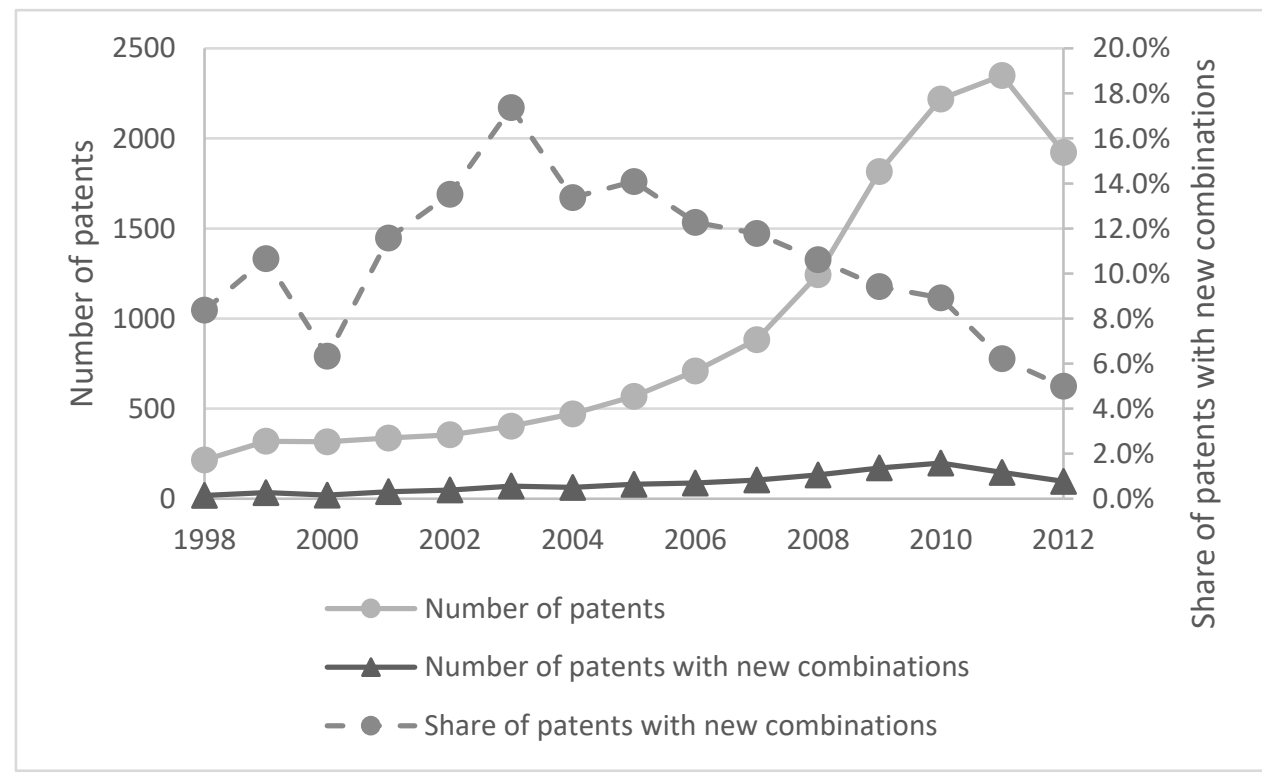

Figure 4.1 Evolution of number of solar PV patents (left y-axis), number of solar PV patents with new combinations of IPC subclasses (left y-axis) and share of patents with new combinations among all solar PV patents (right y-axis) 


\section{Recombinant invention in solar photovoltaic technology}

The number of solar PV patents with new combinations starts to decrease after 2010 in Figure 4.1. A possible explanation for this could be the industry shakeout that started 2010 (Furr and Kapoor, 2018). On the one hand, there is a decrease in patenting activities in solar PV industry because of the decreasing number of patenting firms during the industry shakeout (Carvalho et al., 2017; Furr and Kapoor, 2018). On the other hand, during the industry shakeout, the innovation focus of firms shifted from developing new products to reducing production costs, leading to a decrease of recombinant inventions (Carvalho et al., 2017).

Figure 4.2 shows the evolution of the average technological relatedness between new combinations of IPC subclasses and the average technological relatedness between IPC subclasses which are not recombined. The average technological relatedness between new combinations of IPC subclasses is larger than the average technological relatedness between IPC subclasses which are not combined, indicating that technological change in solar PV technology is indeed path-dependent and that related technologies are more likely to be recombined than unrelated technologies.

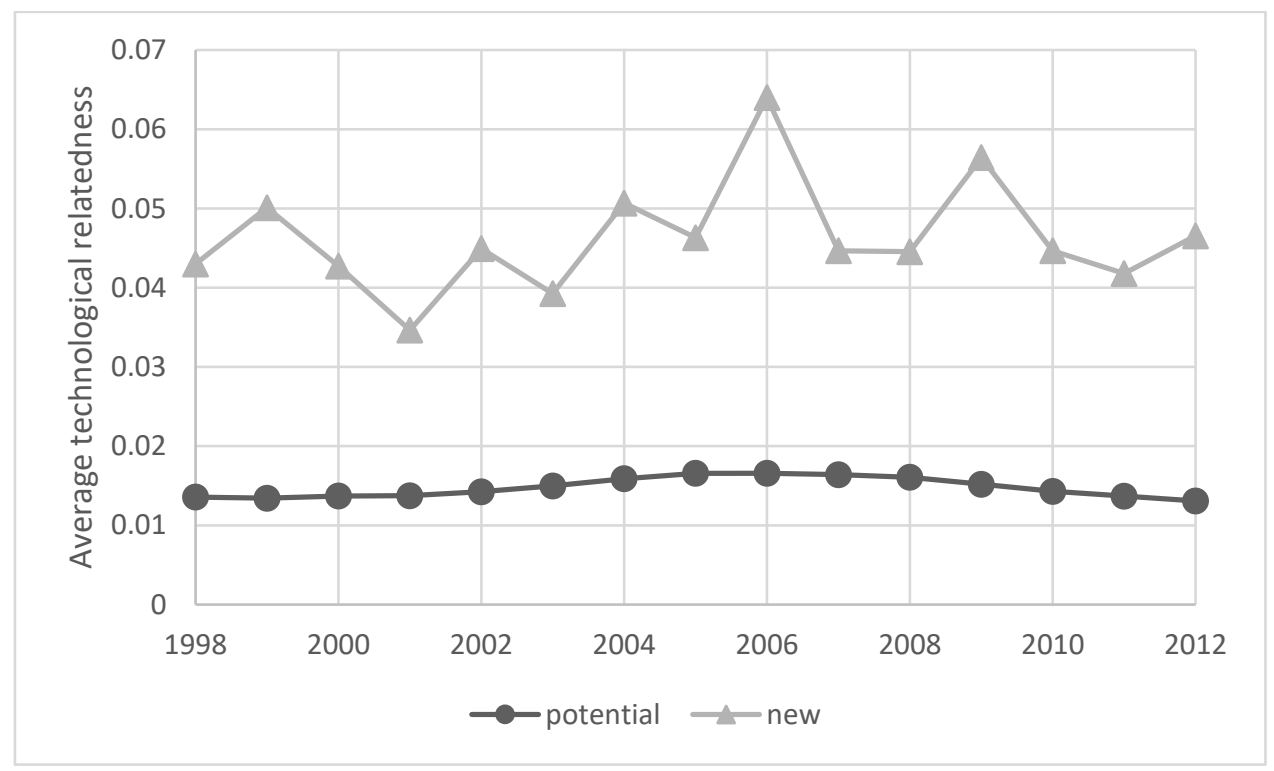

Figure 4.2 Average of technological relatedness between new combination of IPC subclasses and potential combination of IPC subclasses 
Table 4.3 shows the top 15 regions with number of new combinations in solar PV technology. Top regions are concentrated in Japan, Germany and the United States. The number of new combinations from the top 15 regions accounts for $56 \%$ of the total number of new combinations during the period 1998-2012.

Table 4.3 Top regions in the number of patents with new combinations of IPC subclasses

\begin{tabular}{|c|c|c|c|c|c|}
\hline Region & $\begin{array}{l}\text { Number of } \\
\text { new } \\
\text { combinations }\end{array}$ & Share & Region & $\begin{array}{l}\text { Number of } \\
\text { new } \\
\text { combinations }\end{array}$ & Share \\
\hline California, US & 610 & $14.6 \%$ & $\begin{array}{l}\text { Northern- } \\
\text { Kanto, JP }\end{array}$ & 90 & $2.1 \%$ \\
\hline Southern-Kanto, JP & 349 & $8.4 \%$ & $\begin{array}{l}\text { Michigan, } \\
\text { US }\end{array}$ & 82 & $2.0 \%$ \\
\hline Texas, US & 205 & $4.9 \%$ & Hesse, DE & 79 & $1.9 \%$ \\
\hline Massachusetts, US & 152 & $3.6 \%$ & $\begin{array}{l}\text { New Jersey, } \\
\text { US }\end{array}$ & 79 & $1.9 \%$ \\
\hline Kansai region, JP & 143 & $3.4 \%$ & $\begin{array}{l}\text { North Rhine- } \\
\text { Westphalia, } \\
\text { DE }\end{array}$ & 78 & $1.9 \%$ \\
\hline Seoul region, $\mathrm{KR}$ & 125 & $3.0 \%$ & $\begin{array}{l}\text { Baden- } \\
\text { Württemberg, } \\
\text { DE }\end{array}$ & 72 & $1.7 \%$ \\
\hline New York, US & 121 & $2.9 \%$ & $\begin{array}{l}\text { Chinese } \\
\text { Taipei }\end{array}$ & 72 & $1.7 \%$ \\
\hline Bavaria, DE & 102 & $2.4 \%$ & $\begin{array}{l}\text { Top } 15 \\
\text { regions in } \\
\text { total }\end{array}$ & 2360 & $56.4 \%$ \\
\hline
\end{tabular}

\subsubsection{Econometric results}

Table 4.4 presents the results of our econometric analysis. Column (1) reports the model with the $C S_{r, i j}$ and control variables. Column (2) adds the interaction term of $C S_{r, i j}$ and $T R_{i j}$ The coefficient of $C S_{r, i j}$ is positively significant in column (1), indicating that regions are more likely to recombine two technologies when they have a larger knowledge stock in both technologies. This shows that there is place-dependence in the creation of new combinations: regions are more likely to recombine technologies strongly present in their technology portfolios. In column (2), the interaction term of $C S_{r, i j}$ and $T R_{i j}$ is significantly negative, indicating that the impact of $C S_{r, i j}$ on creating a new combination is larger when 


\section{Recombinant invention in solar photovoltaic technology}

the focal technologies are unrelated. This result suggests that geographical proximity can indeed bridge technological distance in the creation of new combinations, as we hypothesized.

Regarding to the control variables, the coefficients of Variety ${ }_{r}$ and Count_field Cre $_{r}$ are significantly positive in both Column (1) and Column (2), indicating that new combinations are more likely to emerge in regions with more diverse knowledge base of larger knowledge stock in solar PV technology. However, the coefficient of External ${ }_{r}$ is significantly negative in both Column (1) and Column (2), indicating that new combinations are less likely to emerge in regions which are more reliant on extra-regional knowledge flows.

Table 4.4 Econometric Results

\begin{tabular}{|l|c|c|}
\hline \multirow{2}{*}{$C S_{r, i j}$} & $(1)$ & $(2)$ \\
\cline { 2 - 3 } & $0.002^{* * *}$ & $0.004^{* * *}$ \\
\hline \multirow{2}{*}{$C S_{r, i j} * T R_{i j}$} & $(0.00)$ & $(0.00)$ \\
\cline { 2 - 3 } & & $-0.005^{* * *}$ \\
\hline Variety $_{r}$ & & $(0.00)$ \\
\hline \multirow{2}{*}{ External } & & $0.684^{* * *}$ \\
\hline & $0.686^{* * *}$ & $(0.05)$ \\
\hline Count_field & $(0.05)$ & $-0.294^{* * *}$ \\
\hline Country Fixed Effects & $-0.303^{* * *}$ & $(0.04)$ \\
\hline Number of Observations & $(0.04)$ & $0.005^{* * *}$ \\
\hline Log Likelihood & $0.006^{* * *}$ & $(0.00)$ \\
\cline { 2 - 4 } & $(0.00)$ & Yes \\
\hline
\end{tabular}

* Significant at $0.1, * *$ Significant at 0.05 and $* * *$ significant at 0.01 . Robust standard errors are reported in the parentheses

\subsubsection{Robustness Check}

We now move to testing whether the results presented for solar PV technologies are common to other fields. To this end, we first re-estimate Equation (3.2) and (3.3) using patents in wind and biofuel technology respectively. We identify patents in wind energy technology using Y02E10/7 code, and biofuel patents using Y02E50/1 code in the CPC.

The results in Table 4.5 are consistent with the results shown in Table 4.4 except the coefficient of the interaction term of $C S_{r, i j}$ and $T R_{i j}$ is insignificant for wind technology. The difference may be explained by the fact that offshore wind technology partly builds on 
the onshore wind technology, whereas the knowledge bases of different generations of solar PV technology and biofuel technology are significantly different (Carvalho et al., 2017; Costantini et al., 2015; Kalthaus, 2019; Wieczorek et al., 2013).

Table 4.5 Robustness check: wind power and biofuel

\begin{tabular}{|l|c|c|c|c|}
\hline & \multicolumn{2}{|c|}{ Wind power } & \multicolumn{2}{c|}{ Biofuel } \\
\hline & $(1)$ & $(2)$ & $(3)$ & $(4)$ \\
\hline$C S_{r, i j}$ & $0.002^{* *}$ & $0.004^{* *}$ & $0.008^{* * *}$ & $0.012^{* * *}$ \\
\hline & $(0.00)$ & $(0.00)$ & $(0.00)$ & $(0.00)$ \\
\hline$C S_{r, i j} * T R_{i j}$ & & -0.007 & & $-0.021^{* * *}$ \\
\hline Variety $_{r}$ & & $(0.00)$ & & $(0.00)$ \\
\hline & $0.908^{* * *}$ & $0.904^{* * *}$ & $0.642^{* * *}$ & $0.641^{* * *}$ \\
\hline External & $(0.06)$ & $(0.06)$ & $(0.03)$ & $(0.03)$ \\
\hline & $-0.278^{* * *}$ & $-0.268^{* * *}$ & $-0.102^{*}$ & $-0.092^{*}$ \\
\hline Count_field $r$ & $(0.04)$ & $(0.04)$ & $(0.04)$ & $(0.04)$ \\
\hline & $0.015^{* * *}$ & $0.015^{* * *}$ & $0.023^{* * *}$ & $0.023^{* * *}$ \\
\hline Country Fixed Effects & $(0.00)$ & $(0.00)$ & $(0.00)$ & $(0.00)$ \\
\hline Number of Observations & Yes & Yes & Yes & Yes \\
\hline Log Likelihood & 1231544 & 1231544 & 1304622 & 1304622 \\
\hline
\end{tabular}

* Significant at $0.1, * *$ Significant at 0.05 and $* * *$ significant at 0.01 . Robust standard errors are reported in the parentheses

We further compare the results using all renewable energy technologies patents and the results using all patents in Table 4.6. The results for renewable energy technologies in column (1) and (2) are consistent with the results in Table 4.4 and Table 4.5, indicating that the observed pattern that geographical proximity can bridge technology distance in the creation of new combinations is common to renewable energy technologies. The coefficient of the interaction term of $C S_{r, i j}$ and $T R_{i j}$ in column (4) is significantly positive in the regressions using all technologies, indicating that the pattern is different that placedependence will further strengthen the path-dependence in recombining related technologies. 
Recombinant invention in solar photovoltaic technology

Table 4.6 Robustness check: renewable energy technologies and all technologies

\begin{tabular}{|l|c|c|c|c|}
\hline & \multicolumn{2}{|c|}{ Renewable energy technologies } & \multicolumn{2}{c|}{ All technologies } \\
\hline & $(1)$ & $(2)$ & $(1)$ & $(2)$ \\
\hline$C S_{r, i j}$ & $0.008^{* * *}$ & $0.010^{* * *}$ & $0.030^{* * *}$ & $0.022^{* * *}$ \\
\hline$C S_{r, i j} * T R_{i j}$ & $(0.00)$ & $(0.00)$ & $(0.00)$ & $(0.00)$ \\
\hline & & $-0.015^{* * *}$ & & $1.764^{* * *}$ \\
\hline Variety $_{r}$ & & $(0.00)$ & & $(0.25)$ \\
\hline & $0.763^{* * *}$ & $0.757^{* * *}$ & $1.189^{* * *}$ & $1.186^{* * *}$ \\
\hline External & $(0.02)$ & $(0.02)$ & $(0.02)$ & $(0.02)$ \\
\hline & $-0.364 * * *$ & $-0.354^{* * *}$ & $-0.024 *$ & $-0.024 *$ \\
\hline Country Fixed Effects & $(0.02)$ & $(0.02)$ & $(0.01)$ & $(0.01)$ \\
\hline Number of Observations & 4721318 & 4721318 & 17412063 & 17412063 \\
\hline Log Likelihood & -38745.498 & -38719.690 & -147116.956 & -147027.895 \\
\hline
\end{tabular}

* Significant at $0.1, * *$ Significant at 0.05 and $* * *$ significant at 0.01 . Robust standard errors are reported in the parentheses

\subsection{Conclusion and discussion}

This paper studies the emergence of new combinations in solar PV technology at the regional level in all OECD and BRICS countries. The results show that unrelated technologies are more likely to be recombined when they are strongly present in the same region, indicating that geographical proximity can bridge technological distance in creating new combinations. Moreover, this pattern is common to renewable energy technologies, while a similar pattern is not observed using all technologies.

This paper presents the first empirical support of the policy framework 'crossspecialisation' proposed by Janssen and Frenken (2019). The 'cross-specialisation' policy framework extended the recent smart specialisation strategies approach which was integrated into the reformed cohesion policy for European Union (Foray, 2018a). Beyond the emphasis on leveraging existing competences of regions for growth opportunities, the 'cross-specialisation' policy framework further highlights the importance of linking strong but unrelated knowledge base in such process (Janssen \& Frenken, 2019). Both smart specialisation strategies approach and 'cross-specialisation' approach highlight the importance of place-based or place-dependent capabilities (Boschma et al., 2017a). Our results show that the place-dependent capabilities are especially important in searching for new combinations of unrelated technologies in the domain of renewable energy technology. 
We understand the outcome to reflect that linking unrelated technologies that are already strongly present in the same region, can reduce both the search cost and the risk of failure the process.

Our findings show that the process in which place-dependence can break the pathdependence of recombining related technologies is common to renewable energy technologies. The development of radical innovations like renewable energy technologies on one hand face the challenge from the overcoming technological distance, on the other hand face the challenge of legitimacy because their potential in disrupting existing socialtechnical systems (Markard and Truffer, 2008). Thus, the recombination of unrelated technologies in an economy can be viewed as middle road where the strongly present technologies being recombined can still provide support for radical innovations (Frenken, 2017). Moreover, given the uneven knowledge accumulation across regions, the recombination of unrelated technologies strongly present in regions can offer various new recombination for selection to avoid technological lock-in (Safarzyńska and van den Bergh, 2013; Sbardella et al., 2018; Zeppini and van den Bergh, 2011). Thus, our findings also provide an empirical support for the geographical perspective of innovation policies aimed at addressing societal challenges like climate change (Coenen et al., 2015; Foray et al., 2012; Foray, 2018a; Frenken, 2017; Wanzenböck and Frenken, 2018).

Although our results show strong correlation between the strong co-presence of unrelated technologies in a region and the likelihood of them being recombined, we have not focused on whether the new combinations of unrelated technologies resulted from 'crossspecialisation' policies. Some new combinations of unrelated technologies might occur without any policy interventions, while others require special coordination process (Foray, 2018b). The recent empirical evaluation of the effectiveness of implemented smart specialisation strategies at the regional level opens future research avenues (D'Adda et al., 2019). Moreover, the potential effectiveness of such 'cross-specialisation' policies depends on the assumption that the recombination of unrelated technologies can facilitate the convergence between them. A dynamic perspective of relatedness is therefore required to assess the impacts of recombination on the evolution of relatedness between technologies (Castaldi, Los \& Frenken, 2015; Boschma, 2017).

Furthermore, learning between unrelated technologies might occur at different spatial level at the same time through different proximities (Malmberg \& Maskell, 2002). It is important to further explore the channels through which unrelated technologies within a region are brought together and recombined. Inter-firm networks might operate at higher, more aggregate level, while spin-off dynamics, labour mobility and daily face-to-face interactions might operate at local level (Boschma, 2005). The micro-processes underlying 


\section{Recombinant invention in solar photovoltaic technology}

proximities can help better designing regional innovation policy tools for facilitating the recombination of unrelated technologies (Janssen and Frenken, 2019).

Finally, although our result show that unrelated technologies strongly present in the same region are more likely to be recombined, new combinations are still heavily concentrated in regions on the technology frontier. It could be the case that the lagging regions may lack the necessary capabilities for achieving such recombination of unrelated technologies. Regions with less diverse knowledge have less options in their search for new combinations.

Moreover, the technological distance could be a challenge for lagging regions more than for regions on the technology frontier. Thus, it is important to focus on how lagging regions can access a variety of extra-regional knowledge elements to build up necessary capabilities for future recombinant inventions (Breschi and Lenzi, 2015; Giuliani et al., 2016; Hausmann and Neffke, 2019; Mudambi et al., 2018; Neffke et al., 2018). 


\section{Chapter 5}

\section{Catching up in renewable energy technological paradigm: can knowledge base facilitate early adoptions of breakthrough inventions}

This chapter is co-authored with Koen Frenken, Gaston Heimeriks and Floor Alkemade, and in preparation for journal submission. 


\begin{abstract}
How we can accelerate the diffusion of new clean energy technologies worldwide is a question of high relevance for energy and climate policies, as well as industrial policies. By tracing the time lag between the introduction and the diffusion of breakthrough inventions in solar photovoltaic technology and wind power technology, this paper shows that the knowledge base of countries facilitates the early adoptions of breakthroughs in both technologies, especially in latecomer countries. The importance of knowledge base in the catching-up process also differs between technologies. There are more opportunities in more dynamic technologies like solar photovoltaic technology. The results of this paper help better understand the catching-up process of countries in the clean energy technological paradigm.
\end{abstract}




\subsection{Introduction}

The decarbonization of our current energy systems to meet the climate change mitigation goal is crucial and urgent, requiring a faster diffusion of new clean energy technologies worldwide. This challenge is especially acute in latecomer countries where the demands for energy grow rapidly (Grubler et al., 2016; Sovacool, 2016). Besides the goal for climate change mitigation, the emergence of the clean energy technological paradigm also offers latecomer countries windows of opportunity to catch up with countries on the technological frontier (Mathews, 2013; Perez, 2016, 2013).

Although existing literature shows that latecomer countries can deploy new clean energy products relatively faster than first movers (Bento et al., 2018; Grubler et al., 2016), for economic development purposes a catch-up can only be achieved through acquiring the capacity for participating in the generation and improvement of technologies instead of the simple use of them (Perez and Soete, 1988). Thus, the capability of being able to enter as early imitators is important for the catching-up process of latecomer countries.

Recent empirical studies in evolutionary economic geography (EEG) highlight the importance of local related capabilities in the development of new technologies (for reviews, see: Boschma, 2017; Hidalgo et al., 2018). It has been found that countries tend to diversify into new technologies that require capabilities also needed for other technologies that a country already masters. Hence, one can expect that a technology diffuses faster to countries with related technologies already present.

Most catch-up studies, however, assume that latecomer countries will follow a strategy to imitate new technologies by leveraging other factors like location, connectivity, natural resources and low labour cost (Fu et al., 2011). Next to these factors, absorptive capacity has been highlighted as important, generally conceptualized in generic terms referring to a country's science base, R\&D investment or human capital. Systematic evidence on the role of absorptive capacity vis-à-vis a particular technology is still lacking.

This paper focuses on the catching-up process for radically new clean energy technologies by investigating the speed at which countries adopt new clean energy technologies. Note that adoption here thus not refer to the use of a radically new technology developed abroad, but to the incremental improvement of a radically new technology developed abroad. Following the recent large-scale assessment of breakthrough inventions based on patent classes (Fleming, 2001; Verhoeven et al., 2016), we traces the spatialtemporal diffusion of breakthroughs in solar photovoltaic technology and wind power technology, and quantify the impacts of local, related capabilities on the time lag between the emergence and the adoption of these breakthroughs across countries. 


\section{Catching up in renewable energy technological paradigm}

The main contributions of this paper are threefold. First, we quantify the catching-up process of latecomer countries in the new clean energy technological paradigm by focusing on the time lag between the emergence and adoption of breakthrough inventions. Second, in a more general sense, we contribute to a better understanding of the temporal dimension in evolutionary economic geography literature by highlighting the importance of local capabilities in facilitating faster adoption of new technologies (Henning, 2019). Third, we shed light upon the locational effects of technology characteristics by comparing the spatial-temporal diffusion pattern of solar photovoltaic technology and wind power technology (Binz and Truffer, 2017; Schmidt and Huenteler, 2016).

The remainder of the paper is structured as follows. In Section 2, we review the relevant literature on the temporal and spatial diffusion of new technologies. In Section 3, we describe the data, econometric model and variables. In Section 4, we present the results of descriptive analysis and econometric analysis. We conclude by discussing the implications of our findings in Section 5.

\subsection{Theoretical background}

\subsubsection{Windows of opportunity and the timing of entry}

The diffusion of new technology is inherently spatial in that new technologies usually emerge in technology centres, and disseminate, through a hierarchy of sub-centres, to the periphery (Hägerstrand, 1973). During the spatial diffusion process, some industrialized countries entered early on, while the comparative advantage would shift to latecomer countries with the further international diffusion of technologies as they reach maturity (Perez and Soete, 1988).

The emergence of radically new technologies often opens windows of opportunity for latecomers to catch up through imitating and improving new technologies earlier (Perez and Soete, 1988). Lee and Malerba (2017) extended the notion of windows of opportunity to various building blocks of sectoral innovation systems. They explain that, besides technological breakthroughs, other forces such as major shifts in market structures and large shifts in politics, could also open such windows of opportunity. Yap and Truffer (2019) further argued that the latter two processes are especially important for the catchingup process in clean energy technologies.

The timing of entry is key for the catching-up process of latecomer countries when a window of opportunity emerges (Perez and Soete, 1988). The evolutionary view of technological change suggests that incremental improvements come along with the diffusion of new technology (Dosi, 1991; Metcalfe, 1981; Rosenberg, 1982). Thus, technologies evolve in a path-dependent way along defined technological trajectories. The 
improvements have a cost and come with the generation of additional experience and skills. Thus, later entry indicates a larger gap with the technological frontier. Moreover, the emergence of a new technological paradigm can shift incumbent trajectories to new directions (Dosi, 1982). Although it might be easier for latecomer countries to enter a new technology at a more mature stage, late entry might lead to a lock-in in a technological paradigm which has exhausted its technological dynamism (Perez and Soete, 1988).

The importance of early entry is further corroborated by recent studies on the search behaviour of inventors and firms show that the utilization of emerging knowledge correlates with a higher technological impact of inventions (Capaldo et al., 2017; Kok et al., 2019; Mukherjee et al., 2017). Moreover, higher utilization rates of recent technologies are also associated with the improvement in performance, or the cost reduction of new technologies (Benson and Magee, 2015, 2014).

However, empirical insights on the timing of entry remain largely qualitative in the catch-up literature (Lee and Malerba, 2017; Perez and Soete, 1988). Kwon, Lee \& Lee (2017) is the first to systematically quantify the catching-up process by investigating the time needed for inventors of a particular country to cite an invention from technological frontier. They showed that Korea, Israel and Taiwan managed to narrow the gap with technological frontier, whereas similar progress is not observed in China and India. However, they only focus on the overall technological progress of specific countries, and fail to explain why certain countries are able to adopt new technologies earlier. We lack systematic quantitative research on the determinants of early entry of latecomer countries in new technology paradigm earlier.

\subsubsection{Local capabilities and the temporal dimension in evolution economic geography}

The original windows of opportunity concept suggested that the diffusion of radically new technologies and new industries is rather independent of the precise industrial structures in the adopting region (Perez and Soete, 1988; Storper and Walker, 1989). Here, the reasoning was that radically new technologies are fundamentally different from previous technology. Hence, what is learnt in the past is of very limited relevance for understanding, and institutionalising, the new technology. Only generic absorptive capacity was considered important.

However, innovations do not diffuse automatically and in isolation (Grubler et al., 2016). Latecomer countries need the capacity to absorb and assimilate the new technology, and overcome the costs of entry (Cohen and Levinthal, 1990; Maskell and Malmberg, 1999; Perez and Soete, 1988). The recent EEG literature highlights the path-and placedependencies of technological change, it shows that countries and regions are more likely to diversify into new products and new technologies that are related to their existing 


\section{Catching up in renewable energy technological paradigm}

knowledge bases (see a review in Boschma (2017) and Hidalgo et al. (2018)). The capabilities of a country open up new opportunities, as well as set constraints, for its future technology development. The logic of related diversification offers a framework that not only enables one to say that "history matters" for territorial development, but also how it matters for particular technologies ( Petralia et al., 2017; Sbardella et al., 2018).

However, as pointed out by Henning (2019), current EEG research only compares the new technology emerging in a country (or region) with the technology structure of the focal country (or region) in the past. It ignores whether the technology that is new to a country (or region) is in itself, at the global level, a recent invention or an existing one. Put differently, EEG focused overwhelmingly on the introduction of novelty while neglecting the diffusion of innovations. The temporal dimension in these studies thus remains rather abstract (Henning, 2019).

A better understanding of the windows of opportunity and the catching-up process requires tracking the real time diffusion of radically new technologies across countries. Bridging the EEG literature with transition studies, Boschma et al. (2017a) categorized new activities emerging in a country (region) along both the geographical dimension and the sectoral dimension. In their view, innovations are seen as activities new to the world, whereas imitations can be seen as new to the country. Countries can imitate a new technology based on their existing related capabilities (replication), or based on external linkages (transplantation).

In this study, we focus on innovations that are new to the world and investigate to what extent the existing related capabilities in a country matter for the speed at which countries adopt a new invention. Radically new technologies or breakthrough inventions are considered the results from the combination of existing knowledge, technologies and artefacts in novel ways (Arthur, 2007; Arts and Veugelers, 2015; Fleming, 2001; Henderson and Clark, 1990; Strumsky and Lobo, 2015; Verhoeven et al., 2016). Building on this view, Pezzoni, Veugelers and Visentin (2019) traced the diffusions of new technologies, and found that the new technologies of which the components were familiar to the inventors' community can diffuse faster. We therefore expect that the local related capabilities of countries can facilitate earlier adoptions.

Note that our theoretical reasoning is similar to the original concept of related diversification (Hidalgo et al., 2007) as we study the local conditions that affect the likelihood that a country diversifies into a new technology. Yet, we offer a new perspective on this process in two ways. First, we look exclusively at radically new technologies.

Second, we go beyond the typical research question of whether or not a country diversifies into a particular technology by analysing how fast a country is able to diversify into this radically new technology. 


\subsection{Research Design}

\subsubsection{Sample and Data}

The data used in this paper are patent applications filed at European patent office (EPO), United States Patent and Trademark Office (USPTO) and through the Patent Cooperation Treaty (PCT-route) from 1980 to 2015. Patent applications are extracted from European Patent Office Worldwide Patent Statistics Database PATSTAT (EPO, 2018 Autumn Version). We only focus on patents assigned to companies and institutions following Mancusi (2008). The type and the unique identifier of applicants are extracted from the PATSTAT Standardized Name table developed by ECOOM in KU Leuven (Du Plessis et al., 2009; Magerman et al., 2009).

Since multiple equivalent patent applications can be filed at different patent offices to protect the intellectual property rights of the same invention, we use IPC codes of all patent applications in the same DOCDB patent family as the technological classifications of the invention under consideration (Martínez, 2011). The year of a DOCDB patent family is based on the application year of its first patent application.

Patent classification codes in which a patent is assigned are considered as proxies for the specific technology components associated with the patented invention (Fleming, 2001). Although some studies also use the backward citations to proxy the knowledge recombination (see the review by Jaffe \& de Rassenfosse (2017)), technological codes are determined by patent examiners; thus, unlike patent citations, they are not biased by firms' strategic considerations. For that reason, co-occurrences of technology codes at the patent level are ideal for determining the technological combinations that led to a patented innovation (Fleming, 2001; Fleming et al., 2007).

We identify the breakthroughs by assessing the new combinations of patent technology codes at the main group level of the International Patent Classifications (IPC) following Verhoeven et al. (2016). A pairwise combination of IPC main groups is considered new if they appear for the first time in (recent) history. We use all the patents applied between 1980 and 1992 to find the already existing combinations and track the emergence of breakthroughs from 1993.

We assign each patent to the country of residence of the first named inventor in the patent document of the first patent in a patent family following Mancusi (2008). The inventor's address can better identify where the R\&D was performed given the significant presence of technology sourcing from multinational corporations (Alkemade et al., 2015; de Rassenfosse and Seliger, 2019).

We focus on the diffusion of breakthroughs in two leading clean energy technologies: solar photovoltaic and wind power. Patents relating to these two technologies are identified 


\section{Catching up in renewable energy technological paradigm}

using the Y02E10/5 code (solar PV) and Y02E10/7 code (wind power) in the newly launched Cooperative Patent Classification (CPC). The Y02 class is developed by EPO experts by combining existing International Patent Classifications (IPC) and European Patent Classifications with a lexical analysis of abstracts or claims in identifying crosssectoral technologies with potential in climate change mitigations (Veefkind et al., 2012a).

\subsubsection{Econometric Model}

In order to trace the determinants of the speed in the spatial-temporal diffusion of breakthroughs in clean energy technologies that are new to the world, we applied the Cox proportional hazard model (Cox, 1972) which has the advantage of estimating the hazard ratios without specifying baseline hazards. We focus on the number of days a country adopts a breakthrough for the first time (new to the country) since the introduction of the breakthrough (new to the world). Hence, we differ from the more typical measurement of diversification as becoming specialised in a particular technology relative to all other countries.

We consider all breakthroughs introduced between 1993 and 2007 to leave an 8-year window forward to this last cohort. We only focus on breakthroughs which are adopted more than 20 times as to be able to apply a threshold for the impacts of new technologies following Pezzoni et al. (2019). Moreover, we focus on breakthroughs introduced by inventors from United States to proxy new technologies developed at the technology frontier following Kwon et al. (2017). As a robustness check, we also use breakthroughs introduced by inventors from Germany and Japan as a robustness check. The number of breakthroughs introduced by these three countries accounts for 70 percent of all breakthroughs introduced during the period 1993-2007. Leydesdorff et al. (2015) show that these three countries are also at the technological frontier of solar photovoltaic technology.

We take the set of breakthroughs and regress them on characteristics of countries adopting them. As emphasised by Griffith et al. (2011), it is crucial to control for unobserved heterogeneity at the new technology level since some technologies diffuse more quickly than others, for example, due to their level of codification or usefulness. The Cox model allows estimating different hazard ratios across groups. We include four variables to stratify our breakthroughs to control the different diffusion speeds across breakthroughs.

First, we include the technological distance between technological components being recombined in the breakthrough inventions by exploring the hierarchical structure of the IPC code classification following Pezzoni et al. (2019). We include a same field dummy (stating whether the IPC main groups in the new combination are from the same technological field) and a same sector dummy (stating whether the pairwise IPC main groups are from different technological fields but the same sector). The IPC main groups are linked to technological fields and sectors based on the concordance table developed by 
Schmoch (2008). Second, we include the intra-technology dummy (stating whether the breakthrough invention is introduced by the same type of renewable energy technology that adopts it). Third, we also include the year in which the focal breakthrough is introduced.

As pointed out by Jaffe, Trajtenberg \& Henderson (1993), and Griffith, Lee \& Reenen (2011), new technologies are more likely to diffuse locally. Thus, we only focus on the international diffusion of breakthroughs to avoid the home bias. We include all OECD countries, EU 28 countries and BRICS countries (Brazil, Russia, India, China and South Africa) as the potential adopting country. Finally, we cluster the standard errors at the country level to control for the unobserved heterogeneity in adopting breakthroughs across countries.

\subsubsection{Explanatory Variables}

The main explanatory variable we are focusing on in this paper is the familiarity of inventors in a country with the technology components being used in a new combination. Familiarity takes the minimum value of the number of patents in a country among the IPC main groups of the breakthrough invention, in the past five years before the adoption taking place, following Clancy (2018). We exclude patents with inventors external to the country to capture the scale effects associated with the agglomeration of inventive activities (Breschi and Lenzi, 2015; Lobo and Strumsky, 2008). A larger value of Familiarity indicates that inventors in the country have a larger knowledge stock in both technological components used in the new combination, thus more likely to adopt new technologies earlier.

We add five control variables to control for the country-level factors which might affect the adoption speed of new technologies. First, we include GDP per capita to control for the level of economic development of a country using data extracted from the Penn States Table 9.1 (Feenstra et al., 2015). Second, we take into account whether the adopting country specializes in solar photovoltaic technology (wind power technology) using the Revealed Technology Advantage index (RTA) following Soete and Wyatt (1983). The RTA takes the value 1 if the share of the solar photovoltaic patents (wind power patents) of a focal country in its total number of patents is larger than the share of solar photovoltaic patents (wind power patents) worldwide, and 0 otherwise. Third, we include the amount of electricity generated from solar photovoltaic (wind power) to control for the impact of domestic market development on the development of new technologies. Fourth, the impact of geographical distance on the speed of spatial diffusion is controlled for using the distance between the capital of United States (Germany/Japan) and the capital of the reusing country. The distance data are extracted from the CEPII database (Mayer and Zignago, 2011). Fifth, we control for the impact of international linkages through multinationals by including the number of patents invented by inventors in the focal 


\section{Catching up in renewable energy technological paradigm}

country while assigned to the same assignee abroad who introduced the new combination in the previous 5 years before the reuse. We expect positive impacts from GDP, RTA, Market, and Same assignee, and negative impact from Distance.

Finally, in order to trace whether latecomer countries are closing the gap with countries at the technological frontier, we include the interactions of Familiarity with GDP per capita and RTA to test whether the impact of Familiarity differs across countries. Here, we expect that being familiar with the technologies being recombined especially helps countries at lower levels of development and countries with a lack of specialisations in solar (wind), to compensate for these unfavourable conditions.

\subsection{Results}

\subsubsection{Descriptive results}

We focus on the spatial-temporal diffusions of 110 breakthrough inventions in solar photovoltaic technology and 65 breakthrough inventions in wind power technology introduced by US inventors among 47 countries, therefore 5170 observations for solar photovoltaic and 3055 observations for wind power. Figure 5.1 shows the distributions of the number of countries adopting of breakthroughs (X-axis) in solar photovoltaic (upper panel) and wind power (lower panel). Most of breakthroughs in both technologies are only adopted by less than 15 countries.

Table 5.1 and Table 5.2 show the summary statistics and the correlation between the explanatory variables for solar photovoltaic and wind power technology respectively. The correlation between independent variables are not high. 

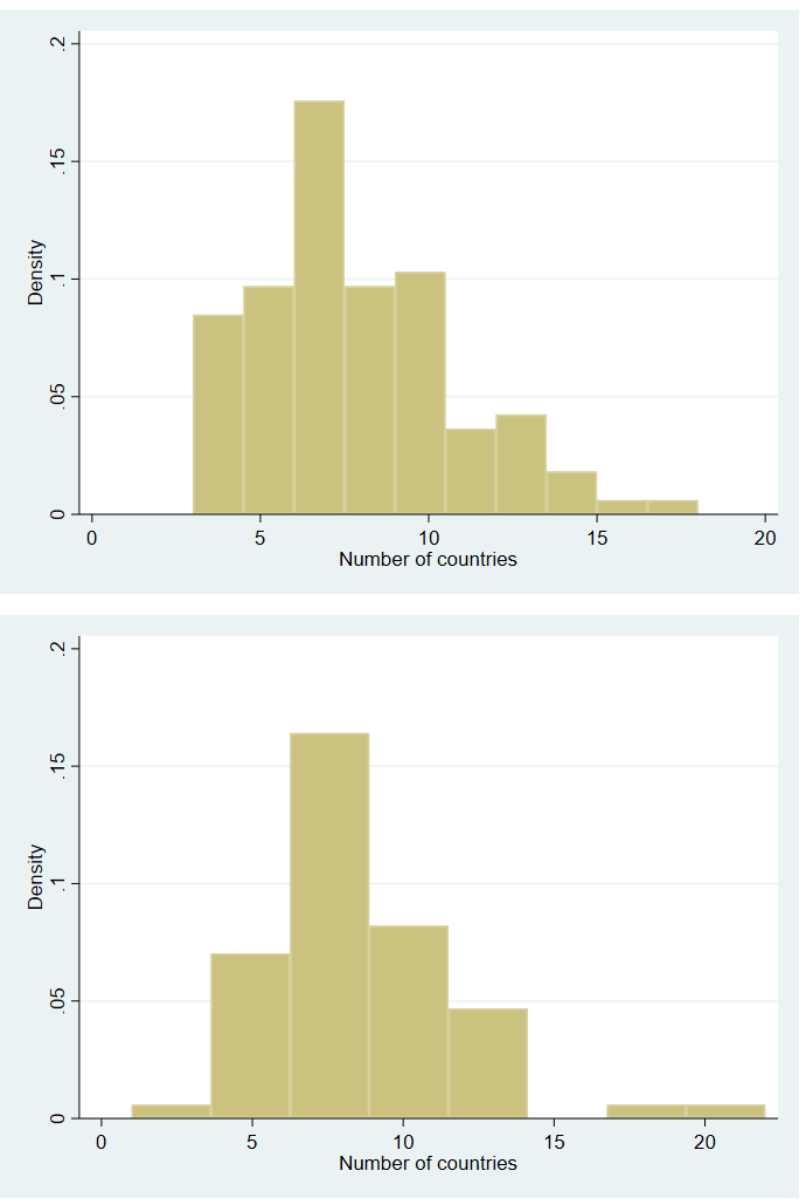

Figure 5.1 Descriptive analysis of the number of adopting countries in solar photovoltaic technology (upper-panel) and wind power technology (lower-panel)

\subsubsection{Econometric results}

Table 5.3 shows the econometric results of solar photovoltaic technology using new combinations introduced by inventors from United States. We divide our sample into pre2000 and post-2000 subsamples. Since the ratification of the Kyoto protocol in 1999, the number of patents in renewable energy technologies grew significantly (Bettencourt et al., 2013). We therefore divide our sample into pre-2000 and post-2000 subsamples following Conti et al. (2018). 
Catching up in renewable energy technological paradigm

\begin{tabular}{|c|c|c|c|c|c|c|}
\hline$\frac{\vec{a}}{\underset{D}{\Delta}}$ & 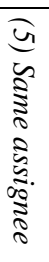 & 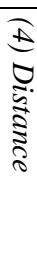 & 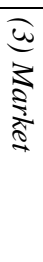 & 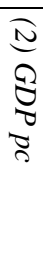 & 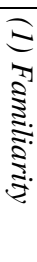 & \\
\hline$\stackrel{u}{\vec{d}}$ & $\frac{u}{\partial}$ & $\frac{u}{d}$ & $\stackrel{u}{\vec{d}}$ & 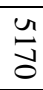 & $\stackrel{u}{\vec{d}}$ & $\underset{\phi}{\text { o }}$ \\
\hline$\stackrel{\circ}{\dot{\omega}}$ & iN & 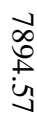 & $\underset{\stackrel{\omega}{\omega}}{\stackrel{N}{*}}$ & $\begin{array}{l}\stackrel{\omega}{N} \\
\stackrel{\Xi}{\Xi}\end{array}$ & $\begin{array}{l}\tilde{\omega} \\
\stackrel{\infty}{\circ}\end{array}$ & $\begin{array}{l}\frac{3}{8} \\
\stackrel{\Xi}{\Xi}\end{array}$ \\
\hline 只 & $\begin{array}{l}\text { Ò } \\
\text { i }\end{array}$ & $\begin{array}{l}\text { 겅 } \\
+ \\
\text { 우 }\end{array}$ & $\begin{array}{l}\stackrel{\partial}{0} \\
\stackrel{+}{+} \\
\dot{\infty} \\
\text { on }\end{array}$ & 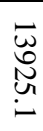 & $\begin{array}{l}\vec{\jmath} \\
\underset{\omega}{\omega}\end{array}$ & 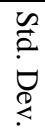 \\
\hline 0 & 0 & $\begin{array}{l}\text { w్ } \\
\dot{\phi}\end{array}$ & 0 & $\begin{array}{l}\tilde{8} \\
\stackrel{1}{+} \\
\text { in }\end{array}$ & 0 & 3 \\
\hline- & $\underset{\mathrm{N}}{\overrightarrow{\mathrm{N}}}$ & $\begin{array}{l}\bar{U} \\
\text { ̊े } \\
\text { a }\end{array}$ & $\underset{\substack{\mathbb{N} \\
\mathbb{N}}}{\stackrel{+}{d}}$ & $\frac{\infty}{\stackrel{\infty}{\sigma}}$ & $\begin{array}{l}\stackrel{N}{\sigma} \\
\text { a }\end{array}$ & $\underset{x}{3}$ \\
\hline$\stackrel{0}{\infty}$ & ? & $\stackrel{0}{0}$ & $\stackrel{0}{\not}$ & $\stackrel{\circ}{\circ}$ & - & $\Xi$ \\
\hline $\begin{array}{l}\text { P } \\
\text { î } \\
\text { U. }\end{array}$ & $\begin{array}{l}1 \\
0\end{array}$ & $\underset{\text { d }}{\dot{1}}$ & $\stackrel{\dot{N}}{\frac{1}{n}}$ & - & & $\mathbb{N}$ \\
\hline 0 & $\stackrel{0}{9}$ & $\stackrel{\circ}{N}$ & - & & & (્) \\
\hline$\stackrel{\circ}{\infty}$ & $\dot{\leftrightarrow}$ & - & & & & I \\
\hline $\begin{array}{l}1 \\
0 \\
0\end{array}$ & - & & & & & (⿹) \\
\hline- & & & & & & (ิ) \\
\hline
\end{tabular}


Chapter 5

\begin{tabular}{|c|c|c|c|c|c|c|}
\hline $\begin{array}{l}\vec{a} \\
\vec{D} \\
\vec{D}\end{array}$ & 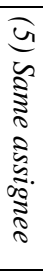 & 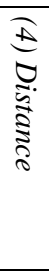 & 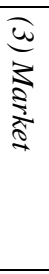 & 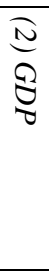 & 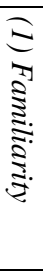 & \\
\hline $\begin{array}{l}\tilde{c}^{\prime} \\
\text { un }\end{array}$ & $\begin{array}{l}\tilde{D}^{\prime} \\
\text { un }\end{array}$ & $\begin{array}{l}\mathscr{U}^{\prime} \\
\text { ŭ }\end{array}$ & $\begin{array}{l}\omega \\
\stackrel{u}{u} \\
u\end{array}$ & $\begin{array}{l}\tilde{u}^{2} \\
\tilde{u}\end{array}$ & $\begin{array}{l}\omega \\
\text { o } \\
u\end{array}$ & $\stackrel{\circ}{\circ}$ \\
\hline in & $\stackrel{\omega}{\omega}_{\omega}^{\omega}$ & $\begin{array}{l}\stackrel{\infty}{\not} \\
\stackrel{0}{+} \\
\dot{y}\end{array}$ & \begin{tabular}{l}
$\underset{\omega}{\omega}$ \\
$\stackrel{+}{ \pm}$ \\
\multirow{v}{*}{}
\end{tabular} & $\begin{array}{l}\stackrel{\omega}{N} \\
\stackrel{\infty}{\circ} \\
\stackrel{\nu}{\beth}\end{array}$ & $\begin{array}{l}\infty \\
\dot{b}\end{array}$ & $\begin{array}{l}\frac{3}{8} \\
\cong\end{array}$ \\
\hline $\begin{array}{l}\circ \\
\stackrel{b}{0}\end{array}$ & $\underset{\text { i }}{\stackrel{H}{0}}$ & $\begin{array}{l}\text { Nu } \\
\text { U. } \\
. \\
\omega\end{array}$ & $\begin{array}{l}\frac{N}{\infty} \\
\stackrel{N}{\sigma} \\
\dot{\alpha}\end{array}$ & $\begin{array}{l}\omega \\
\infty \\
\infty \\
\infty \\
\infty\end{array}$ & $\underset{\sim}{N}$ & 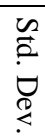 \\
\hline 0 & 0 & $\begin{array}{l}\stackrel{\sim}{\omega} \\
\stackrel{\phi}{+}\end{array}$ & 0 & $\begin{array}{l}\mathscr{U}_{0} \\
\dot{0} \\
\dot{\varphi}\end{array}$ & 0 & 3 \\
\hline- & ర్తి & $\begin{array}{l}\overrightarrow{\text { Ŭ }} \\
\stackrel{0}{0} \\
\text { vo }\end{array}$ & $\begin{array}{l}\vec{\infty} \\
\ddot{y} \\
\vec{\sigma} \\
\alpha\end{array}$ & $\begin{array}{l}\stackrel{\infty}{\omega} \\
\underset{\infty}{\infty} \\
\stackrel{\omega}{\omega} \\
\underset{\omega}{\omega}\end{array}$ & $\underset{\infty}{+}$ & $\underset{0}{3}$ \\
\hline $\begin{array}{l}\dot{1} \\
\stackrel{\circ}{\not} \\
\dot{\perp}\end{array}$ & $\stackrel{0}{\circ}$ & $\begin{array}{l}0 \\
\dot{0} \\
\text { Un }\end{array}$ & $\begin{array}{l}\stackrel{0}{\sim} \\
\underset{\sim}{\sim}\end{array}$ & $\begin{array}{l}\text { O } \\
\text { ᄋ } \\
\text { N }\end{array}$ & - & 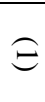 \\
\hline $\begin{array}{l}\dot{\infty} \\
\stackrel{\infty}{\circ}\end{array}$ & $\stackrel{\dot{0}}{\circ}$ & $\stackrel{\dot{\infty}}{\stackrel{\infty}{+}}$ & $\frac{b}{0}$ & - & & (N) \\
\hline $\begin{array}{l}\stackrel{b}{\circ} \\
\stackrel{\infty}{\infty}\end{array}$ & $\begin{array}{l}\stackrel{0}{N} \\
\frac{a}{a}\end{array}$ & 요 & - & & & (્) \\
\hline$\stackrel{\dot{0}}{\stackrel{\circ}{\phi}}$ & $\begin{array}{l}0 \\
\stackrel{0}{\mathcal{u}} \\
\text { und }\end{array}$ & - & & & & 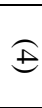 \\
\hline $\begin{array}{l}\dot{0} \\
8 \\
8\end{array}$ & - & & & & & (⿹ \\
\hline- & & & & & & (a) \\
\hline
\end{tabular}




\section{Catching up in renewable energy technological paradigm}

The coefficients of Familiarity are significantly positive in all six models, indicating that countries adopt new combinations earlier if they are familiar with the technology components used in the new combinations. Although the coefficients of GDP are not significant, the coefficients of Familiarity ${ }^{*} G D P$ are significantly positive in the full sample, and in the sub-sample of pre-2000 new combinations, and significantly negative in the sub-sample of post-2000 new combinations. The results indicate that the impacts of Familiarity on the speed of adoption have become more important for emerging countries in the recent years. This indicates an acceleration of the spatial diffusion of solar photovoltaic technology (Binz et al., 2017b).

The coefficients of $R T A$ are not significant. However, after the introduction the interaction term Familiarity*RTA, the coefficients of RTA are positive in the full sample and sub-sample of pre-2000 model, while the coefficients of Familiarity*RTA are significantly negative in all three models. The results show that familiarity with the technological components used in the new combination is more important for countries without a specialization in solar photovoltaic technology. This can be explained by the dynamic inventive pattern of solar photovoltaic technologies; several new types of solar photovoltaic cells emerged during the focal period (Kalthaus, 2019), allowing latecomer countries to catch-up.

Of other control variables, the coefficients of Same assignee are significantly positive in the full sample and in the sub-sample of new combinations introduced after 2000, indicating that knowledge transfer is faster within the network of multinational companies. This is in line with the findings in Phene et al. (2005). The coefficients of Distance and Market are not significant (with the exception that Market is significantly negative in column (2)). This indicates, unexpectedly, that the size of the domestic market may slow down the adoption of new technologies. This may be related to findings that suggest that demand-pull polices are more likely to introduce incremental improvement (Hoppmann et al., 2013; Nemet, 2009), thus less likely to facilitate more risky early adoptions of breakthrough inventions. Moreover, the diffusion of early generations of new technologies can also lead to technological lock-in which hampers the development of new generations of technologies (Franceschini and Alkemade, 2016). 
Table 5.3 Econometric results: Solar photovoltaic

\begin{tabular}{|c|c|c|c|c|c|c|}
\hline & (1) & (2) & (3) & (4) & (5) & (6) \\
\hline & \multicolumn{2}{|l|}{ 1993-2007 } & \multicolumn{2}{|l|}{ Pre-2000 } & \multicolumn{2}{|l|}{ Post-2000 } \\
\hline \multirow[t]{2}{*}{ Familiarity } & $0.211 * * *$ & $1.576 * * *$ & $0.213 * * *$ & $1.889 * * *$ & $1.007 * * *$ & $2.426 * * *$ \\
\hline & $(0.04)$ & $(0.20)$ & $(0.04)$ & $(0.23)$ & $(0.16)$ & $(0.37)$ \\
\hline \multirow[t]{2}{*}{$R T A$} & 0.675 & 0.560 & 0.665 & 0.568 & 0.543 & 0.488 \\
\hline & $(0.44)$ & $(0.44)$ & $(0.47)$ & $(0.45)$ & $(0.43)$ & $(0.42)$ \\
\hline \multirow[t]{2}{*}{$G D P$} & 0.034 & 0.053 & -0.044 & -0.017 & 0.139 & -0.079 \\
\hline & $(0.18)$ & $(0.17)$ & (0.19) & $(0.18)$ & $(0.17)$ & $(0.13)$ \\
\hline \multirow[t]{2}{*}{ Market } & -0.220 & $-0.537 *$ & -0.392 & -0.882 & -0.086 & -0.200 \\
\hline & $(0.20)$ & $(0.32)$ & $(0.37)$ & $(0.78)$ & $(0.10)$ & $(0.12)$ \\
\hline \multirow[t]{2}{*}{ Distance } & 0.139 & 0.160 & 0.126 & 0.149 & 0.184 & 0.150 \\
\hline & $(0.22)$ & $(0.22)$ & $(0.24)$ & $(0.23)$ & $(0.19)$ & $(0.20)$ \\
\hline \multirow[t]{2}{*}{ Same assignee } & $0.081 * * *$ & $0.075^{* * *}$ & 0.050 & 0.032 & $0.533 * * *$ & $0.530 * * *$ \\
\hline & $(0.03)$ & $(0.03)$ & $(0.04)$ & $(0.04)$ & $(0.11)$ & $(0.11)$ \\
\hline \multirow[t]{2}{*}{ Familiarity $* G D P$} & & $0.210^{*}$ & & $0.341^{*}$ & & $-1.254 * * *$ \\
\hline & & $(0.12)$ & & $(0.18)$ & & $(0.35)$ \\
\hline \multirow[t]{2}{*}{ Familiarity*RTA } & & $-1.425 * * *$ & & $-1.774 * * *$ & & $-0.927 * * *$ \\
\hline & & $(0.19)$ & & $(0.23)$ & & $(0.23)$ \\
\hline Observations & 5170 & 5170 & 2961 & 2961 & 1739 & 1739 \\
\hline Log likelihood & -3889.248 & -3799.358 & -2118.874 & -2039.937 & -1367.174 & -1342.662 \\
\hline
\end{tabular}

Table 5.3 shows the econometric results of wind power technology. Similar to solar photovoltaic technology, the coefficients of Familiarity are significantly positive in all six columns. Of the controls, the Distance and Market are not significant again, whereas the Same assignee are positive significant in the full sample and the sub-sample of post-2000.

Although the coefficients of GDP are not significant, the coefficients of

Familiarity ${ }^{*} G D P$ are significantly positive in the full sample and in the sub-sample of post2000 new combinations. The results also show that the impacts of Familiarity on the speed of adoption becomes more important for emerging countries in wind power technology in the recent years.

The coefficients of RTA are also not significant. However, the coefficients of Familiarity $* R T A$ are significantly positive in the full model and the sub-sample of the post2000 model. The results show that the familiarity with technological components used in the new combination is more important for countries already specialized in wind power technology, indicating a strong path-dependent process. 
Catching up in renewable energy technological paradigm

Table 5.4 Econometric results: Wind power

\begin{tabular}{|c|c|c|c|c|c|c|}
\hline & $(1)$ & (2) & (3) & (4) & $(5)$ & $(6)$ \\
\hline & \multicolumn{2}{|l|}{ 1993-2007 } & \multicolumn{2}{|l|}{ Pre-2000 } & \multicolumn{2}{|l|}{ Post-2000 } \\
\hline \multirow[t]{2}{*}{ Familiarity } & $0.256 * * *$ & $0.422 * * *$ & $0.221 * * *$ & $0.445^{* * * *}$ & $0.263 * * *$ & $0.461 * * *$ \\
\hline & $(0.04)$ & $(0.08)$ & $(0.05)$ & $(0.13)$ & $(0.04)$ & $(0.09)$ \\
\hline \multirow[t]{2}{*}{$R T A$} & 0.471 & 0.495 & 0.341 & 0.413 & 0.636 & 0.621 \\
\hline & $(0.41)$ & $(0.43)$ & $(0.42)$ & $(0.42)$ & $(0.40)$ & $(0.45)$ \\
\hline \multirow[t]{2}{*}{$G D P$} & 0.216 & 0.110 & 0.229 & 0.136 & 0.233 & 0.099 \\
\hline & $(0.17)$ & $(0.16)$ & $(0.16)$ & $(0.17)$ & $(0.17)$ & $(0.16)$ \\
\hline \multirow[t]{2}{*}{ Market } & 0.069 & -0.185 & 0.155 & -0.157 & 0.041 & -0.258 \\
\hline & $(0.11)$ & $(0.22)$ & $(0.11)$ & $(0.35)$ & $(0.12)$ & $(0.22)$ \\
\hline \multirow[t]{2}{*}{ Distance } & -0.006 & -0.054 & -0.032 & -0.091 & 0.026 & -0.032 \\
\hline & $(0.16)$ & $(0.18)$ & $(0.20)$ & $(0.23)$ & $(0.16)$ & $(0.19)$ \\
\hline \multirow[t]{2}{*}{ Same assignee } & $0.073 * *$ & 0.038 & 0.013 & -0.041 & $0.078 * *$ & 0.036 \\
\hline & $(0.04)$ & $(0.04)$ & $(0.10)$ & $(0.09)$ & $(0.04)$ & $(0.04)$ \\
\hline \multirow[t]{2}{*}{$\begin{array}{l}\text { Familiarity } \\
*_{G D P}\end{array}$} & & $-0.462 * *$ & & -0.403 & & $-0.594 * * *$ \\
\hline & & $(0.18)$ & & $(0.30)$ & & $(0.20)$ \\
\hline \multirow[t]{2}{*}{$\begin{array}{l}\text { Familiarity } \\
*_{R T A}\end{array}$} & & $0.173^{*}$ & & 0.093 & & $0.216^{* *}$ \\
\hline & & $(0.10)$ & & $(0.16)$ & & $(0.09)$ \\
\hline Observations & 3055 & 3055.000 & 893 & 893 & 1786.000 & 1786.000 \\
\hline $\begin{array}{l}\text { Log } \\
\text { likelihood }\end{array}$ & -2444.059 & -2424.017 & -781.850 & -775.303 & -1351.962 & -1335.566 \\
\hline
\end{tabular}

The different results between solar photovoltaic technology and wind power technology indicate that the spatial-temporal diffusion of new technologies is influenced by the technology characteristics. Lee and Malerba (2017) also highlight heterogeneity across technologies and sectors in the catching-up process. The recent conceptual framework of the Global Innovation Systems (GISs) further categorized solar photovoltaic technology as a more footloose GIS, and wind turbine technology as more spatial sticky GIS (Binz and Truffer, 2017; Schmidt and Huenteler, 2016). The difference of the locational impacts arises from the difference in the technology characteristics (Huenteler et al., 2016). Solar photovoltaic technology is considered to follow the STI (science-technology-innovation) innovation model and standardized massive production which requires more manufacturing capabilities, whereas wind turbine technology is considered to follow the DUI (doing, using 
and interacting) innovation mode which requires more design capabilities. Knowledge transfer in solar photovoltaic technology is often embodied in capital goods like manufacturing equipment which can be transferred across globalized markets, whereas the knowledge transfer in wind turbine technology is mostly the transfer of tacit knowledge (Binz and Truffer, 2017; Schmidt and Huenteler, 2016). Thus, it is more difficult for countries without previous knowledge accumulation to catch up to the technological frontier for wind turbine technology.

\subsubsection{Robustness check}

In order to check the robustness of our results, we first focus on the spatial-temporal diffusions of new combinations introduced by inventors from Japan and Germany. Table 5.5 and Table 5.6 show the results from the robustness check for solar photovoltaic and wind power respectively. Most results are consistent with the results in Table 5.3 and Table 5.4. One interesting finding is the different impacts of Distance on the diffusion speed of new combinations introduced by inventors Japan and Germany in solar photovoltaic technology. The impacts of Distance are negative on the diffusion of new combinations introduced by Japanese inventors, whereas these are positive on the diffusion of new combinations introduced by German inventors. This confirms the global leadership of Germany in solar photovoltaic industry (Binz and Anadon, 2018; Nemet, 2019; Quitzow, 2015; Wu and Mathews, 2012).

Second, we re-estimated the model by calculating the hazard rate for each new combination instead of using stratified groups. The results are shown in column (1)-(3) in Table 5.7 and Table 5.8. Third, we only focus on the Top one percent of the new combinations introduced each year to test whether the results are sensitive to the change of threshold for breakthroughs. The results are shown in column (4)-(6) in Table 5.7 and Table 5.8. A final concern is that our results might be driven by the adoption of new combinations made by the same assignee which introduced the new combination (Phene et al., 2005). We therefore dropped adoption of new combinations from the same assignee and re-estimated all models. The results are shown in column (7)-(9). The results in Table 5.7 and Table 5.8 are consistent with the results in Table 5.2 and Table 5.3. 
Catching up in renewable energy technological paradigm

Table 5.5 Robustness check: Solar photovoltaic

\begin{tabular}{|c|c|c|c|c|c|c|}
\hline & \multicolumn{4}{|c|}{ Japan } & \multicolumn{3}{c|}{ Germany } \\
\hline & \multicolumn{2}{|c|}{ Full sample } & Post-2000 & \multicolumn{2}{c|}{ Full sample } & Post-2000 \\
\hline & $(1)$ & $(2)$ & $(3)$ & $(4)$ & $(5)$ & $(6)$ \\
\hline Familiarity & $0.298^{* * *}$ & $0.369^{* * *}$ & $1.480^{* * *}$ & $0.145^{* * *}$ & $1.775^{* * *}$ & $5.680^{* * *}$ \\
\hline & $(0.03)$ & $(0.10)$ & $(0.46)$ & $(0.04)$ & $(0.24)$ & $(1.06)$ \\
\hline RTA & -0.293 & -0.278 & -0.212 & 0.565 & 0.474 & 0.225 \\
\hline & $(0.67)$ & $(0.64)$ & $(0.65)$ & $(0.52)$ & $(0.49)$ & $(0.54)$ \\
\hline GDP & 0.160 & 0.154 & -0.001 & 0.141 & -0.038 & $-0.473^{* *}$ \\
\hline & $(0.19)$ & $(0.19)$ & $(0.19)$ & $(0.21)$ & $(0.20)$ & $(0.20)$ \\
\hline Market & -0.320 & -0.355 & -0.348 & -0.617 & $-0.721 *$ & $-1.326^{* * *}$ \\
\hline & $(0.22)$ & $(0.24)$ & $(0.30)$ & $(0.58)$ & $(0.37)$ & $(0.47)$ \\
\hline Distance & $-0.649 * *$ & $-0.631 *$ & $-0.543 *$ & $0.337 * *$ & $0.331 * *$ & $0.306^{*}$ \\
\hline Same assignee & $0.024 * *$ & $0.025 *$ & $0.026^{* *}$ & $0.303 * * *$ & $0.201 * * *$ & $0.189^{* *}$ \\
\hline & $(0.01)$ & $(0.01)$ & $(0.01)$ & $(0.03)$ & $(0.02)$ & $(0.08)$ \\
\hline Familiarity*GDP & & -0.063 & $-0.999^{* * *}$ & & $-1.075^{* * * *}$ & $-4.286^{* * *}$ \\
\hline & & $(0.09)$ & $(0.36)$ & & $(0.16)$ & $(0.89)$ \\
\hline Familiarity*RTA & & -0.039 & -0.208 & & $-1.317^{* * * *}$ & $-3.014 * * *$ \\
\hline & & $(0.27)$ & $(0.37)$ & & $(0.17)$ & $(0.83)$ \\
\hline Observations & 5875.000 & 5875.000 & 1833.000 & 2397.000 & 2397.000 & 470.000 \\
\hline Log likelihood & -3985.301 & -3983.446 & -1219.283 & -1732.007 & -1672.767 & -256.738 \\
\hline
\end{tabular}


Chapter 5

Table 5.6 Robustness check: Wind power

\begin{tabular}{|c|c|c|c|c|c|c|}
\hline & \multicolumn{3}{|c|}{ Japan } & \multicolumn{3}{|c|}{ Germany } \\
\hline & \multicolumn{2}{|c|}{ Full sample } & \multirow{2}{*}{$\frac{\text { Post-2000 }}{(3)}$} & \multicolumn{2}{|c|}{ Full sample } & \multirow{2}{*}{$\frac{\text { Post-2000 }}{(6)}$} \\
\hline & (1) & (2) & & (4) & (5) & \\
\hline \multirow[t]{2}{*}{ Familiarity } & $0.445 * * *$ & $0.368 * * *$ & -0.012 & $0.309 * * *$ & $0.333 * * *$ & $0.286 * * *$ \\
\hline & $(0.09)$ & $(0.07)$ & $(0.19)$ & $(0.05)$ & $(0.06)$ & $(0.05)$ \\
\hline \multirow[t]{2}{*}{$R T A$} & 0.560 & 0.493 & 0.557 & 0.383 & 0.371 & 0.479 \\
\hline & $(0.49)$ & $(0.49)$ & $(0.46)$ & $(0.42)$ & $(0.42)$ & $(0.46)$ \\
\hline \multirow[t]{2}{*}{$G D P$} & 0.200 & 0.180 & 0.130 & 0.230 & 0.225 & 0.224 \\
\hline & $(0.17)$ & $(0.18)$ & $(0.18)$ & $(0.16)$ & $(0.16)$ & $(0.17)$ \\
\hline \multirow[t]{2}{*}{ Market } & 0.029 & 0.028 & 0.048 & -0.029 & -0.028 & 0.009 \\
\hline & $(0.11)$ & $(0.11)$ & $(0.16)$ & $(0.07)$ & $(0.07)$ & $(0.07)$ \\
\hline \multirow[t]{2}{*}{ Distance } & -0.266 & -0.284 & $-0.335^{*}$ & 0.037 & 0.039 & 0.101 \\
\hline & $(0.19)$ & $(0.20)$ & $(0.20)$ & $(0.17)$ & $(0.17)$ & $(0.16)$ \\
\hline \multirow[t]{2}{*}{ Same assignee } & $0.184 *$ & $0.205 * * *$ & $0.533 * * *$ & $0.090 * * *$ & $0.095 * * *$ & $0.084 * * *$ \\
\hline & $(0.11)$ & $(0.08)$ & $(0.09)$ & $(0.01)$ & $(0.01)$ & $(0.01)$ \\
\hline \multirow[t]{2}{*}{$\begin{array}{c}\text { Familiarity } \\
{ }^{*} G D P\end{array}$} & & -0.006 & -0.178 & & -0.059 & 0.002 \\
\hline & & $(0.05)$ & $(0.15)$ & & $(0.04)$ & $(0.05)$ \\
\hline \multirow[t]{2}{*}{$\begin{array}{c}\text { Familiarity } \\
\quad * R T A \\
\end{array}$} & & 0.187 & $0.810^{* * *}$ & & 0.173 & 0.150 \\
\hline & & $(0.13)$ & $(0.18)$ & & $(0.13)$ & $(0.12)$ \\
\hline Observations & 846.000 & 846.000 & 376.000 & 4747.000 & 4747.000 & 2538.000 \\
\hline Log likelihood & -582.500 & -580.423 & -279.338 & -5102.293 & -5089.371 & -2458.478 \\
\hline
\end{tabular}


Catching up in renewable energy technological paradigm

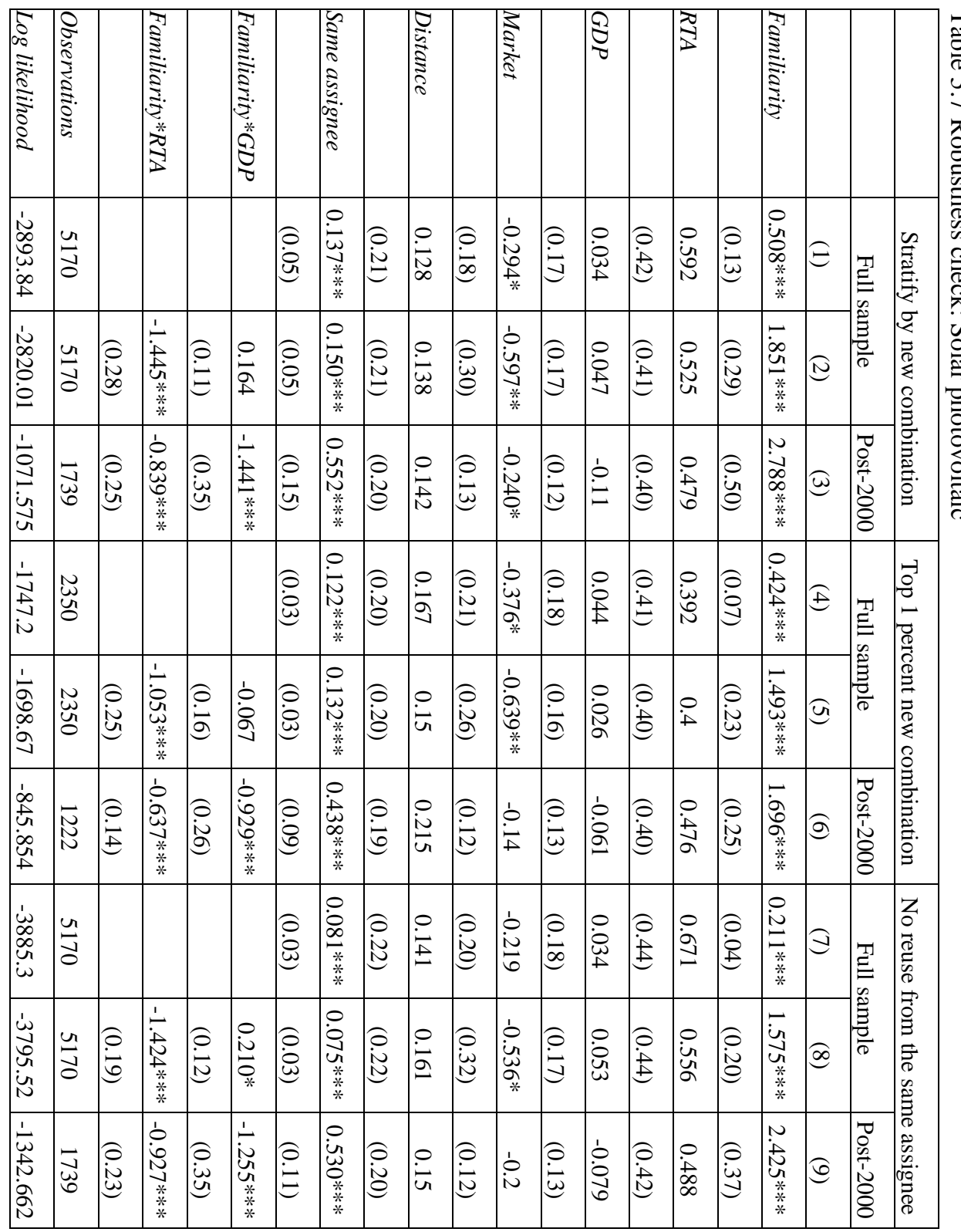




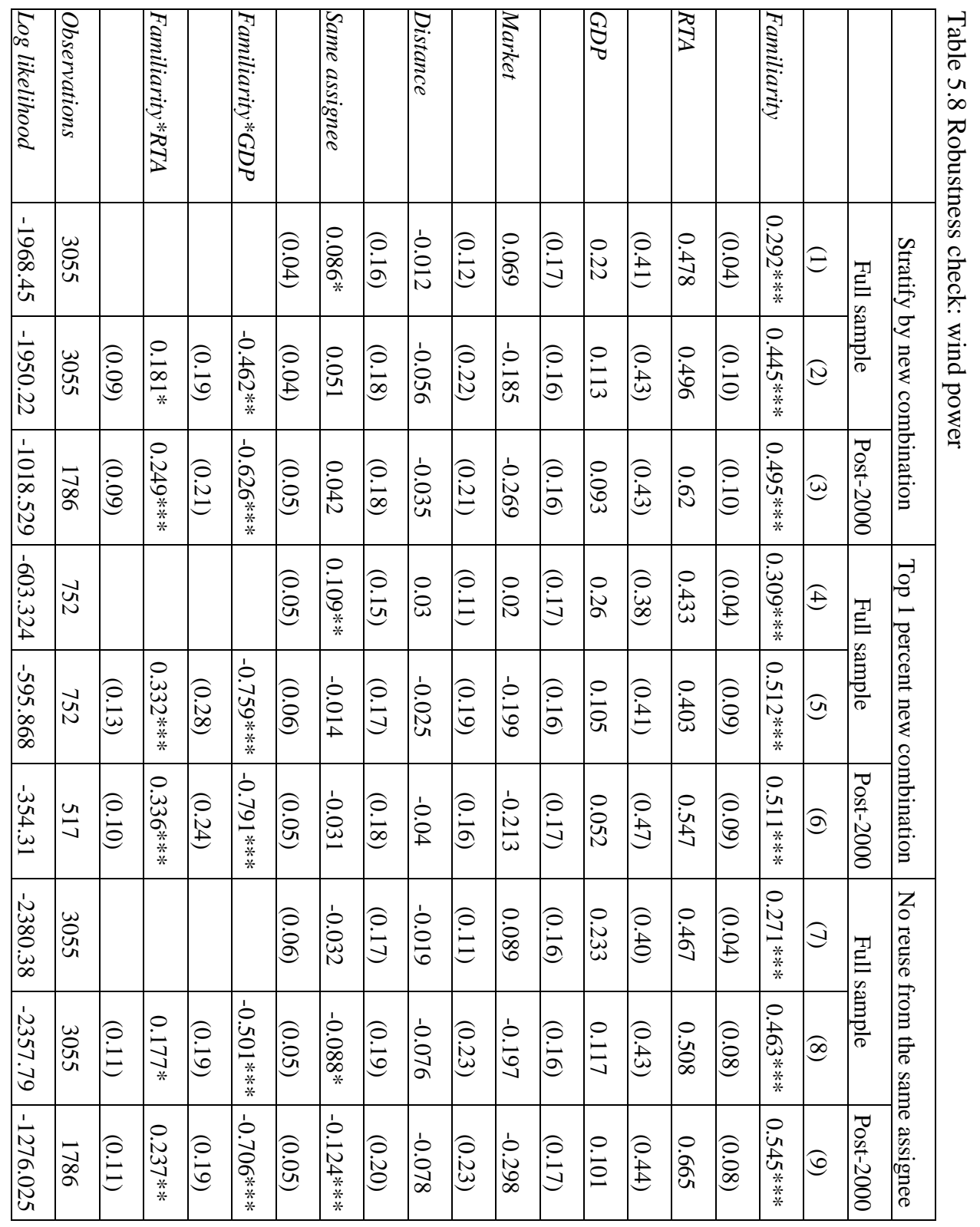




\section{Catching up in renewable energy technological paradigm}

\subsection{Conclusions}

The catching-up of latecomer countries in emerging technological paradigms can only be achieved through imitating and improving the new technologies as early imitators (Perez and Soete, 1988). In this paper, we focus on the determinants of early entry in clean energy technologies by tracing the spatial-temporal diffusions of breakthroughs in solar photovoltaic technology and wind power technology. Following the view of breakthroughs as the recombination of existing technologies, our results suggest that the familiarity of countries with the technology components recombined in the breakthroughs can facilitate earlier adoptions in both technologies, especially in countries with lower levels of economic development.

Our results provide the first systematic evidence of whether and how countries catchingup process of latecomer countries in clean energy technological paradigm (Mathews, 2013; Perez, 2016, 2013). We highlight the importance of local capabilities in reducing the risk and uncertainty of early entry. Hence, our analysis extends the research program of Evolutionary Economic Geography in two ways. First, where most studies lump new and old technologies together in a single analysis, we look exclusively at radically new technologies in order to study the spatial-temporal diffusion of novelty. Second, we do not just analyse whether a country diversifies into new technology or not, as is common in related diversification studies so far, but analyse how fast a country is able to diversify into this radically new technology. On a methodological note, our study design also has the advantage that we can we measure diversification is a straightforward way by simply observing at what date a country first adopts a radically new technology. Here, we differ from previous studies that measure diversification as becoming specialised in a particular technology relative to all other countries. Such studies rely on the Relative Technological Advantage index to indicate specialisation (RTA $>1$ ), which has known disadvantages (Laursen, 2015).

Furthermore, our comparison of the two technologies shows that for solar photovoltaic technology, the knowledge base of countries is more important for countries without specialisation, whereas for wind power technology, the knowledge base of countries is more important for countries with specialisation. This finding suggests that the catching-up process of latecomer countries is also affected by the technology characteristics of different clean energy technologies (Binz and Truffer, 2017; Lee and Malerba, 2017; Schmidt and Huenteler, 2016).

This paper highlights the importance of knowledge base of countries in the early adoption of new technologies. Several questions remain for the future research. First, as our results show that international linkages are also important for the earlier adoption of new technologies, more actor-level analyses are required in order to understand the introduction 
of novelty in a region and the structural change processes that may follow (Boschma, 2017; Hausmann and Neffke, 2019; Henning, 2019; Neffke et al., 2018). Second, although we find that the knowledge base of countries can facilitate early adoptions, institutional and organizational changes might be necessary to enhance local absorptive capacity for scaling up new technologies faster (Grubler et al., 2016). Third, it is important to focus on the impacts of the spatial-temporal diffusion on the cost reduction and performance improvement of new technologies to better understand the technology evolution in real time (Benson and Magee, 2015, 2014; Kavlak et al., 2018; Nemet, 2019). 
Catching up in renewable energy technological paradigm 
Chapter 6

6 Conclusion 
This thesis aimed to bring a global perspective to the Evolutionary Economic Geography (EEG) literature by investigating the local-global interactions in technology development, specifically focusing on the development of renewable energy technologies. The main research question addressed in this thesis are:

1) What aspects of place-dependence drive the innovation activities of renewable energy technologies?

2) How does place-dependence affect the global development trajectories of renewable energy technologies?

3) How do countries catch up in renewable energy technologies by utilizing local and global knowledge?

In this concluding chapter, I first summarize the main empirical findings. Next, main conclusions derived from these findings are provided. I further discuss the contributions and limitations of this work, and highlight some important issues for further research. Finally, I provide policy implications following our empirical findings.

\subsection{Main empirical findings}

Chapter 2 focuses on the knowledge production of countries in renewable energy technologies. Previous studies in EEG suggest that countries (regions) are more likely to develop new technologies related to their existing local knowledge base (Boschma, 2017; Boschma et al., 2017a; Content and Frenken, 2016; Hidalgo et al., 2018). A similar pattern is also observed in the development of clean technologies (Montresor and Quatraro, 2019; Perruchas et al., 2019; Tanner, 2016, 2014; van den Berge et al., 2019). This chapter calculates technological specialisations of countries, technological relatedness and international knowledge spillovers in inventor networks using patent data. The empirical findings show that countries benefit from both the local and the global related knowledge base in developing renewable energy technologies, providing empirical evidence for the global innovation systems concept proposed by Binz and Truffer (2017).

Chapter 2 further highlights the place-dependence of renewable energy technologies by investigating the heterogeneous benefits countries derive from local and global related knowledge in developing renewable energy technologies. The empirical findings show that domestic market formation and development play an important role in shaping the placespecific benefits from local and global knowledge. First, technological relatedness has a larger impact in countries with a larger domestic market for renewables, suggesting an important role of market formation and development in strengthening the path-dependent process towards more related renewable energy technologies. Second, for middle- and lowincome countries, the domestic market for renewables of a country helps better utilize global knowledge. This has implications for the catching-up strategy of latecomer 


\section{Conclusion}

countries: Sustainability transitions open new opportunities for latecomer countries to catch up by engaging with the global innovation systems of clean energy technologies (Mathews, 2013; Meckling and Hughes, 2018; Perez, 2016) and the creation of domestic markets can help latecomer countries to seize these opportunities (Binz et al., 2017a; Yap and Truffer, 2019).

The knowledge dynamics of the global renewable energy innovation systems are multiscalar in that both knowledge flows between different TISs and NISs are important for future knowledge development (Binz and Truffer, 2017). Chapter 3 provides a first systematic empirical analysis of these multi-scalar knowledge dynamics by considering both technological and geographical dimensions. Furthermore, this chapter highlights the importance of national innovation systems in the knowledge development of global renewable energy innovation systems. Although sustainability transitions are increasingly global (Meckling and Hughes, 2018), the understanding of place-specificity is crucial for formulating better transition pathways for individual countries and facilitating future technology development (Hansen and Coenen, 2015).

This chapter employs renewable energy patents and patent citations in studying the impacts of knowledge flows following Nemet (2012). The empirical findings show that the impacts of external knowledge flows critically depend on the absorptive capacity of countries, resulting from the knowledge diffusion between domestic actors in an innovation system. Countries with larger absorptive capacity benefit from domestic knowledge originating in other TISs, whereas international knowledge flows within a TIS are more important for countries with smaller knowledge bases. The findings complement previous studies focusing on such knowledge flows in TIS research (Battke et al., 2016; Stephan et al., 2019) that under conceptualize the importance of geographical dimension. The analysis in this chapter addresses place-specificity by showing that countries with different levels of absorptive capacity should explore different dimensions (technological or geographical) in searching for external knowledge.

Recent studies in EEG show that countries and regions occasionally develop new technologies that are rather unrelated to their existing knowledge base (Montresor and Quatraro, 2017; Neffke et al., 2018; Petralia et al., 2017). In such studies, however, it remains unclear whether the new technologies emerging at the local level also represent the global new niches deviating from the regime technology. Chapter 4 engages with this question by building on the diversification typology proposed by Boschma et al. (2017). In the study, I distinguish between local place-dependence and global path-dependence. Following the recombinant view of technological change, this chapter identifies breakthrough inventions in solar photovoltaic technology that have the potential to disrupt 
global path-dependence, and investigates whether the emergence of breakthrough inventions is place-dependent in building on locally available yet unrelated technologies.

This chapter identifies breakthrough inventions by looking at the new combination of patent classes in solar photovoltaic technology. The empirical results show that unrelated technologies are more likely to be recombined when they are strongly present in the same region, indicating that place-dependence can indeed break global path-dependence.

Moreover, this pattern is common to renewable energy technologies which are considered radical and complex (Barbieri et al., 2020), while a similar pattern is not observed using all technologies. Thus, the recombination of unrelated technologies already existing locally can be viewed as a smart way to aim for breakthrough inventions while still building on local capabilities (Frenken, 2017).

Having identified conditions for breakthrough inventions in Chapter 4, Chapter 5 further focuses on the catching-up of countries in the clean energy technology paradigm by comparing the spatial-temporal diffusions of breakthrough inventions in solar photovoltaic and wind power technology. Perez and Soete (1988) suggest that the catching-up of latecomer countries in emerging technological paradigms can only be achieved through imitating and improving the new technologies as early imitators. The empirical findings suggest that the local related capabilities can facilitate earlier adoptions of breakthroughs in both technologies, especially in countries with lower levels of economic development. Our results provide the first systematic evidence of latecomer countries catch up in the new clean energy technological paradigm based on local related capabilities (Mathews, 2013; Perez, 2016, 2013).

Furthermore, the spatial-temporal diffusion patterns of solar photovoltaic technology and wind power technology are different in that there are more opportunities for latecomer countries to catch up based on related capabilities in solar photovoltaic technology than for wind power technology. This finding suggests that the catching-up process of latecomer countries is also affected by the technology characteristics of the different clean energy technologies (Binz and Truffer, 2017; Schmidt and Huenteler, 2016).

\subsection{Conclusions}

This thesis investigates the multi-scalar knowledge dynamics in global renewable energy innovation systems, highlighting the place-dependence of renewable energy technologies. Chapter 2 confirms that place-dependence of renewable energy technologies originates in the path-dependent process towards technologies related to a country's existing knowledge base. Place-dependence also helps to understand how countries benefit differently from local and global knowledge. Chapter 2 and Chapter 3 show that the absorptive capacity of countries resulting from domestic markets for renewables and knowledge diffusion between 


\section{Conclusion}

actors within an innovation system moderates the impacts of local and global knowledge.

Place-dependent local technology development can also affect global technology development. The empirical findings of Chapter 3 and Chapter 4 show that the recombination of locally available, yet unrelated technologies can contribute to global technology development. More importantly, Chapter 4 shows that such approach can facilitate the emergence of breakthrough inventions with the potential to shift existing technological trajectories to new directions, i.e., break global path-dependence. However, such a process is most likely to be observed in countries and regions with large absorptive capacity.

The thesis also answers the research question of how countries can catch up in the global renewable energy innovation system. The empirical findings of Chapter 2 and Chapter 5 show that both local and global knowledge can help countries catch up in renewable energy technologies, both in developing new specialisations and in adopting breakthrough inventions earlier. For middle- and low-income countries, domestic markets for renewables help utilize both local and global knowledge. Local related capabilities are also more important in these countries in facilitating early adoptions of breakthrough inventions.

\subsection{Contributions, limitations and future research}

The main contribution of thesis is that it brings the global perspective into evolutionary economic geography (EEG), and provides a comprehensive understanding of the multiscalar knowledge dynamics in the conceptual framework of 'global innovation systems' proposed by Binz and Truffer (2017). More specifically, this thesis provides systematic evidences on how renewable energy technologies are place-dependent by articulating how local technology development can contribute to global technology development.

Theoretical and methodological pluralism have gained increasingly recognition in both the EEG literature (Boschma et al., 2017a; Hassink et al., 2014) and the sustainability transition literature (Geels et al., 2016a; Roberts et al., 2018; Turnheim et al., 2015). This thesis adds to these developments by linking the EEG literature with the TIS approach in sustainability transition literature in two ways.

First, the global perspective of technology development in the TIS literature helps to distinguish place-dependence from global path-dependence. Implementing the diversification typology along geographical and technological dimensions proposed by Boschma et al. (2017a), this thesis identifies breakthrough inventions with potentials to disrupt path-dependence following the recombinant view of technological change (Arthur, 2007; Fleming, 2001; Henderson and Clark, 1990; Verhoeven et al., 2016). This thesis provides empirical evidence on how place-dependence can break global path-dependence by introducing breakthrough inventions new to a technology based on local knowledge in 
unrelated technologies. Furthermore, the focus on spatial-temporal diffusion of new technologies provides empirical evidence on how local capabilities can facilitate catchingup of countries when windows of opportunities emerge, which is still largely conceptual (without convincing empirical support) in the current EEG literature (Boschma et al., 2017a; Lee and Malerba, 2017).

Second, the TIS approach in the sustainability transition literature can help to better understand how emerging technologies evolve in interactions between knowledge and other resources like market and finance, and between actors from different technologies and countries (Binz and Truffer, 2017; Hekkert et al., 2007). The TIS functions and how they interact with each other in generating positive feedback loops therefore help EEG literature understand the unique opportunities and constrains for countries with respect to global technology development beyond the local knowledge base perspective. This thesis points out the moderating roles of market formation and knowledge diffusions between domestic actors in an innovation system in utilizing both local and global knowledge.

This thesis is not without limitation. First, this thesis employs patents to proxy the inventions, and patent citations as well as the adoption of new combinations as diffusion of inventions. Patent statistics suffer from the drawback that not all innovations are patented (Griliches, 1990; Pavitt, 1985), especially process innovations which play a significant role in the cost reduction of renewable energy technologies (Kavlak et al., 2018). Moreover, this thesis identifies breakthrough inventions based on the technology classes, there lacks evidence on the extent the novelty indicator this thesis employs captures the truly radical inventions in renewable energy technologies. Thus, future research should focus on how to implement mixed methods in identifying key breakthroughs in renewable energy technologies.

Second, although this thesis explores the place-dependence of renewable energy technologies, recent studies show that the spatial trajectories of renewable energy technologies are also influenced by technology-specific characteristics (Binz and Truffer, 2017; Schmidt and Huenteler, 2016). The difference between the spatial-temporal diffusion patterns between solar photovoltaic technology and wind power technology shown in Chapter 5 sheds light upon this topic that the catching-up process of latecomer countries is also affected by the technology characteristics (Lee and Malerba, 2017). There are more opportunities for catching up in more dynamic technologies like solar photovoltaic technology. However, this thesis does not systematically investigate the difference between different types of renewable energy technology, and the difference between renewable energy technologies and other technologies.

Most renewable energy technologies consist of multiple components in their value chains (Malhotra et al., 2019; Stephan et al., 2017). Hence, the difficulties in developing new 


\section{Conclusion}

technologies also lies in the way how different components of the focal technology interact with each other (Frenken, 2006; McNerney et al., 2011; Murmann and Frenken, 2006). Modularity of components also affects the spatial trajectories of technologies, yet this is understudied in current EEG literature. For complex technologies with a high level of modularity like solar photovoltaic technology, latecomer countries can enter in relatively less complex segments of the value chain and move along the value chain through learning by interacting (Binz and Anadon, 2018; Malhotra et al., 2019). From a view of supply chain management, components of high complexity and low modularity are less likely to be outsourced, leaving less opportunities for latecomer countries (Novak and Eppinger, 2001). Thus, future research should focus on the systematic delineation of characteristics of renewable energy technologies taking into account both complexity and modularity, and investigate the location choices of supply chain outsourcing.

Third, a comprehensive understanding of the place-dependence of technology evolution also requires a micro-perspective, which could be taken up in follow-up research (Boschma, 2017; Henning, 2019). For example, Chapter 2 results suggest that global inventor network can facilitate the catch-up of renewable energy technologies. It is thus important to further understand how such networks form as well as what other channels exist through which knowledge are transferred globally (Popp, 2011). Besides investment and mobility of inventors across borders (Binz and Anadon, 2018; Hausmann and Neffke, 2019; Luo et al., 2017; Neffke et al., 2018), global innovation networks maintained by MNCs also gain increasing attentions recently (Cano-Kollmann et al., 2016; Mudambi et al., 2018; Noailly and Ryfisch, 2015). Indeed, the results in Chapter 5 show that the innovation network within the MNCs can facilitate earlier adoptions of breakthrough inventions. Hence, how to leverage resources to tap into global innovation networks is an important research topic for EEG and GIS, especially for latecomer countries. Furthermore, it should also be important to focus on how external actors can induce structural change of a region (Breschi and Lenzi, 2015; Hausmann and Neffke, 2019; Neffke et al., 2018).

The empirical findings of Chapter 3 and Chapter 4 further suggest that the recombination of locally available unrelated technologies can facilitate breakthrough inventions. However, there lack insights on the actors introducing the breakthroughs in such process. Public actors (Corradini and De Propris, 2017; Fleming et al., 2019; Gilbert and Campbell, 2015) and spin-offs from other segments of the supply chain (Adams et al., 2015; Klepper, 2007) play an important role in this process. It is therefore important to focus on the boundary spanning actors and the determinants of their boundary spanning activities. Overall, the micro-perspective can help evaluate the impacts of policies by focusing on how actors respond to multi-level policy interventions and how they actively engage in the policy making process to facilitate structural change (Uyarra et al., 2017). 
A final limitation worth noting is that demand in this thesis is investigated in a rather simple way by looking at the size of domestic market for renewables in each country. Market development in one country can facilitate the technology development in other countries (Binz and Anadon, 2018; Binz and Truffer, 2017; Dechezleprêtre and Glachant, 2014; Horbach et al., 2014; Quitzow, 2015). Furthermore, the TIS and sustainability transition literature highlight the importance of niche market creation (Dewald and Truffer, 2011; Hekkert et al., 2007). Frequent interactions between inventors and pioneer users could facilitate radical technological change (Garud and Karnøe, 2003). Thus, future research could further investigate the impacts of both international and niche market on the innovative performance of countries in renewable energy technologies.

\subsection{Policy implications}

The current achievements of clean energy innovations are heavily influenced by various government policies (Harrison et al., 2017; Rodrik, 2014), and are shaped by vested interests in clean energy innovations (Schmidt et al., 2019). Given the urgency of climate change mitigation, policy interventions will continue to play an important role in facilitating innovations with potential to address climate change and other societal challenges (Boon and Edler, 2018; Foray et al., 2012; Frenken, 2017; Mazzucato, 2018; Weber and Rohracher, 2012).

Based on the empirical findings, this thesis formulates different policy implications in developing renewable energy technologies at different locations. For countries with large absorptive capacities, this thesis provides empirical support for the 'cross-specialisation' policy framework proposed by Janssen and Frenken (2019). They suggest that promoting crossovers between unrelated technologies in an economy can facilitate the emergence of radical innovations. The strong presence of unrelated technologies in a region can compensate the lack of cognitive proximity as well as provide institutional support for the radical innovations (Frenken, 2017; Janssen and Frenken, 2019). Leveraging local capabilities in building new competences in regions is the key policy goal of the recent smart specialisation strategies which have been integrated in the European regional policy (Balland et al., 2019; Foray, 2018b).

For middle- and low-income countries, this thesis suggests that domestic market for renewables plays an important role in utilizing local and global related knowledge to catch up in renewable energy technologies. This is in line with the recent call for demand-side innovation policies (Boon and Edler, 2018). Market formation and development can increase the public acceptance of innovation, as well as provides legitimacy and guidance for the innovation process itself (Frenken, 2017; Weber and Rohracher, 2012). Through active shaping of the selection environment and guiding the search process for both local 


\section{Conclusion}

and global resources, latecomer countries can endogenize the windows of opportunity in catching-up process (Yap and Truffer, 2019).

Overall, this thesis highlights the patterns of place-dependence in the multi-scalar innovation dynamics of renewable energy technologies. Given the clear direction in facilitating innovations to address climate change, this policy implications formulated based on the empirical findings of this thesis resonate with the recent mission-oriented policies (Foray, 2018a; Foray et al., 2012; Mazzucato, 2018). Most importantly, this thesis contributes to the understanding of the geography dimension in mission-oriented innovation policies (Foray, 2018a; Uyarra et al., 2020; Wanzenböck and Frenken, 2018). Policies for a country or region need consideration of the place-specific conditions, and how the focal country and region are connected to global technology regimes as well as to emerging niches at different locations. In doing so, mission-oriented policies can better guide the search process for resources needed to address place-specific climate change challenges, and at the same time collectively contribute to the global climate change mitigation. 


\section{References}

Adams, P., Fontana, R., Malerba, F., 2015. User-Industry Spinouts: Downstream Industry Knowledge as a Source of New Firm Entry and Survival. Organization Science 27, 18-35. https://doi.org/10.1287/orsc.2015.1029

Alkemade, F., Frenken, K., Hekkert, M., Schwoon, M., 2009. A complex systems methodology to transition management. Journal of Evolutionary Economics 19, 527-543. https://doi.org/10.1007/s00191-009-0144-x

Alkemade, F., Heimeriks, G., Schoen, A., Villard, L., Laurens, P., 2015. Tracking the internationalization of multinational corporate inventive activity: national and sectoral characteristics. Research Policy, The New Data Frontier 44, 1763-1772. https://doi.org/10.1016/j.respol.2015.01.007

Andersen, A.D., Steen, M., Mäkitie, T., Hanson, J., Thune, T.M., Soppe, B., 2019. The role of inter-sectoral dynamics in sustainability transitions: A comment on the transitions research agenda. Environmental Innovation and Societal Transitions. https://doi.org/10.1016/j.eist.2019.11.009

Antonelli, C., 1999. The evolution of the industrial organisation of the production of knowledge. Cambridge J Econ 23, 243-260. https://doi.org/10.1093/cje/23.2.243

Antonelli, C., Krafft, J., Quatraro, F., 2010. Recombinant knowledge and growth: The case of ICTs. Structural Change and Economic Dynamics 21, 50-69. https://doi.org/10.1016/j.strueco.2009.12.001

Arellano, M., Bond, S., 1991. Some Tests of Specification for Panel Data: Monte Carlo Evidence and an Application to Employment Equations. Rev Econ Stud 58, $277-$ 297. https://doi.org/10.2307/2297968

Arthur, W.B., 2007. The structure of invention. Research Policy 36, 274-287. https://doi.org/10.1016/j.respol.2006.11.005

Arts, S., Veugelers, R., 2015. Technology familiarity, recombinant novelty, and breakthrough invention. Ind Corp Change 24, 1215-1246. https://doi.org/10.1093/icc/dtu029

Bahar, D., Hausmann, R., Hidalgo, C.A., 2014. Neighbors and the evolution of the comparative advantage of nations: Evidence of international knowledge diffusion? Journal of International Economics 92, 111-123. https://doi.org/10.1016/j.jinteco.2013.11.001

Baldwin, C.Y., Clark, K.B., 2000. Design Rules: The power of modularity. MIT Press. 
Balland, P.-A., Boschma, R., Crespo, J., Rigby, D.L., 2019. Smart specialization policy in the European Union: relatedness, knowledge complexity and regional diversification. Regional Studies 53, 1252-1268. https://doi.org/10.1080/00343404.2018.1437900

Balland, P.-A., Boschma, R., Frenken, K., 2015. Proximity and Innovation: From Statics to Dynamics. Regional Studies 49, 907-920. https://doi.org/10.1080/00343404.2014.883598

Balland, P.-A., Rigby, D., 2017. The Geography of Complex Knowledge. Economic Geography 93, 1-23. https://doi.org/10.1080/00130095.2016.1205947

Barbieri, N., Marzucchi, A., Rizzo, U., 2020. Knowledge sources and impacts on subsequent inventions: Do green technologies differ from non-green ones? Research Policy 49, 103901. https://doi.org/10.1016/j.respol.2019.103901

Barbieri, N., Perruchas, F., Consoli, D., 2018. Specialization, diversification and environmental technology life-cycle (No. 1838), Papers in Evolutionary Economic Geography (PEEG). Utrecht University, Department of Human Geography and Spatial Planning, Group Economic Geography.

Battke, B., Schmidt, T.S., Stollenwerk, S., Hoffmann, V.H., 2016. Internal or external spillovers-Which kind of knowledge is more likely to flow within or across technologies. Research Policy 45, 27-41. https://doi.org/10.1016/j.respol.2015.06.014

Benson, C.L., Magee, C.L., 2015. Quantitative Determination of Technological Improvement from Patent Data. PLOS ONE 10, e0121635. https://doi.org/10.1371/journal.pone.0121635

Benson, C.L., Magee, C.L., 2014. On improvement rates for renewable energy technologies: Solar PV, wind turbines, capacitors, and batteries. Renewable Energy 68, 745-751. https://doi.org/10.1016/j.renene.2014.03.002

Bento, N., Fontes, M., 2015. Spatial diffusion and the formation of a technological innovation system in the receiving country: The case of wind energy in Portugal. Environmental Innovation and Societal Transitions 15, 158-179. https://doi.org/10.1016/j.eist.2014.10.003

Bento, N., Wilson, C., Anadon, L.D., 2018. Time to get ready: Conceptualizing the temporal and spatial dynamics of formative phases for energy technologies. Energy Policy 119, 282-293. https://doi.org/10.1016/j.enpol.2018.04.015

Bergek, A., Hekkert, M., Jacobsson, S., Markard, J., Sandén, B., Truffer, B., 2015. Technological innovation systems in contexts: Conceptualizing contextual structures and interaction dynamics. Environmental Innovation and Societal Transitions 16, 51-64. https://doi.org/10.1016/j.eist.2015.07.003 
Bergek, A., Jacobsson, S., Carlsson, B., Lindmark, S., Rickne, A., 2008. Analyzing the functional dynamics of technological innovation systems: A scheme of analysis. Research Policy 37, 407-429. https://doi.org/10.1016/j.respol.2007.12.003

Bettencourt, L.M.A., Trancik, J.E., Kaur, J., 2013. Determinants of the Pace of Global Innovation in Energy Technologies. PLOS ONE 8, e67864. https://doi.org/10.1371/journal.pone.0067864

Binz, C., Anadon, L.D., 2018. Unrelated diversification in latecomer contexts: Emergence of the Chinese solar photovoltaics industry. Environmental Innovation and Societal Transitions 28, 14-34. https://doi.org/10.1016/j.eist.2018.03.005

Binz, C., Coenen, L., Murphy, J.T., Truffer, B., 2020. Geographies of transition-From topical concerns to theoretical engagement: A commentary on the transitions research agenda. Environmental Innovation and Societal Transitions 34, 1-3. https://doi.org/10.1016/j.eist.2019.11.002

Binz, C., Gosens, J., Hansen, T., Hansen, U.E., 2017a. Toward Technology-Sensitive Catching-Up Policies: Insights from Renewable Energy in China. World Development 96, 418-437. https://doi.org/10.1016/j.worlddev.2017.03.027

Binz, C., Tang, T., Huenteler, J., 2017b. Spatial lifecycles of cleantech industries - The global development history of solar photovoltaics. Energy Policy 101, 386-402. https://doi.org/10.1016/j.enpol.2016.10.034

Binz, C., Truffer, B., 2017. Global Innovation Systems-A conceptual framework for innovation dynamics in transnational contexts. Research Policy 46, 1284-1298. https://doi.org/10.1016/j.respol.2017.05.012

Binz, C., Truffer, B., Coenen, L., 2014. Why space matters in technological innovation systems-Mapping global knowledge dynamics of membrane bioreactor technology. Research Policy 43, 138-155. https://doi.org/10.1016/j.respol.2013.07.002

Blundell, R., Bond, S., 1998. Initial conditions and moment restrictions in dynamic panel data models. Journal of Econometrics 87, 115-143. https://doi.org/10.1016/S03044076(98)00009-8

Bointner, R., 2014. Innovation in the energy sector: Lessons learnt from R\&D expenditures and patents in selected IEA countries. Energy Policy 73, 733-747. https://doi.org/10.1016/j.enpol.2014.06.001

Boon, W., Edler, J., 2018. Demand, challenges, and innovation. Making sense of new trends in innovation policy. Sci Public Policy 45, 435-447. https://doi.org/10.1093/scipol/scy014

Boschma, R., 2017. Relatedness as driver of regional diversification: a research agenda. Regional Studies 51, 351-364. https://doi.org/10.1080/00343404.2016.1254767 
Boschma, R., 2005. Proximity and Innovation: A Critical Assessment. Regional Studies 39, 61-74. https://doi.org/10.1080/0034340052000320887

Boschma, R., Balland, P.-A., Kogler, D.F., 2015. Relatedness and technological change in cities: the rise and fall of technological knowledge in US metropolitan areas from 1981 to 2010. Ind Corp Change 24, 223-250. https://doi.org/10.1093/icc/dtu012

Boschma, R., Capone, G., 2016. Relatedness and diversification in the European Union (EU-27) and European Neighbourhood Policy countries. Environ Plann C Gov Policy 34, 617-637. https://doi.org/10.1177/0263774X15614729

Boschma, R., Capone, G., 2015. Institutions and diversification: Related versus unrelated diversification in a varieties of capitalism framework. Research Policy 44, 1902 1914. https://doi.org/10.1016/j.respol.2015.06.013

Boschma, R., Coenen, L., Frenken, K., Truffer, B., 2017a. Towards a theory of regional diversification: combining insights from Evolutionary Economic Geography and Transition Studies. Regional Studies 51, 31-45. https://doi.org/10.1080/00343404.2016.1258460

Boschma, R., Heimeriks, G., Balland, P.-A., 2014. Scientific knowledge dynamics and relatedness in biotech cities. Research Policy 43, 107-114. https://doi.org/10.1016/j.respol.2013.07.009

Boschma, R., Martín, V., Minondo, A., 2017b. Neighbour regions as the source of new industries. Papers in Regional Science 96, 227-245. https://doi.org/10.1111/pirs.12215

Boschma, R., Minondo, A., Navarro, M., 2013. The Emergence of New Industries at the Regional Level in Spain: A Proximity Approach Based on Product Relatedness. Economic Geography 89, 29-51. https://doi.org/10.1111/j.19448287.2012.01170.x

Bosetti, V., Carraro, C., Massetti, E., Tavoni, M., 2008. International energy R\&D spillovers and the economics of greenhouse gas atmospheric stabilization. Energy Economics, Technological Change and the Environment 30, 2912-2929. https://doi.org/10.1016/j.eneco.2008.04.008

Breschi, S., Lenzi, C., 2015. The Role of External Linkages and Gatekeepers for the Renewal and Expansion of US Cities' Knowledge Base, 1990-2004. Regional Studies 49, 782-797. https://doi.org/10.1080/00343404.2014.954534

Breschi, S., Lissoni, F., 2009. Mobility of skilled workers and co-invention networks: an anatomy of localized knowledge flows. J Econ Geogr 9, 439-468. https://doi.org/10.1093/jeg/lbp008

Breschi, S., Lissoni, F., 2001. Knowledge Spillovers and Local Innovation Systems: A Critical Survey. ICC 10, 975-1005. https://doi.org/10.1093/icc/10.4.975 
Breschi, S., Lissoni, F., Malerba, F., 2003. Knowledge-relatedness in firm technological diversification. Research Policy 32, 69-87. https://doi.org/10.1016/S00487333(02)00004-5

Cano-Kollmann, M., Cantwell, J., Hannigan, T.J., Mudambi, R., Song, J., 2016. Knowledge connectivity: An agenda for innovation research in international business. J Int Bus Stud 47, 255-262. https://doi.org/10.1057/jibs.2016.8

Capaldo, A., Lavie, D., Messeni Petruzzelli, A., 2017. Knowledge Maturity and the Scientific Value of Innovations: The Roles of Knowledge Distance and Adoption. Journal of Management 43, 503-533. https://doi.org/10.1177/0149206314535442

Carlsson, B., 2006. Internationalization of innovation systems: A survey of the literature. Research Policy 35, 56-67. https://doi.org/10.1016/j.respol.2005.08.003

Carlsson, B., Jacobsson, S., Holmén, M., Rickne, A., 2002. Innovation systems: analytical and methodological issues. Research Policy, Innovation Systems 31, 233-245. https://doi.org/10.1016/S0048-7333(01)00138-X

Carlsson, B., Stankiewicz, R., 1991. On the nature, function and composition of technological systems. J Evol Econ 1, 93-118. https://doi.org/10.1007/BF01224915

Carvalho, M., Dechezleprêtre, A., Glachant, M., 2017. Understanding the dynamics of global value chains for solar photovoltaic technologies (No. 40), WIPO Economic Research Working Papers. World Intellectual Property Organization - Economics and Statistics Division.

Castaldi, C., Frenken, K., Los, B., 2015. Related Variety, Unrelated Variety and Technological Breakthroughs: An analysis of US State-Level Patenting. Regional Studies 49, 767-781. https://doi.org/10.1080/00343404.2014.940305

Caviggioli, F., 2016. Technology fusion: Identification and analysis of the drivers of technology convergence using patent data. Technovation 55-56, 22-32. https://doi.org/10.1016/j.technovation.2016.04.003

Cherp, A., Vinichenko, V., Jewell, J., Suzuki, M., Antal, M., 2017. Comparing electricity transitions: A historical analysis of nuclear, wind and solar power in Germany and Japan. Energy Policy 101, 612-628. https://doi.org/10.1016/j.enpol.2016.10.044

Choi, H., 2018. Technology-push and demand-pull factors in emerging sectors: evidence from the electric vehicle market. Industry and Innovation 25, 655-674. https://doi.org/10.1080/13662716.2017.1346502

Clancy, M.S., 2018. Inventing by combining pre-existing technologies: Patent evidence on learning and fishing out. Research Policy 47, 252-265. https://doi.org/10.1016/j.respol.2017.10.015 
Coenen, L., Benneworth, P., Truffer, B., 2012. Toward a spatial perspective on sustainability transitions. Research Policy, Special Section on Sustainability Transitions 41, 968-979. https://doi.org/10.1016/j.respol.2012.02.014

Coenen, L., Hansen, T., Rekers, J.V., 2015. Innovation Policy for Grand Challenges. An Economic Geography Perspective. Geography Compass 9, 483-496. https://doi.org/10.1111/gec3.12231

Cohen, W.M., Levinthal, D.A., 1990. Absorptive Capacity: A New Perspective on Learning and Innovation. Administrative Science Quarterly 35, 128-152. https://doi.org/10.2307/2393553

Colombelli, A., Krafft, J., Quatraro, F., 2014. The emergence of new technology-based sectors in European regions: A proximity-based analysis of nanotechnology. Research Policy 43, 1681-1696. https://doi.org/10.1016/j.respol.2014.07.008

Content, J., Frenken, K., 2016. Related variety and economic development: a literature review. European Planning Studies 24, 2097-2112. https://doi.org/10.1080/09654313.2016.1246517

Conti, C., Mancusi, M.L., Sanna-Randaccio, F., Sestini, R., Verdolini, E., 2018. Transition towards a green economy in Europe: Innovation and knowledge integration in the renewable energy sector. Research Policy 47, 1996-2009. https://doi.org/10.1016/j.respol.2018.07.007

Corradini, C., De Propris, L., 2017. Beyond local search: Bridging platforms and intersectoral technological integration. Research Policy 46, 196-206. https://doi.org/10.1016/j.respol.2016.09.017

Cortinovis, N., Xiao, J., Boschma, R., van Oort, F.G., 2017. Quality of government and social capital as drivers of regional diversification in Europe. J Econ Geogr 17, 1179-1208. https://doi.org/10.1093/jeg/lbx001

Costantini, V., Crespi, F., Curci, Y., 2015. A keyword selection method for mapping technological knowledge in specific sectors through patent data: the case of biofuels sector. Economics of Innovation and New Technology 24, 282-308. https://doi.org/10.1080/10438599.2014.942583

Cox, D.R., 1972. Regression models and life-tables. Journal of the Royal Statistical Society: Series B (Methodological) 34, 187-202.

Criscuolo, P., Verspagen, B., 2008. Does it matter where patent citations come from? Inventor vs. examiner citations in European patents. Research Policy, Special Section Knowledge Dynamics out of Balance: Knowledge Biased, Skewed and Unmatched 37, 1892-1908. https://doi.org/10.1016/j.respol.2008.07.011 
D’Adda, D., Guzzini, E., Iacobucci, D., Palloni, R., 2019. Is Smart Specialisation Strategy coherent with regional innovative capabilities? Regional Studies 53, 1004-1016. https://doi.org/10.1080/00343404.2018.1523542

de la Tour, A., Glachant, M., Ménière, Y., 2011. Innovation and international technology transfer: The case of the Chinese photovoltaic industry. Energy Policy, Special Section on Offshore wind power planning, economics and environment 39, 761770. https://doi.org/10.1016/j.enpol.2010.10.050

de Rassenfosse, G., Dernis, H., Guellec, D., Picci, L., van Pottelsberghe de la Potterie, B., 2013. The worldwide count of priority patents: A new indicator of inventive activity. Research Policy 42, 720-737. https://doi.org/10.1016/j.respol.2012.11.002

de Rassenfosse, G., Seliger, F., 2019. Sources of knowledge flow between developed and developing nations. Sci Public Policy. https://doi.org/10.1093/scipol/scz042

Dechezleprêtre, A., Glachant, M., 2014. Does Foreign Environmental Policy Influence Domestic Innovation? Evidence from the Wind Industry. Environ Resource Econ 58, 391-413. https://doi.org/10.1007/s10640-013-9705-4

Dechezleprêtre, A., Glachant, M., Haščič, I., Johnstone, N., Ménière, Y., 2011. Invention and Transfer of Climate Change-Mitigation Technologies: A Global Analysis. Rev Environ Econ Policy 5, 109-130. https://doi.org/10.1093/reep/req023

Dechezleprêtre, A., Ménière, Y., Mohnen, M., 2017. International patent families: from application strategies to statistical indicators. Scientometrics 111, 793-828. https://doi.org/10.1007/s11192-017-2311-4

Desrochers, P., Leppälä, S., 2011. Opening up the 'Jacobs Spillovers' black box: local diversity, creativity and the processes underlying new combinations. J Econ Geogr 11, 843-863. https://doi.org/10.1093/jeg/lbq028

Dewald, U., Truffer, B., 2011. Market Formation in Technological Innovation SystemsDiffusion of Photovoltaic Applications in Germany. Industry and Innovation 18, 285-300. https://doi.org/10.1080/13662716.2011.561028

Dosi, G., 1991. The Research on Innovation Diffusion: An Assessment, in: Nakićenović, N., Grübler, A. (Eds.), Diffusion of Technologies and Social Behavior. Springer Berlin Heidelberg, pp. 179-208.

Dosi, G., 1982. Technological paradigms and technological trajectories: A suggested interpretation of the determinants and directions of technical change. Research Policy 11, 147-162. https://doi.org/10.1016/0048-7333(82)90016-6

Du Plessis, M., Van Looy, B., Song, X., Magerman, T., 2009. Data production methods for harmonized patent indicators: Assignee sector allocation. Luxembourg: EUROSTAT working paper and studies. 
Eriksson, R.H., 2011. Localized Spillovers and Knowledge Flows: How Does Proximity Influence the Performance of Plants? Economic Geography 87, 127-152. https://doi.org/10.1111/j.1944-8287.2011.01112.x

Essletzbichler, J., 2015. Relatedness, Industrial Branching and Technological Cohesion in US Metropolitan Areas. Regional Studies 49, 752-766. https://doi.org/10.1080/00343404.2013.806793

Fankhauser, S., Bowen, A., Calel, R., Dechezleprêtre, A., Grover, D., Rydge, J., Sato, M., 2013. Who will win the green race? In search of environmental competitiveness and innovation. Global Environmental Change 23, 902-913. https://doi.org/10.1016/j.gloenvcha.2013.05.007

Feenstra, R.C., Inklaar, R., Timmer, M.P., 2015. The Next Generation of the Penn World Table. American Economic Review 105, 3150-3182. https://doi.org/10.1257/aer.20130954

Feldman, M.P., Kogler, D.F., Rigby, D.L., 2015. rKnowledge: The Spatial Diffusion and Adoption of rDNA Methods. Regional Studies 49, 798-817. https://doi.org/10.1080/00343404.2014.980799

Ferguson, J.-P., Carnabuci, G., 2017. Risky Recombinations: Institutional Gatekeeping in the Innovation Process. Organization Science 28, 133-151. https://doi.org/10.1287/orsc.2016.1106

Fleming, L., 2001. Recombinant Uncertainty in Technological Search. Management Science 47, 117-132. https://doi.org/10.1287/mnsc.47.1.117.10671

Fleming, L., Greene, H., Li, G., Marx, M., Yao, D., 2019. Government-funded research increasingly fuels innovation. Science 364, 1139-1141. https://doi.org/10.1126/science.aaw2373

Fleming, L., Mingo, S., Chen, D., 2007. Collaborative Brokerage, Generative Creativity, and Creative Success. Administrative Science Quarterly 52, 443-475. https://doi.org/10.2189/asqu.52.3.443

Fleming, L., Sorenson, O., 2001. Technology as a complex adaptive system: evidence from patent data. Research Policy 30, 1019-1039. https://doi.org/10.1016/S00487333(00)00135-9

Foray, D., 2018a. Smart specialization strategies as a case of mission-oriented policy-a case study on the emergence of new policy practices. Ind Corp Change 27, 817832. https://doi.org/10.1093/icc/dty030

Foray, D., 2018b. Smart specialisation strategies and industrial modernisation in European regions - theory and practice. Cambridge J Econ 42, 1505-1520. https://doi.org/10.1093/cje/bey022 
Foray, D., Mowery, D.C., Nelson, R.R., 2012. Public R\&D and social challenges: What lessons from mission R\&D programs? Research Policy, The need for a new generation of policy instruments to respond to the Grand Challenges 41, 16971702. https://doi.org/10.1016/j.respol.2012.07.011

Franceschini, S., Alkemade, F., 2016. Non-disruptive regime changes-The case of competing energy efficient lighting trajectories. Environmental Innovation and Societal Transitions 21, 56-68. https://doi.org/10.1016/j.eist.2016.04.003

Frenken, K., 2017. A Complexity-Theoretic Perspective on Innovation Policy. Complexity, Governance \& Networks 0, 35-47. https://doi.org/10.20377/cgn-41

Frenken, K., 2006. A fitness landscape approach to technological complexity, modularity, and vertical disintegration. Structural Change and Economic Dynamics 17, 288 305. https://doi.org/10.1016/j.strueco.2006.01.001

Frenken, K., Boschma, R.A., 2007. A theoretical framework for evolutionary economic geography: industrial dynamics and urban growth as a branching process. J Econ Geogr 7, 635-649. https://doi.org/10.1093/jeg/lbm018

Fu, X., Pietrobelli, C., Soete, L., 2011. The Role of Foreign Technology and Indigenous Innovation in the Emerging Economies: Technological Change and Catching-up. World Development, Special Section (pp. 1204-1270): Foreign Technology and Indigenous Innovation in the Emerging Economies 39, 1204-1212. https://doi.org/10.1016/j.worlddev.2010.05.009

Furr, N., Kapoor, R., 2018. Capabilities, technologies, and firm exit during industry shakeout: Evidence from the global solar photovoltaic industry. Strat Mgmt J 39, 33-61. https://doi.org/10.1002/smj.2709

Gallagher, K.S., Grübler, A., Kuhl, L., Nemet, G., Wilson, C., 2012. The Energy Technology Innovation System. Annu. Rev. Environ. Resour. 37, 137-162. https://doi.org/10.1146/annurev-environ-060311-133915

Galunic, D.C., Rodan, S., 1998. Resource recombinations in the firm: knowledge structures and the potential for schumpeterian innovation. Strategic Management Journal 19, 1193-1201. https://doi.org/10.1002/(SICI)1097-0266(1998120)19:12<1193::AIDSMJ5>3.0.CO;2-F

Garrone, P., Piscitello, L., Wang, Y., 2014. Innovation Performance and International Knowledge Spillovers: Evidence from the Renewable Energy Sector in OECD Countries. Industry and Innovation 21, 574-598. https://doi.org/10.1080/13662716.2015.1011913

Garud, R., Karnøe, P., 2003. Bricolage versus breakthrough: distributed and embedded agency in technology entrepreneurship. Research Policy, Special Issue on 
Technology Entrepreneurship and Contact Information for corresponding authors 32, 277-300. https://doi.org/10.1016/S0048-7333(02)00100-2

Geels, F.W., 2018. Disruption and low-carbon system transformation: Progress and new challenges in socio-technical transitions research and the Multi-Level Perspective. Energy Research \& Social Science 37, 224-231. https://doi.org/10.1016/j.erss.2017.10.010

Geels, F.W., Berkhout, F., Vuuren, D.P. van, 2016a. Bridging analytical approaches for low-carbon transitions. Nature Clim Change 6, 576-583. https://doi.org/10.1038/nclimate2980

Geels, F.W., Kern, F., Fuchs, G., Hinderer, N., Kungl, G., Mylan, J., Neukirch, M., Wassermann, S., 2016b. The enactment of socio-technical transition pathways: A reformulated typology and a comparative multi-level analysis of the German and UK low-carbon electricity transitions (1990-2014). Research Policy 45, 896-913. https://doi.org/10.1016/j.respol.2016.01.015

Gertler, M.S., 2003. Tacit knowledge and the economic geography of context, or The undefinable tacitness of being (there). J Econ Geogr 3, 75-99. https://doi.org/10.1093/jeg/3.1.75

Gilbert, B.A., Campbell, J.T., 2015. The geographic origins of radical technological paradigms: A configurational study. Research Policy 44, 311-327. https://doi.org/10.1016/j.respol.2014.08.006

Giuliani, E., Martinelli, A., Rabellotti, R., 2016. Is Co-Invention Expediting Technological Catch Up? A Study of Collaboration between Emerging Country Firms and EU Inventors. World Development 77, 192-205. https://doi.org/10.1016/j.worlddev.2015.08.019

Gosens, J., Lu, Y., Coenen, L., 2015. The role of transnational dimensions in emerging economy 'Technological Innovation Systems' for clean-tech. Journal of Cleaner Production 86, 378-388. https://doi.org/10.1016/j.jclepro.2014.08.029

Greene, W.H., 2011. Econometric Analysis. Pearson Education.

Griffith, R., Lee, S., Reenen, J.V., 2011. Is distance dying at last? Falling home bias in fixed-effects models of patent citations. Quantitative Economics 2, 211-249. https://doi.org/10.3982/QE59

Griliches, Z., 1990. Patent Statistics as Economic Indicators: A Survey. Journal of Economic Literature 28, 1661-1707.

Grubler, A., Wilson, C., Nemet, G., 2016. Apples, oranges, and consistent comparisons of the temporal dynamics of energy transitions. Energy Research \& Social Science 22, 18-25. https://doi.org/10.1016/j.erss.2016.08.015 
Guan, J.C., Yan, Y., 2016. Technological proximity and recombinative innovation in the alternative energy field. Research Policy, Patent Use 45, 1460-1473. https://doi.org/10.1016/j.respol.2016.05.002

Guellec, D., van Pottelsberghe de la Potterie, B., 2001. The internationalisation of technology analysed with patent data. Research Policy 30, 1253-1266. https://doi.org/10.1016/S0048-7333(00)00149-9

Guo, Q., He, C., 2017. Production space and regional industrial evolution in China. GeoJournal 82, 379-396. https://doi.org/10.1007/s10708-015-9689-4

Hägerstrand, T., 1973. Innovation Diffusion as a Spatial Process. University of Chicago Press.

Hall, B.H., Jaffe, A., Trajtenberg, M., 2005. Market Value and Patent Citations. The RAND Journal of Economics 36, 16-38.

Hansen, T., Coenen, L., 2015. The geography of sustainability transitions: Review, synthesis and reflections on an emergent research field. Environmental Innovation and Societal Transitions 17, 92-109. https://doi.org/10.1016/j.eist.2014.11.001

Harrison, A., Martin, L.A., Nataraj, S., 2017. Green Industrial Policy in Emerging Markets. Annual Review of Resource Economics 9, 253-274. https://doi.org/10.1146/annurev-resource-100516-053445

Haščič, I., Migotto, M., 2015. Measuring environmental innovation using patent data. https://doi.org/10.1787/5js009kf48xw-en

Haščič, I., Silva, J., Johnstone, N., 2015. The Use of Patent Statistics for International Comparisons and Analysis of Narrow Technological Fields (OECD Science, Technology and Industry Working Papers). Organisation for Economic Cooperation and Development, Paris.

Hassink, R., Klaerding, C., Marques, P., 2014. Advancing Evolutionary Economic Geography by Engaged Pluralism. Regional Studies 48, 1295-1307. https://doi.org/10.1080/00343404.2014.889815

Hausman, J.A., Abrevaya, J., Scott-Morton, F.M., 1998. Misclassification of the dependent variable in a discrete-response setting. Journal of Econometrics 87, 239-269. https://doi.org/10.1016/S0304-4076(98)00015-3

Hausmann, R., Klinger, B., 2007. The Structure of the Product Space and the Evolution of Comparative Advantage (No. 146), CID Working Papers. Center for International Development at Harvard University.

Hausmann, R., Neffke, F.M.H., 2019. The workforce of pioneer plants: The role of worker mobility in the diffusion of industries. Research Policy 48, 628-648. https://doi.org/10.1016/j.respol.2018.10.017 
He, C., Yan, Y., Rigby, D., 2018. Regional industrial evolution in China. Papers in Regional Science 97, 173-198. https://doi.org/10.1111/pirs.12246

Heimeriks, G., Boschma, R., 2014. The path- and place-dependent nature of scientific knowledge production in biotech 1986-2008. J Econ Geogr 14, 339-364. https://doi.org/10.1093/jeg/lbs052

Heimeriks, G., Li, D., Lamers, W., Meijer, I., Yegros, A., 2019. Scientific knowledge production in European regions: patterns of growth, diversity and complexity. European Planning Studies 27, 2123-2143. https://doi.org/10.1080/09654313.2019.1645814

Hekkert, M., Negro, S.O., 2009. Functions of innovation systems as a framework to understand sustainable technological change: Empirical evidence for earlier claims. Technological Forecasting and Social Change, Evolutionary Methodologies for Analyzing Environmental Innovations and the Implications for Environmental Policy 76, 584-594. https://doi.org/10.1016/j.techfore.2008.04.013

Hekkert, M., Suurs, R.A.A., Negro, S.O., Kuhlmann, S., Smits, R.E.H.M., 2007. Functions of innovation systems: A new approach for analysing technological change. Technological Forecasting and Social Change 74, 413-432. https://doi.org/10.1016/j.techfore.2006.03.002

Henderson, R.M., Clark, K.B., 1990. Architectural Innovation: The Reconfiguration of Existing Product Technologies and the Failure of Established Firms. Administrative Science Quarterly 35, 9-30. https://doi.org/10.2307/2393549

Henning, M., 2019. Time should tell (more): evolutionary economic geography and the challenge of history. Regional Studies 53, 602-613. https://doi.org/10.1080/00343404.2018.1515481

Henning, M., Stam, E., Wenting, R., 2013. Path Dependence Research in Regional Economic Development: Cacophony or Knowledge Accumulation? Reg. Stud. 47, 1348-1362. https://doi.org/10.1080/00343404.2012.750422

Hidalgo, C.A., Balland, P.-A., Boschma, R., Delgado, M., Feldman, M., Frenken, K., Glaeser, E., He, C., Kogler, D.F., Morrison, A., Neffke, F., Rigby, D., Stern, S., Zheng, S., Zhu, S., 2018. The Principle of Relatedness, in: Morales, A.J., Gershenson, C., Braha, D., Minai, A.A., Bar-Yam, Y. (Eds.), Unifying Themes in Complex Systems IX, Springer Proceedings in Complexity. Springer International Publishing, pp. 451-457.

Hidalgo, C.A., Hausmann, R., 2009. The building blocks of economic complexity. PNAS 106, 10570-10575. https://doi.org/10.1073/pnas.0900943106 
Hidalgo, C.A., Klinger, B., Barabási, A.-L., Hausmann, R., 2007. The Product Space Conditions the Development of Nations. Science 317, 482-487. https://doi.org/10.1126/science.1144581

Hoppmann, J., Peters, M., Schneider, M., Hoffmann, V.H., 2013. The two faces of market support-How deployment policies affect technological exploration and exploitation in the solar photovoltaic industry. Research Policy 42, 989-1003. https://doi.org/10.1016/j.respol.2013.01.002

Horbach, J., Chen, Q., Rennings, K., Vögele, S., 2014. Do lead markets for clean coal technology follow market demand? A case study for China, Germany, Japan and the US. Environmental Innovation and Societal Transitions, Global Diffusion of Environmental Innovations 10, 42-58. https://doi.org/10.1016/j.eist.2013.08.002

Horrace, W.C., Oaxaca, R.L., 2006. Results on the bias and inconsistency of ordinary least squares for the linear probability model. Economics Letters 90, 321-327. https://doi.org/10.1016/j.econlet.2005.08.024

Huenteler, J., Schmidt, T.S., Ossenbrink, J., Hoffmann, V.H., 2016. Technology life-cycles in the energy sector - Technological characteristics and the role of deployment for innovation. Technological Forecasting and Social Change 104, 102-121. https://doi.org/10.1016/j.techfore.2015.09.022

IEA, 2015. Energy technology perspectives 2015: mobilising innovation to accelerate climate action. International Energy Agency (IEA).

Jaffe, A.B., de Rassenfosse, G., 2017. Patent citation data in social science research: Overview and best practices. Journal of the Association for Information Science and Technology 68, 1360-1374. https://doi.org/10.1002/asi.23731

Jaffe, A.B., Newell, R.G., Stavins, R.N., 2002. Environmental Policy and Technological Change. Environ Resource Econ 22, 41-70. https://doi.org/10.1023/A:1015519401088

Jaffe, A.B., Trajtenberg, M., 2002. Patents, Citations, and Innovations: A Window on the Knowledge Economy. MIT Press.

Jaffe, A.B., Trajtenberg, M., Henderson, R., 1993. Geographic Localization of Knowledge Spillovers as Evidenced by Patent Citations. The Quarterly Journal of Economics 108, 577-598. https://doi.org/10.2307/2118401

Janssen, M.J., Frenken, K., 2019. Cross-specialisation policy: rationales and options for linking unrelated industries. Cambridge Journal of Regions, Economy and Society 12, 195-212. https://doi.org/10.1093/cjres/rsz001

Jean, J., Brown, P.R., Jaffe, R.L., Buonassisi, T., Bulović, V., 2015. Pathways for solar photovoltaics. Energy Environ. Sci. 8, 1200-1219.

https://doi.org/10.1039/C4EE04073B 
Johnstone, N., Haščič, I., Popp, D., 2010. Renewable Energy Policies and Technological Innovation: Evidence Based on Patent Counts. Environ Resource Econ 45, 133 155. https://doi.org/10.1007/s10640-009-9309-1

Kalthaus, M., 2019. Identifying technological sub-trajectories in patent data: the case of photovoltaics. Economics of Innovation and New Technology 28, 407-434. https://doi.org/10.1080/10438599.2018.1523356

Kaplan, S., Tripsas, M., 2008. Thinking about technology: Applying a cognitive lens to technical change. Research Policy 37, 790-805. https://doi.org/10.1016/j.respol.2008.02.002

Kauffman, S.A., 1993. The Origins of Order: Self-organization and Selection in Evolution. Oxford University Press.

Kavlak, G., McNerney, J., Trancik, J.E., 2018. Evaluating the causes of cost reduction in photovoltaic modules. Energy Policy 123, 700-710. https://doi.org/10.1016/j.enpol.2018.08.015

Keller, W., 2004. International Technology Diffusion. Journal of Economic Literature 42, 752-782.

Kemp, R., Never, B., 2017. Green transition, industrial policy, and economic development. Oxf Rev Econ Policy 33, 66-84. https://doi.org/10.1093/oxrep/grw037

Klepper, S., 2007. Disagreements, Spinoffs, and the Evolution of Detroit as the Capital of the U.S. Automobile Industry. Management Science 53, 616-631. https://doi.org/10.1287/mnsc. 1060.0683

Kogler, D.F., Essletzbichler, J., Rigby, D.L., 2017. The evolution of specialization in the EU15 knowledge space. J Econ Geogr 17, 345-373. https://doi.org/10.1093/jeg/lbw024

Kogler, D.F., Rigby, D.L., Tucker, I., 2013. Mapping Knowledge Space and Technological Relatedness in US Cities. European Planning Studies 21, 1374-1391. https://doi.org/10.1080/09654313.2012.755832

Kogut, B., Zander, U., 1992. Knowledge of the Firm, Combinative Capabilities, and the Replication of Technology. Organization Science 3, 383-397.

Köhler, J., Geels, F.W., Kern, F., Markard, J., Onsongo, E., Wieczorek, A., Alkemade, F., Avelino, F., Bergek, A., Boons, F., Fünfschilling, L., Hess, D., Holtz, G., Hyysalo, S., Jenkins, K., Kivimaa, P., Martiskainen, M., McMeekin, A., Mühlemeier, M.S., Nykvist, B., Pel, B., Raven, R., Rohracher, H., Sandén, B., Schot, J., Sovacool, B., Turnheim, B., Welch, D., Wells, P., 2019. An agenda for sustainability transitions research: State of the art and future directions. Environmental Innovation and Societal Transitions 31, 1-32. https://doi.org/10.1016/j.eist.2019.01.004 
Kok, H., Faems, D., de Faria, P., 2019. Dusting Off the Knowledge Shelves: Recombinant Lag and the Technological Value of Inventions. Journal of Management 45, $2807-$ 2836. https://doi.org/10.1177/0149206318765926

Krafft, J., Quatraro, F., Saviotti, P.P., 2011. The knowledge-base evolution in biotechnology: a social network analysis. Economics of Innovation and New Technology 20, 445-475. https://doi.org/10.1080/10438599.2011.562355

Kwon, S., Lee, J., Lee, S., 2017. International Trends in Technological Progress: Evidence from Patent Citations, 1980-2011. The Economic Journal 127, F50-F70. https://doi.org/10.1111/ecoj.12314

Laurens, P., Bas, C.L., Lhuillery, S., Schoen, A., 2017. The determinants of cleaner energy innovations of the world's largest firms: the impact of firm learning and knowledge capital. Economics of Innovation and New Technology 26, 311-333. https://doi.org/10.1080/10438599.2016.1193940

Laursen, K., 2015. Revealed comparative advantage and the alternatives as measures of international specialization. Eurasian Bus Rev 5, 99-115. https://doi.org/10.1007/s40821-015-0017-1

Lee, K., Malerba, F., 2017. Catch-up cycles and changes in industrial leadership:Windows of opportunity and responses of firms and countries in the evolution of sectoral systems. Research Policy 46, 338-351. https://doi.org/10.1016/j.respol.2016.09.006

Leydesdorff, L., 2015. Can technology life-cycles be indicated by diversity in patent classifications? The crucial role of variety. Scientometrics 105, 1441-1451. https://doi.org/10.1007/s11192-015-1639-x

Leydesdorff, L., Alkemade, F., Heimeriks, G., Hoekstra, R., 2015. Patents as instruments for exploring innovation dynamics: geographic and technological perspectives on "photovoltaic cells." Scientometrics 102, 629-651. https://doi.org/10.1007/s11192-014-1447-8

Lobo, J., Strumsky, D., 2008. Metropolitan patenting, inventor agglomeration and social networks: A tale of two effects. Journal of Urban Economics 63, 871-884. https://doi.org/10.1016/j.jue.2007.07.005

Lundvall, B.-Å., 1992. National Systems of Innovation: Toward a Theory of Innovation and Interactive Learning. Pinter, London.

Luo, S., Lovely, M.E., Popp, D., 2017. Intellectual returnees as drivers of indigenous innovation: Evidence from the Chinese photovoltaic industry. World Econ 40, 2424-2454. https://doi.org/10.1111/twec.12536 
Magerman, T., Grouwels, J., Song, X., Van Looy, B., 2009. Data production methods for harmonized patent indicators: patentee name harmonization. Luxembourg: EUROSTAT Working Paper and Studies.

Mäkitie, T., Andersen, A.D., Hanson, J., Normann, H.E., Thune, T.M., 2018. Established sectors expediting clean technology industries? The Norwegian oil and gas sector's influence on offshore wind power. Journal of Cleaner Production 177, 813-823. https://doi.org/10.1016/j.jclepro.2017.12.209

Malerba, F., 2002. Sectoral systems of innovation and production. Research Policy, Innovation Systems 31, 247-264. https://doi.org/10.1016/S0048-7333(01)00139-1

Malerba, F., Mancusi, M.L., Montobbio, F., 2013. Innovation, international R\&D spillovers and the sectoral heterogeneity of knowledge flows. Rev World Econ 149, 697722. https://doi.org/10.1007/s10290-013-0167-0

Malerba, F., Orsenigo, L., 1996. Schumpeterian patterns of innovation are technologyspecific. Research Policy 25, 451-478. https://doi.org/10.1016/00487333(95)00840-3

Malhotra, A., Schmidt, T.S., Huenteler, J., 2019. The role of inter-sectoral learning in knowledge development and diffusion: Case studies on three clean energy technologies. Technological Forecasting and Social Change 146, 464-487. https://doi.org/10.1016/j.techfore.2019.04.018

Malmberg, A., Maskell, P., 2002. The Elusive Concept of Localization Economies: Towards a Knowledge-Based Theory of Spatial Clustering. Environ Plan A 34, 429-449. https://doi.org/10.1068/a3457

Mancusi, M.L., 2008. International spillovers and absorptive capacity: A cross-country cross-sector analysis based on patents and citations. Journal of International Economics 76, 155-165. https://doi.org/10.1016/j.jinteco.2008.06.007

Mao, X., He, C., 2019. Product relatedness and export specialisation in China's regions: a perspective of global-local interactions. Cambridge J Regions Econ Soc 12, 105 126. https://doi.org/10.1093/cjres/rsy031

March, J.G., 1991. Exploration and Exploitation in Organizational Learning. Organization Science 2, 71-87.

Markard, J., Hekkert, M., Jacobsson, S., 2015. The technological innovation systems framework: Response to six criticisms. Environmental Innovation and Societal Transitions 16, 76-86. https://doi.org/10.1016/j.eist.2015.07.006

Markard, J., Truffer, B., 2006. Innovation processes in large technical systems: Market liberalization as a driver for radical change? Research Policy 35, 609-625. https://doi.org/10.1016/j.respol.2006.02.008 
Martin, B.R., 2016. Twenty challenges for innovation studies. Sci Public Policy 43, 432450. https://doi.org/10.1093/scipol/scv077

Martin, R., 2010. Roepke Lecture in Economic Geography—Rethinking Regional Path Dependence: Beyond Lock-in to Evolution. Economic Geography 86, 1-27. https://doi.org/10.1111/j.1944-8287.2009.01056.x

Martin, R., Sunley, P., 2006. Path dependence and regional economic evolution. J Econ Geogr 6, 395-437. https://doi.org/10.1093/jeg/lb1012

Martínez, C., 2011. Patent families: When do different definitions really matter? Scientometrics 86, 39-63. https://doi.org/10.1007/s11192-010-0251-3

Maskell, P., Malmberg, A., 1999. Localised learning and industrial competitiveness. Cambridge J Econ 23, 167-185. https://doi.org/10.1093/cje/23.2.167

Mathews, J.A., 2013. The renewable energies technology surge: A new techno-economic paradigm in the making? Futures 46, 10-22. https://doi.org/10.1016/j.futures.2012.12.001

Matsuo, T., Schmidt, T.S., 2019. Managing tradeoffs in green industrial policies: The role of renewable energy policy design. World Development 122, 11-26. https://doi.org/10.1016/j.worlddev.2019.05.005

Mayer, T., Zignago, S., 2011. Notes on CEPII's Distances Measures: The GeoDist Database (SSRN Scholarly Paper No. ID 1994531). Social Science Research Network, Rochester, NY.

Mazzucato, M., 2018. Mission-oriented innovation policies: challenges and opportunities. Industrial and Corporate Change 27, 803-815. https://doi.org/10.1093/icc/dty034

McNerney, J., Farmer, J.D., Redner, S., Trancik, J.E., 2011. Role of design complexity in technology improvement. PNAS 108, 9008-9013. https://doi.org/10.1073/pnas.1017298108

Meckling, J., Hughes, L., 2018. Global interdependence in clean energy transitions. Business and Politics 20, 467-491. https://doi.org/10.1017/bap.2018.25

Metcalfe, J.S., 1981. Impulse and diffusion in the study of technical change. Futures 13, 347-359. https://doi.org/10.1016/0016-3287(81)90120-8

Miguelez, E., Moreno, R., 2018. Relatedness, external linkages and regional innovation in Europe. Regional Studies 52, 688-701. https://doi.org/10.1080/00343404.2017.1360478

Montresor, S., Quatraro, F., 2019. Green technologies and Smart Specialisation Strategies: a European patent-based analysis of the intertwining of technological relatedness and key enabling technologies. Regional Studies 0, 1-12. https://doi.org/10.1080/00343404.2019.1648784 
Montresor, S., Quatraro, F., 2017. Regional Branching and Key Enabling Technologies:

Evidence from European Patent Data. Economic Geography 93, 367-396.

https://doi.org/10.1080/00130095.2017.1326810

Mowery, D.C., Rosenberg, N., 1998a. Paths of Innovation: Technological Change in 20th-

Century America. Cambridge University Press.

Mowery, D.C., Rosenberg, N., 1998b. Paths of Innovation: Technological Change in 20thCentury America. Cambridge University Press.

Mudambi, R., Narula, R., Santangelo, G.D., 2018. Location, collocation and innovation by multinational enterprises: a research agenda. Industry and Innovation 25, 229-241. https://doi.org/10.1080/13662716.2017.1415135

Mukherjee, S., Romero, D.M., Jones, B., Uzzi, B., 2017. The nearly universal link between the age of past knowledge and tomorrow's breakthroughs in science and technology: The hotspot. Science Advances 3, e1601315.

https://doi.org/10.1126/sciadv.1601315

Murmann, J.P., Frenken, K., 2006. Toward a systematic framework for research on dominant designs, technological innovations, and industrial change. Research Policy 35, 925-952. https://doi.org/10.1016/j.respol.2006.04.011

Neffke, F., Hartog, M., Boschma, R., Henning, M., 2018. Agents of Structural Change: The Role of Firms and Entrepreneurs in Regional Diversification. Economic Geography 94, 23-48. https://doi.org/10.1080/00130095.2017.1391691

Neffke, F., Henning, M., 2013. Skill relatedness and firm diversification. Strategic Management Journal 34, 297-316. https://doi.org/10.1002/smj.2014

Neffke, F., Henning, M., Boschma, R., 2011. How Do Regions Diversify over Time? Industry Relatedness and the Development of New Growth Paths in Regions. Economic Geography 87, 237-265. https://doi.org/10.1111/j.19448287.2011.01121.x

Negro, S.O., Alkemade, F., Hekkert, M., 2012. Why does renewable energy diffuse so slowly? A review of innovation system problems. Renewable and Sustainable Energy Reviews 16, 3836-3846. https://doi.org/10.1016/j.rser.2012.03.043

Nelson, R.R., 1993. National Innovation Systems: A Comparative Analysis. Oxford University Press.

Nelson, R.R., Winter, S.G., 1982. An Evolutionary Theory of Economic Change. Belknap Press of Harvard University Press.

Nemet, G.F., 2019. How Solar Energy Became Cheap: A Model for Low-Carbon Innovation. Routledge.

Nemet, G.F., 2012. Inter-technology knowledge spillovers for energy technologies. Energy Economics 34, 1259-1270. https://doi.org/10.1016/j.eneco.2012.06.002 
Nemet, G.F., 2009. Demand-pull, technology-push, and government-led incentives for nonincremental technical change. Research Policy 38, 700-709. https://doi.org/10.1016/j.respol.2009.01.004

Nesta, L., Saviotti, P.P., 2005. Coherence of the Knowledge Base and the Firm's Innovative Performance: Evidence from the U.S. Pharmaceutical Industry. The Journal of Industrial Economics 53, 123-142.

Nesta, L., Vona, F., Nicolli, F., 2014. Environmental policies, competition and innovation in renewable energy. Journal of Environmental Economics and Management 67, 396-411. https://doi.org/10.1016/j.jeem.2014.01.001

Nicolli, F., Vona, F., 2016. Heterogeneous policies, heterogeneous technologies: The case of renewable energy. Energy Economics 56, 190-204. https://doi.org/10.1016/j.eneco.2016.03.007

Noailly, J., Ryfisch, D., 2015. Multinational firms and the internationalization of green R\&D: A review of the evidence and policy implications. Energy Policy 83, 218 228. https://doi.org/10.1016/j.enpol.2015.03.002

Nooteboom, B., 2000. Learning and Innovation in Organizations and Economies. OUP Oxford.

Nooteboom, B., Van Haverbeke, W., Duysters, G., Gilsing, V., van den Oord, A., 2007. Optimal cognitive distance and absorptive capacity. Research Policy 36, 10161034. https://doi.org/10.1016/j.respol.2007.04.003

Novak, S., Eppinger, S.D., 2001. Sourcing By Design: Product Complexity and the Supply Chain. Management Science 47, 189-204. https://doi.org/10.1287/mnsc.47.1.189.10662

Pavitt, K., 1985. Patent statistics as indicators of innovative activities: Possibilities and problems. Scientometrics 7, 77-99. https://doi.org/10.1007/BF02020142

Perez, C., 2016. 11. Capitalism, Technology and a Green Global Golden Age: The Role of History in Helping to Shape the Future. The Political Quarterly 86, 191-217. https://doi.org/10.1111/1467-923X.12240

Perez, C., 2013. Unleashing a golden age after the financial collapse: Drawing lessons from history. Environmental Innovation and Societal Transitions, Economic-financial crisis and sustainability transition 6, 9-23. https://doi.org/10.1016/j.eist.2012.12.004

Perez, C., Soete, L., 1988. Catching up in technology: entry barriers and windows of opportunity, in: Technical Change and Economic Theory. Pinter Publishers, London, pp. 458-479. 
Perruchas, F., Consoli, D., Barbieri, N., 2019. Specialisation, Diversification and the Ladder of Green Technology Development (SSRN Scholarly Paper No. ID 3336857). Social Science Research Network, Rochester, NY.

Petralia, S., Balland, P.-A., Morrison, A., 2017. Climbing the ladder of technological development. Research Policy 46, 956-969. https://doi.org/10.1016/j.respol.2017.03.012

Phene, A., Fladmoe-Lindquist, K., Marsh, L., 2006. Breakthrough innovations in the U.S. biotechnology industry: the effects of technological space and geographic origin. Strat. Mgmt. J. 27, 369-388. https://doi.org/10.1002/smj.522

Phene, A., Madhok, A., Liu, K., 2005. Knowledge Transfer within the Multinational Firm: What Drives the Speed of Transfer? MIR: Management International Review 45, 53-74.

Pinheiro, F.L., Alshamsi, A., Hartmann, D., Boschma, R., Hidalgo, C.A., 2018. Shooting High or Low: Do Countries Benefit from Entering Unrelated Activities? arXiv:1801.05352 [physics, q-fin].

Popp, D., 2017. From science to technology: The value of knowledge from different energy research institutions. Research Policy 46, 1580-1594. https://doi.org/10.1016/j.respol.2017.07.011

Popp, D., 2016. Economic analysis of scientific publications and implications for energy research and development. Nature Energy 1, 16020. https://doi.org/10.1038/nenergy.2016.20

Popp, D., 2011. International Technology Transfer, Climate Change, and the Clean Development Mechanism. Rev Environ Econ Policy 5, 131-152. https://doi.org/10.1093/reep/req018

Popp, D., Hascic, I., Medhi, N., 2011. Technology and the diffusion of renewable energy. Energy Economics, Special Issue on The Economics of Technologies to Combat Global Warming 33, 648-662. https://doi.org/10.1016/j.eneco.2010.08.007

Quitzow, R., 2015. Dynamics of a policy-driven market: The co-evolution of technological innovation systems for solar photovoltaics in China and Germany. Environmental Innovation and Societal Transitions 17, 126-148. https://doi.org/10.1016/j.eist.2014.12.002

Quitzow, R., Huenteler, J., Asmussen, H., 2017. Development trajectories in China's wind and solar energy industries: How technology-related differences shape the dynamics of industry localization and catching up. Journal of Cleaner Production 158, 122-133. https://doi.org/10.1016/j.jclepro.2017.04.130 
Rennings, K., 2000. Redefining innovation - eco-innovation research and the contribution from ecological economics. Ecological Economics 32, 319-332. https://doi.org/10.1016/S0921-8009(99)00112-3

Riedl, M., Geishecker, I., 2014. Keep it simple: estimation strategies for ordered response models with fixed effects. Journal of Applied Statistics 41, 2358-2374. https://doi.org/10.1080/02664763.2014.909969

Rigby, D.L., 2015. Technological Relatedness and Knowledge Space: Entry and Exit of US Cities from Patent Classes. Regional Studies 49, 1922-1937. https://doi.org/10.1080/00343404.2013.854878

Roberts, C., Geels, F.W., Lockwood, M., Newell, P., Schmitz, H., Turnheim, B., Jordan, A., 2018. The politics of accelerating low-carbon transitions: Towards a new research agenda. Energy Research \& Social Science 44, 304-311. https://doi.org/10.1016/j.erss.2018.06.001

Rodrik, D., 2014. Green industrial policy. Oxf Rev Econ Policy 30, 469-491. https://doi.org/10.1093/oxrep/gru025

Rosenberg, N., 1982. Inside the Black Box: Technology and Economics. Cambridge University Press.

Safarzyńska, K., van den Bergh, J.C.J.M., 2013. An evolutionary model of energy transitions with interactive innovation-selection dynamics. J Evol Econ 23, $271-$ 293. https://doi.org/10.1007/s00191-012-0298-9

Santoalha, A., Boschma, R., 2019. Diversifying in green technologies in European regions: does political support matter? (No. 1922), Papers in Evolutionary Economic Geography (PEEG). Utrecht University, Department of Human Geography and Spatial Planning, Group Economic Geography.

Saviotti, P.P., Frenken, K., 2008. Export variety and the economic performance of countries. J Evol Econ 18, 201-218. https://doi.org/10.1007/s00191-007-0081-5

Sbardella, A., Perruchas, F., Napolitano, L., Barbieri, N., Consoli, D., 2018. Green Technology Fitness. Entropy 20, 776. https://doi.org/10.3390/e20100776

Scherer, F.M., 1982. Inter-Industry Technology Flows and Productivity Growth. The Review of Economics and Statistics 64, 627-634. https://doi.org/10.2307/1923947

Schmidheiny, K., Brülhart, M., 2011. On the equivalence of location choice models: Conditional logit, nested logit and Poisson. Journal of Urban Economics 69, 214 222. https://doi.org/10.1016/j.jue.2010.09.004

Schmidt, T.S., Battke, B., Grosspietsch, D., Hoffmann, V.H., 2016. Do deployment policies pick technologies by (not) picking applications?-A simulation of investment decisions in technologies with multiple applications. Research Policy 45, 19651983. https://doi.org/10.1016/j.respol.2016.07.001 
Schmidt, T.S., Huenteler, J., 2016. Anticipating industry localization effects of clean technology deployment policies in developing countries. Global Environmental Change 38, 8-20. https://doi.org/10.1016/j.gloenvcha.2016.02.005

Schmidt, T.S., Schmid, N., Sewerin, S., 2019. Policy goals, partisanship and paradigmatic change in energy policy - analyzing parliamentary discourse in Germany over 30 years. Climate Policy 19, 771-786. https://doi.org/10.1080/14693062.2019.1594667

Schmidt, T.S., Sewerin, S., 2018. Measuring the temporal dynamics of policy mixes - An empirical analysis of renewable energy policy mixes' balance and design features in nine countries. Research Policy. https://doi.org/10.1016/j.respol.2018.03.012

Schmoch, U., 2008. Concept of a Technology Classification for Country Comparisons.

Singh, J., 2005. Collaborative Networks as Determinants of Knowledge Diffusion Patterns. Management Science 51, 756-770. https://doi.org/10.1287/mnsc.1040.0349

Singh, J., Fleming, L., 2010. Lone Inventors as Sources of Breakthroughs: Myth or Reality? Management Science 56, 41-56. https://doi.org/10.1287/mnsc.1090.1072

Soete, L.G., Wyatt, S.M.E., 1983. The use of foreign patenting as an internationally comparable science and technology output indicator. Scientometrics 5, 31-54. https://doi.org/10.1007/BF02097176

Sorenson, O., Fleming, L., 2004. Science and the diffusion of knowledge. Research Policy 33, 1615-1634. https://doi.org/10.1016/j.respol.2004.09.008

Sorenson, O., Rivkin, J.W., Fleming, L., 2006. Complexity, networks and knowledge flow. Research Policy 35, 994-1017. https://doi.org/10.1016/j.respol.2006.05.002

Sovacool, B.K., 2016. How long will it take? Conceptualizing the temporal dynamics of energy transitions. Energy Research \& Social Science, Energy Transitions in Europe: Emerging Challenges, Innovative Approaches, and Possible Solutions 13, 202-215. https://doi.org/10.1016/j.erss.2015.12.020

Stephan, A., Bening, C.R., Schmidt, T.S., Schwarz, M., Hoffmann, V.H., 2019. The role of inter-sectoral knowledge spillovers in technological innovations: The case of lithium-ion batteries. Technological Forecasting and Social Change 148, 119718. https://doi.org/10.1016/j.techfore.2019.119718

Stephan, A., Schmidt, T.S., Bening, C.R., Hoffmann, V.H., 2017. The sectoral configuration of technological innovation systems: Patterns of knowledge development and diffusion in the lithium-ion battery technology in Japan. Research Policy 46, 709-723. https://doi.org/10.1016/j.respol.2017.01.009

Storper, M., Venables, A.J., 2004. Buzz: face-to-face contact and the urban economy. J Econ Geogr 4, 351-370. https://doi.org/10.1093/jnlecg/lbh027 
Storper, M., Walker, R., 1989. The capitalist imperative: Territory, technology, and industrial growth. Blackwell.

Strumsky, D., Lobo, J., 2015. Identifying the sources of technological novelty in the process of invention. Research Policy 44, 1445-1461. https://doi.org/10.1016/j.respol.2015.05.008

Suurs, R.A.A., Hekkert, M.P., 2009. Cumulative causation in the formation of a technological innovation system: The case of biofuels in the Netherlands. Technological Forecasting and Social Change 76, 1003-1020. https://doi.org/10.1016/j.techfore.2009.03.002

Tanner, A.N., 2016. The emergence of new technology-based industries: the case of fuel cells and its technological relatedness to regional knowledge bases. J Econ Geogr 16, 611-635. https://doi.org/10.1093/jeg/lbv011

Tanner, A.N., 2014. Regional Branching Reconsidered: Emergence of the Fuel Cell Industry in European Regions. Economic Geography 90, 403-427. https://doi.org/10.1111/ecge.12055

Tavassoli, S., Carbonara, N., 2014. The role of knowledge variety and intensity for regional innovation. Small Bus Econ 43, 493-509. https://doi.org/10.1007/s11187-0149547-7

Torre, A., Rallet, A., 2005. Proximity and Localization. Regional Studies 39, 47-59. https://doi.org/10.1080/0034340052000320842

Trancik, J.E., Jean, J., Kavlak, G., Klemun, M.M., Edwards, M.R., McNerney, J., Miotti, M., Brown, P.R., Mueller, J.M., Needell, Z.A., 2015. Technology Improvement and Emissions Reductions as Mutually Reinforcing Efforts: Observations from the Global Development of Solar and Wind Energy (Technical Report). MIT.

Turnheim, B., Berkhout, F., Geels, F., Hof, A., McMeekin, A., Nykvist, B., van Vuuren, D., 2015. Evaluating sustainability transitions pathways: Bridging analytical approaches to address governance challenges. Global Environmental Change 35, 239-253. https://doi.org/10.1016/j.gloenvcha.2015.08.010

Uyarra, E., Flanagan, K., Magro, E., Wilson, J.R., Sotarauta, M., 2017. Understanding regional innovation policy dynamics: Actors, agency and learning. Environment and Planning C: Politics and Space 35, 559-568. https://doi.org/10.1177/2399654417705914

Uyarra, E., Zabala-Iturriagagoitia, J.M., Flanagan, K., Magro, E., 2020. Public procurement, innovation and industrial policy: Rationales, roles, capabilities and implementation. Research Policy 49, 103844. https://doi.org/10.1016/j.respol.2019.103844 
van den Berge, M., Weterings, A., Alkemade, F., 2019. Do existing regional specialisations stimulate or hinder diversification into cleantech? Environmental Innovation and Societal Transitions. https://doi.org/10.1016/j.eist.2019.10.002

Veefkind, V., Hurtado-Albir, J., Angelucci, S., Karachalios, K., Thumm, N., 2012a. A new EPO classification scheme for climate change mitigation technologies. World Patent Information 34, 106-111. https://doi.org/10.1016/j.wpi.2011.12.004

Veefkind, V., Hurtado-Albir, J., Angelucci, S., Karachalios, K., Thumm, N., 2012b. A new EPO classification scheme for climate change mitigation technologies. World Patent Information 34, 106-111. https://doi.org/10.1016/j.wpi.2011.12.004

Verdolini, E., Galeotti, M., 2011. At home and abroad: An empirical analysis of innovation and diffusion in energy technologies. Journal of Environmental Economics and Management 61, 119-134. https://doi.org/10.1016/j.jeem.2010.08.004

Verhoeven, D., Bakker, J., Veugelers, R., 2016. Measuring technological novelty with patent-based indicators. Research Policy 45, 707-723. https://doi.org/10.1016/j.respol.2015.11.010

Veugelers, R., 2012. Which policy instruments to induce clean innovating? Research Policy, The need for a new generation of policy instruments to respond to the Grand Challenges 41, 1770-1778. https://doi.org/10.1016/j.respol.2012.06.012

Veugelers, R., Pezzoni, M., Visentin, F., 2019. How Fast is this Novel Technology Going to Be a Hit? (SSRN Scholarly Paper No. ID 3315382). Social Science Research Network, Rochester, NY.

Wanzenböck, I., Frenken, K., 2018. The subsidiarity principle: Turning challenge-oriented innovation policy on its head (No. 1806), Papers in Evolutionary Economic Geography (PEEG). Utrecht University, Department of Human Geography and Spatial Planning, Group Economic Geography.

Weber, K.M., Rohracher, H., 2012. Legitimizing research, technology and innovation policies for transformative change: Combining insights from innovation systems and multi-level perspective in a comprehensive 'failures' framework. Research Policy, Special Section on Sustainability Transitions 41, 1037-1047. https://doi.org/10.1016/j.respol.2011.10.015

Weber, K.M., Truffer, B., 2017. Moving innovation systems research to the next level: towards an integrative agenda. Oxf Rev Econ Policy 33, 101-121. https://doi.org/10.1093/oxrep/grx002

Wieczorek, A.J., Negro, S.O., Harmsen, R., Heimeriks, G.J., Luo, L., Hekkert, M.P., 2013. A review of the European offshore wind innovation system. Renewable and Sustainable Energy Reviews 26, 294-306. https://doi.org/10.1016/j.rser.2013.05.045 
Wilson, C., Grubler, A., 2011. Lessons from the history of technological change for clean energy scenarios and policies. Natural Resources Forum 35, 165-184. https://doi.org/10.1111/j.1477-8947.2011.01386.x

Wu, C.-Y., Mathews, J.A., 2012. Knowledge flows in the solar photovoltaic industry: Insights from patenting by Taiwan, Korea, and China. Research Policy 41, 524 540. https://doi.org/10.1016/j.respol.2011.10.007

Xiao, J., Boschma, R., Andersson, M., 2018. Industrial Diversification in Europe: The Differentiated Role of Relatedness. Economic Geography 94, 514-549. https://doi.org/10.1080/00130095.2018.1444989

Yap, X.-S., Truffer, B., 2019. Shaping selection environments for industrial catch-up and sustainability transitions: A systemic perspective on endogenizing windows of opportunity. Research Policy, New Frontiers in Science, Technology and Innovation Research from SPRU's 50th Anniversary Conference 48, 1030-1047. https://doi.org/10.1016/j.respol.2018.10.002

Zeppini, P., van den Bergh, J.C.J.M., 2011. Competing Recombinant Technologies for Environmental Innovation: Extending Arthur's Model of Lock-In. Industry and Innovation 18, 317-334. https://doi.org/10.1080/13662716.2011.561031

Zhu, S., He, C., Zhou, Y., 2017. How to jump further and catch up? Path-breaking in an uneven industry space. J Econ Geogr 17, 521-545.

https://doi.org/10.1093/jeg/lbw047 


\section{Summary}

Climate change mitigation requires rapid decarbonization of the current energy systems worldwide. Developing renewable energy technologies is not only an important way to help countries achieve their carbon emission reduction goals, but is also considered increasingly promising for economic development in both industrialized and emerging countries. Government interventions will therefore continue to play an important role in developing renewable energy technologies.

The increasing globalization of technology development allows countries to obtain resources like knowledge, market access and finance from other countries for developing domestic renewable energy technologies. However, countries differ significantly in their capabilities and choices of renewable energy technologies as a result of their unique history, their existing knowledge base as well as a broader set of institutional and geographical conditions.

The goal of this thesis is therefore to increase our understanding of the place-dependence of renewable energy technologies for formulating better policies to guide the technology development and transition pathway of countries. This thesis consists of four empirical chapters, and focuses on three sets of research questions: 1) What aspects of placedependence drive the innovation activities of renewable energy technologies? 2) How does place-dependence affect the global development trajectories of renewable energy technologies? 3) How do countries catch up in renewable energy technologies by utilizing local and global knowledge?

Chapter 2 focuses on the knowledge production of countries in renewable energy technologies. I test whether countries are more likely to develop renewable energy technologies based on their existing knowledge base in related technologies. The empirical findings show that countries benefit from both the local and the global related knowledge base in developing renewable energy technologies. Moreover, the domestic market for renewables plays an important role in shaping the place-specific benefits from local and global knowledge that middle- and low-income countries with larger domestic market can benefit more from global related knowledge base.

Chapter 3 focuses on the impacts of external knowledge on the development of renewable energy technologies. Both technological and geographical dimensions are important in the search process of external knowledge. The empirical findings show that the impacts of external knowledge critically depend on the absorptive capacity of countries, resulting from the knowledge diffusion between domestic actors in an innovation system. 
Domestic knowledge from other technologies are important for countries with larger absorptive capacity, whereas countries with smaller absorptive capacity benefits more from international knowledge in the same technology.

Chapter 4 further shows how the place-dependence can shift the direction of global technology development. I identify breakthrough inventions in solar photovoltaic technology based on the new combination of unrelated technologies which has potential to break the path-dependence of global technology trajectories. I then investigate whether the breakthrough inventions are place-dependent in building on locally available technologies. The empirical results show that unrelated technologies are more likely to be combined in breakthrough inventions when they are strongly present in the same region. Moreover, this pattern is common to renewable energy technologies which are considered radical and complex, while a similar pattern is not observed using all technologies.

Chapter 5 focuses on how countries can catch up in the low-carbon energy paradigm by adopting breakthrough inventions in renewable energy technologies earlier. I test whether the knowledge base of countries in related technologies can accelerate the catching up process. The empirical findings suggest that the domestic capabilities of countries in related technologies can facilitate the earlier adoptions of breakthrough inventions, especially in countries with lower levels of economic development. However, the spatial-temporal diffusion patterns of solar photovoltaic technology and wind power technology are different that there are more opportunities for latecomer countries to catch up in solar photovoltaic technology than for wind power technology.

In sum, this thesis leads to three conclusions. First, the place-dependence of renewable energy technologies originates from the path-dependent process towards technologies related to a country's existing knowledge base and the different benefits that countries enjoy from the availability of locally and globally related knowledge. Second, placedependence can affect the global development of renewable energy technologies. Locally available - yet unrelated- technologies can offer different opportunities for breakthrough inventions with potential to shift the global technology trajectories. Third, for middle- and low-income countries, domestic markets for renewables help utilize both local and global knowledge. The domestically related capabilities are also more important in these countries in facilitating early adoptions of breakthrough inventions. 


\section{Samenvatting}

De beperking van klimaatverandering vereist een snelle decarbonisatie van de huidige energiesystemen wereldwijd. Het ontwikkelen van hernieuwbare energietechnologieën is niet alleen een belangrijke manier om landen te helpen hun doelstellingen voor vermindering van de $\mathrm{CO}_{2}$-emissie te bereiken, maar wordt ook steeds meer als veelbelovend beschouwd voor de economische ontwikkeling in zowel geïndustrialiseerde als opkomende landen. Overheidsinterventies zullen daarom een belangrijke rol blijven spelen bij de ontwikkeling van hernieuwbare energietechnologieën.

Door de toenemende globalisering van technologieontwikkeling kunnen landen middelen zoals kennis, markttoegang en financiering uit andere landen verwerven voor het ontwikkelen van eigen hernieuwbare energietechnologieën. Landen verschillen echter aanzienlijk in hun capaciteiten en keuzes voor hernieuwbare energietechnologieën als gevolg van hun unieke geschiedenis, kennisbasis en bredere institutionele en geografische omstandigheden.

Het doel van dit proefschrift is daarom om het inzicht in de plaatsafhankelijkheid van hernieuwbare energietechnologieën te vergroten om daarmee beter beleid te formuleren om de technologische ontwikkeling en het transitiepad van landen te sturen. Dit proefschrift bestaat uit vier empirische hoofdstukken en richt zich op drie sets onderzoeksvragen: 1) Welke aspecten van plaatsafhankelijkheid sturen de innovatieactiviteiten van hernieuwbare energietechnologieën? 2) Hoe beïnvloedt plaatsafhankelijkheid de mondiale ontwikkelingstrajecten van hernieuwbare energietechnologieën? 3) Hoe halen landen achterstand in de ontwikkeling van hernieuwbare energietechnologie in door gebruik te maken van lokale en globale kennis?

Hoofdstuk 2 richt zich op de landelijke kennisproductie op het gebied van hernieuwbare energietechnologieën. Ik test of landen meer kans hebben om hernieuwbare energietechnologieën te ontwikkelen op basis van hun bestaande capaciteiten in gerelateerde technologieën. De empirische bevindingen tonen aan dat landen profiteren van zowel de lokale als de globale gerelateerde kennisbasis bij het ontwikkelen van hernieuwbare energietechnologieën. Bovendien speelt de binnenlandse markt voor hernieuwbare energiebronnen een belangrijke rol bij het vormgeven van de plaatsgebonden voordelen van lokale en mondiale kennis, zodat landen met een middelhoog en laag inkomen met een grotere binnenlandse markt meer kunnen profiteren van de globale kennisbasis.

Hoofdstuk 3 richt zich op de effecten van externe kennis op de ontwikkeling van hernieuwbare energietechnologieën. Zowel technologische als geografische dimensies zijn belangrijk in het zoeken naar externe kennis. Uit de empirische bevindingen blijkt dat de 
effecten van externe kennis kritisch afhangen van het absorptievermogen van landen als gevolg van de kennisverspreiding tussen binnenlandse actoren in een innovatiesysteem. Binnenlandse kennis van andere technologieën is belangrijk voor landen met een groter absorptievermogen, terwijl landen met een kleiner absorptievermogen meer profiteren van internationale kennis in dezelfde technologie.

Hoofdstuk 4 laat verder zien hoe de plaatsafhankelijkheid de richting van globale technologische ontwikkeling kan veranderen. Ik identificeer baanbrekende uitvindingen (breakthrough inventions) in fotovoltaïsche zonnetechnologie die op basis van een nieuwe combinatie van niet-verwante technologieën de padafhankelijkheid van mondiale technologietrajecten kan doorbreken. Vervolgens onderzoek ik of deze uitvindingen plaatsafhankelijk zijn bij het voortbouwen op lokaal beschikbare technologieën. De empirische resultaten tonen aan dat niet-verwante technologieën vaker worden gecombineerd in baanbrekende uitvindingen wanneer ze sterk aanwezig zijn in dezelfde regio. Bovendien is dit patroon gebruikelijk bij hernieuwbare energietechnologieën die als radicaal en complex worden beschouwd, terwijl een vergelijkbaar patroon niet wordt waargenomen bij alle technologieën.

Hoofdstuk 5 richt zich op hoe landen een inhaalslag kunnen maken in het duurzame energieparadigma door eerdere baanbrekende uitvindingen in hernieuwbare energietechnologieën over te nemen. Ik test of de kennisbasis van landen in gerelateerde technologieën dit inhaalproces kan versnellen. De empirische bevindingen suggereren dat de binnenlandse capaciteiten van landen in aanverwante technologieën eerdere adoptie van baanbrekende uitvindingen kunnen vergemakkelijken, vooral in landen met een lager niveau van economische ontwikkeling. De ruimtelijk-temporele diffusiepatronen van fotovoltaïsche zonne-energietechnologie en windenergietechnologie zijn echter verschillend; voor laatkomer-landen zijn er meer kansen om de zonne-fotovoltaïsche technologie in te halen dan voor windenergie-technologie.

Samenvattend leidt dit proefschrift tot drie conclusies. Ten eerste komt de plaatsafhankelijkheid van hernieuwbare energietechnologieën voort uit het padafhankelijke proces naar technologieën, welke verband houden met de bestaande kennisbasis van een land en met de verschillende voordelen van lokale en globale gerelateerde kennis van landen. Ten tweede kan de plaatsafhankelijkheid van invloed zijn op de globale technologische ontwikkeling doordat lokaal beschikbare, maar niet-verwante technologieën kansen kunnen bieden voor baanbrekende uitvindingen die de globale technologietrajecten op het gebied van hernieuwbare energietechnologieën kunnen veranderen. Ten derde helpen de binnenlandse markten voor hernieuwbare energiebronnen voor landen met een midden- en een laag inkomen de lokale en globale kennis te benutten. De binnenlandse 
capaciteiten zijn in deze landen ook belangrijker bij het vergemakkelijken van vroege adoptie van baanbrekende uitvindingen. 


\section{List of Figures}

Figure 2.1 Number of patents by type of renewable energy technology (3-year moving average). Note: Solar thermal, tidal, wave and ocean, biofuel and waste and geothermal are shown on the right axis. 20

Figure 4.1 Evolution of number of solar PV patents (left y-axis), number of solar PV patents with new combinations of IPC subclasses (left y-axis) and share of patents with new combinations among all solar PV patents (right y-axis). 67

Figure 4.2 Average of technological relatedness between new combination of IPC subclasses and potential combination of IPC subclasses. 68

Figure 5.1 Descriptive analysis of the number of adopting countries in solar photovoltaic technology (upper-panel) and wind power technology (lower-panel) 85 


\section{List of Tables}

Table 1.1 Summary of empirical chapters .................................................................... 12

Table 2.1 Specialisations of top 10 patenting countries in renewable energies ....................25

Table 2.2 Summary statistics of knowledge production in renewable energy technologies 26

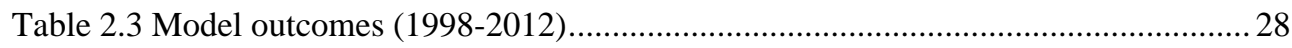

Table 2.4 Model outcomes (1998-2012): Income level ....................................................29

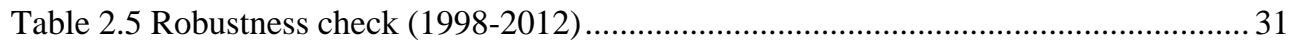

Table 2.6 Robustness check (1998-2012): Income level .................................................... 32

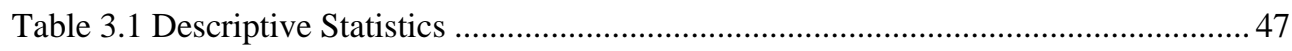

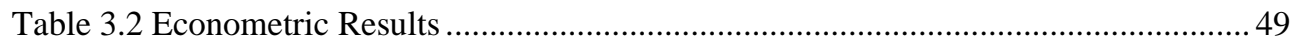

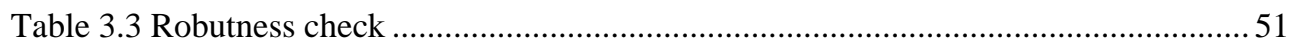

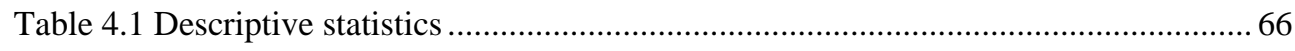

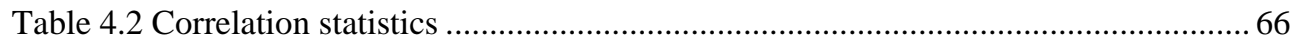

Table 4.3 Top regions in the number of patents with new combinations of IPC subclasses 69

Table 4.4 Econometric Results ....................................................................................... 70

Table 4.5 Robustness check: wind power and biofuel..................................................... 71

Table 4.6 Robustness check: renewable energy technologies and all technologies..............72

Table 5.1 Summary statistics: Solar photovoltaic ............................................................ 86

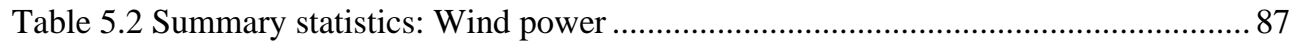

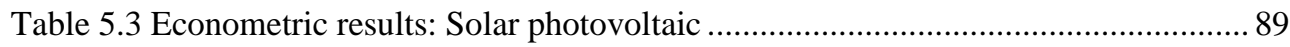

Table 5.4 Econometric results: Wind power.............................................................. 90

Table 5.5 Robustness check: Solar photovoltaic …………………………………........ 92

Table 5.6 Robustness check: Wind power ..................................................................... 93

Table 5.7 Robustness check: Solar photovoltaic ……………………………………....... 94

Table 5.8 Robustness check: wind power.................................................................... 95 


\section{Acknowledgements}

Back in the winter of 2013 when I decided to pursue a career in academia, I wouldn't believe completing my $\mathrm{PhD}$ in Utrecht University. Utrecht University was my dream school since I developed interests in evolutionary economic geography. First of all, I want to thank my co-authors and mentors. Floor, you offered me the opportunity and guided me through the journey with great patience. I wouldn't be able to make it without your support. Gaston, I enjoyed all those discussions of complex ideas with you. I am very proud that we were able to operationalize them. Koen, thank you for all the insightful and considerate advices. I learnt immensely the charm of interdisciplinarity from you. I also feel very fortunate to have Ron Boschma, Bernhard Truffer, Carolina Castaldi, Ruddi Bekkers and Davide Consoli in the evaluation committee. I learned a lot from you over the last years.

The Copernicus Institute I worked at during my $\mathrm{PhD}$ has the best working environment one can ever expect. Thanks to everyone who contributed. I am truly honoured to be part of it. I am lucky to have wonderful colleagues and friends from Innovation Studies group so I didn't walk alone during this journey. Mart and Toon, we shared office for many years and became close friends. Dorith and Simona, I can't imagine how much fun I would miss without all those parties you organized. Denise, Iris, Adriaan, Mary, Lukas, Karla, Mignon, Jarno, Frank, Taneli, Laura, Thomas, Shan and many colleagues and friends I have met over the years, thank you for the inspiration, fun and care. I also want to thank Darja, Mina, Ankit, Aziiz, Peter, Matthew, Elena, Qi and many colleagues and friends from the TIS group in TU/e. I had great time during those Thursdays in Eindhoven.

I want to thank all the Chinese friends I have met in Netherlands. 你们让我在异乡的生活 变得丰富多彩。感谢晓滨, 肖玲, 其兵, 张璐, 玉珑, 孙哲等羽毛球友, 和你们打 球是我最放松的时候。感谢冰莹, 王磬, 施婷, 化宇等北大校友, 和你们的聚会每 次都很开心。感谢东龙, 老徐, 张杰等刚来荷兰认识的朋友, 大家互相扶持的那段 时光非常难忘。

I want to thank my parents for their love and support. 爸爸, 妈妈, 感谢你们对我一直以 来无条件的爱和支持, 我爱你们。父母在, 不远游, 游必有方。

杨帆, 感谢最初几年的陪伴, 很遗憾我们并没有能够战胜距离。Egdar, I am glad that we were able to go through the last part of our $\mathrm{PhD}$ journeys together. I am more thankful 
than I can say.

It is a special moment when I am writing these words. I hope I celebrate with you soon.

Deyu Li

Cambridge, April 2020 


\section{Curriculum Vitae}

Deyu Li (Chongqing, 1989) obtained his BSc in Economic Geography and BA (minor) in Economics from Peking University in 2011, and his MSc in Economic Geography from the same university in 2014. During his master study, Deyu developed interests in renewable energy technologies. His master thesis followed the evolutionary economic geography literature and investigated the industry evolution of Chinese cities. After his master study, Deyu started his $\mathrm{PhD}$ in Innovation studies at Copernicus Institute of Sustainable Development of Utrecht University in March 2015 where his two research interests came together. He applied theories and methods from the evolutionary economic geography literature to understand the development of renewable energy technologies of countries with a global perspective. He published two scientific journals and presented at several international conferences.

After his PhD, Deyu was employed by University of Cambridge as a research associate on energy technology innovation and policy. The project focuses on the impacts of the geographical shifts of manufacturing on the direction of wind energy innovations. Deyu will continue his research in understanding the local and global dynamics of renewable energy technologies. 


\section{List of publications}

Guo, Q., He, C., Li, D., 2016. Entrepreneurship in China: The role of localisation and urbanisation economies. Urban Studies 53, 2584-2606.

https://doi.org/10.1177/0042098015595598

Heimeriks, G., Li, D., Lamers, W., Meijer, I., Yegros, A., 2019. Scientific knowledge production in European regions: patterns of growth, diversity and complexity.

European Planning Studies 27, 2123-2143.

https://doi.org/10.1080/09654313.2019.1645814

Li, D., Heimeriks, G., Alkemade, F., 2020. The emergence of renewable energy technologies at country level: relatedness, international knowledge spillovers and domestic energy markets. Industry and Innovation, 1-23.

https://doi.org/10.1080/13662716.2020.1713734 
